Portland State University

PDXScholar

Summer 8-21-2013

\title{
Neighborhood Commercial Corridor Change: Portland, Oregon 1990-2010
}

Kelly Ann Howsley-Glover

Portland State University

Follow this and additional works at: https://pdxscholar.library.pdx.edu/open_access_etds

Part of the Urban, Community and Regional Planning Commons, Urban Studies Commons, and the Urban Studies and Planning Commons

Let us know how access to this document benefits you.

\section{Recommended Citation}

Howsley-Glover, Kelly Ann, "Neighborhood Commercial Corridor Change: Portland, Oregon 1990-2010" (2013). Dissertations and Theses. Paper 1409.

https://doi.org/10.15760/etd.1409

This Dissertation is brought to you for free and open access. It has been accepted for inclusion in Dissertations and Theses by an authorized administrator of PDXScholar. Please contact us if we can make this document more accessible: pdxscholar@pdx.edu. 
Neighborhood Commercial Corridor Change: Portland, Oregon 1990-2010

by

Kelly Ann Howsley

A dissertation submitted in partial fulfillment of the requirements for the degree of

Doctor of Philosophy

in

Urban Studies

Dissertation Committee:

Carl Abbott, Chair

Sy Adler

Thomas Harvey

Greg Schrock

Portland State University

2013 


\begin{abstract}
Commercial corridors in neighborhoods experiencing change have been relegated to a footnote in research on residential phenomena. It is taken for granted that the process of change experience by businesses within these neighborhoods mirrors that of the residential change. This assumption is often predicated on the underlying model of invasion succession, suggesting that inmovers displace native populations, whether they are residents or businesses.

Analyzing time series data on neighborhood commercial corridor change, research attempted to first test data against the invasion succession model to see if it is an effective framework for analysis. Second, through comparison of case study areas and data along the aggregated corridor, insights are advanced to spur development of a valid model for examining neighborhood commercial corridor change as a unique process with regular spatio-temporal patterns. This framework, it is suggested, is the first step towards understanding the impact of external forces, including social actors, on the neighborhood commercial landscape.
\end{abstract}




\title{
DEDICATION
}

\author{
To and in Loving Memory of \\ Susan and Richard Howsley
}

"A wonderful fact to reflect upon, that every human creature is constituted to be that profound secret and mystery to every other."-Charles Dickens 


\section{ACKNOWLEDGEMENTS}

The author wishes to express sincere appreciation to her committee. Dr. Schrock was a late, but invaluable addition; Dr. Adler a constant, thoughtful advisor; Dr. Martin for her insights; and Dr. Harvey for his unwavering perspective. Special thanks to Dr. Carl Abbott who has been a major influence and support over the course of the degree program. His kindness, humor, insight, and patience went above and beyond the call of duty and is truly humbling.

Also, without parallel, the support of the Howsley-Glover extended clan has been a sustaining force and a great source of comfort, laughter, and love. I owe my sanity and humor to my husband who has unconditionally buoyed me through two graduate degrees and all the life changes which accompany a prolonged stay in academics. "Being deeply loved by someone gives you strength, while loving someone deeply gives you courage." 


\section{TABLE OF CONTENTS}

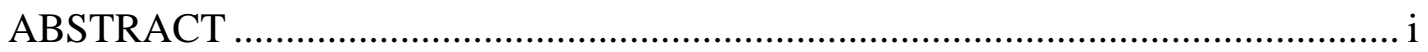

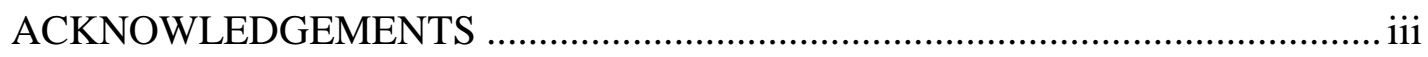

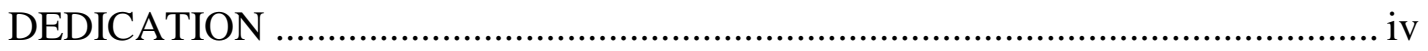

LIST OF TABLES ............................................................................ vi

LIST OF FIGURES ................................................................................. vii

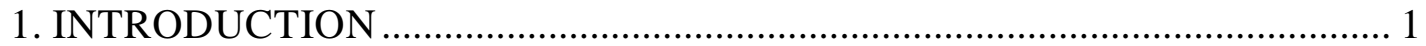

STATEMENT OF THE PROBLEM....................................................... 1

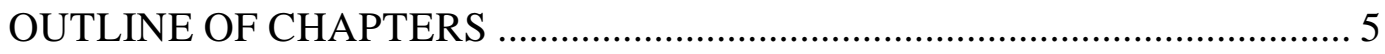

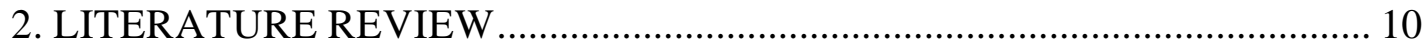

CENTRALITY, SPACE AND TIME ........................................................... 10

THE SIGNIFICANCE OF NEIGHBORHOOD COMMERCE ........................ 19

RETAIL TYPES IN TIME AND SPACE ................................................... 26

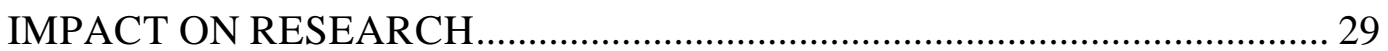

3. RESEARCH DESIGN AND METHODS ….............................................. 31

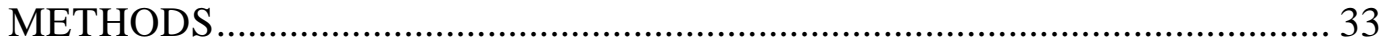

UNIT OF ANALYSIS AND CASE STUDY APPROACH ........................... 34

THE NEIGHBORHOOD: HISTORICAL DATA ........................................ 41

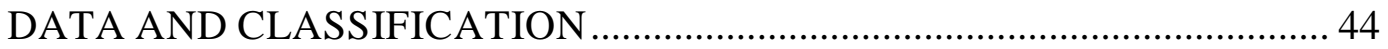

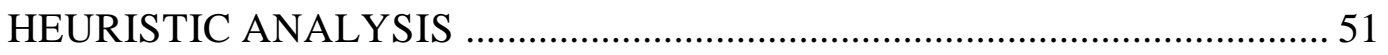

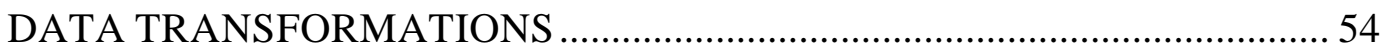

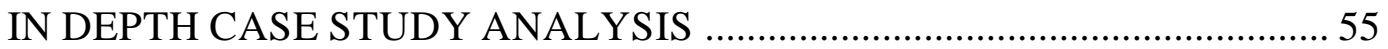

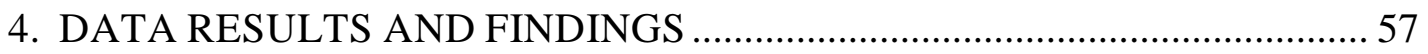

TOTAL BUSINESSES AND TENURE ..................................................... 57

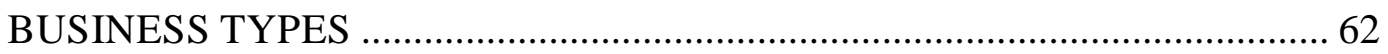

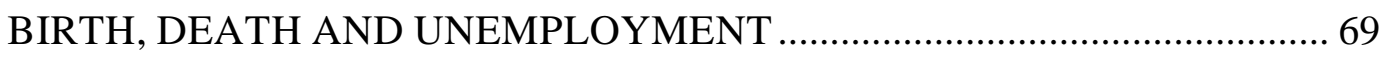


INVASION SUCCESSION AND THE PEARSON PRODUCT MOMENT CORRELATION COEFFICIENT ……………......................................... 74

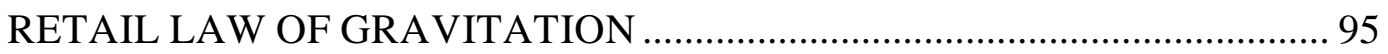

5. DISCUSSION AND RECOMMENDATIONS …………………………...... 102

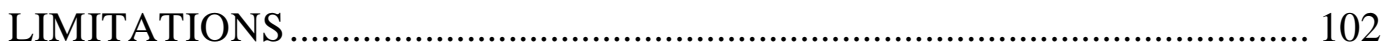

DISCUSSION AND RECOMMENDATIONS ………………….................. 103

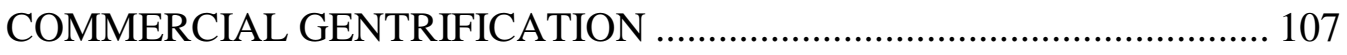

RECOMMENDATIONS FOR RESEARCH.............................................. 110

RECOMMENDATIONS FOR PRACTITIONERS ................................... 111

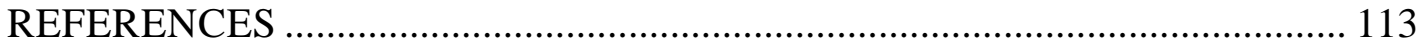

APPENDIX A - Neighborhoodbusinesses.ods ................................ 137

APPENDIX B - Neighborhoodmaps.pdf ....................................138 


\section{LIST OF TABLES}

TABLES

2

3

4

5

6

7

8

9
PAGE

Business Type Classification 49

Total business numbers for street in five year increments $\quad 58$

Standard Interpretation of Pearson Correlation Coefficient $\quad 75$

Pearson Correlation Coefficient of Total Birth and Death per $\quad 78$

Case Study Area with Standard Interpretation

Total Birth and Death Correlations by 10 block $\leq$ Segments $\quad 80$

NE Alberta and SE Hawthorne Pearson Correlation 80

Coefficients by 10 block segments staggering variables

Total Shopper Birth and Death Convenience by 10 Block $\leq \quad 87$

Segments

SE Hawthorne Shopper Births and Convenience Deaths with 88 and without Professional Services

Segment Neighborhood Populations for $2000 \& 2010 \quad 97$

Segment Total Businesses for $2000 \& 2010 \quad 97$ 


\section{LIST OF FIGURES}

\begin{tabular}{|c|c|c|}
\hline \multicolumn{2}{|c|}{ FIGURES } & \multirow{2}{*}{$\begin{array}{l}\text { PAGE } \\
61\end{array}$} \\
\hline 1 & $\begin{array}{l}\text { Average Tenure for Hawthorne and Alberta by five year } \\
\text { increments rounded two decimals }\end{array}$ & \\
\hline 2 & NE $\&$ SE $28^{\text {th }}$ & 70 \\
\hline 3 & $\mathrm{NE} 42^{\text {nd }}$ & 70 \\
\hline 4 & NE Alberta & 71 \\
\hline 5 & NW $21^{\text {st }}$ & 71 \\
\hline 6 & NW $23^{\text {rd }}$ & 71 \\
\hline 7 & SE Belmont & 71 \\
\hline 8 & SE Hawthorne & 72 \\
\hline 9 & Annual Unemployment Rate PMSA & 72 \\
\hline 10 & Total Businesses by Street & 73 \\
\hline 11A & $\begin{array}{l}\text { Graphic Version of Table } 11 \text { total Pearson Correlation } \\
\text { Coefficient Scale }\end{array}$ & 79 \\
\hline 11B & with NE $42^{\text {nd }}$ and SE Belmont (control cases) removed & 79 \\
\hline 12 & Total Business Births NE Alberta By 10 Block Segments & 81 \\
\hline 13 & Total Business Deaths NE Alberta By 10 Block Segments & 81 \\
\hline 14A-B & $\begin{array}{l}\text { Total convenience and shopper businesses for } 2^{\text {nd }} \text { and } 3^{\text {rd }} \\
\text { segments of NE Alberta over time }\end{array}$ & 82 \\
\hline 15 & $\begin{array}{l}\text { NE Alberta Total Birth and Average Tenure by } 10 \text { Block } \\
\text { Segments }\end{array}$ & 83 \\
\hline 16 & $\begin{array}{l}\text { PCC Segment } 2 \text { NE Alberta By Five Year Increments with } \\
\text { Death Year After Birth }\end{array}$ & 84 \\
\hline 17A-H & $\begin{array}{l}\text { Total Shopper and Convenience Businesses (Excluding } \\
\text { Professional and Commercial Services) }\end{array}$ & $91-92$ \\
\hline 18 & $\begin{array}{l}\text { Total across five year increments by block on NE Alberta } \\
\text { and } 7^{\text {th }}-30^{\text {th }}\end{array}$ & 99 \\
\hline 19 & $\begin{array}{l}\text { Total across five year increments by block on SE Hawthorne } \\
\text { and } 20^{\text {th }}-50^{\text {th }}\end{array}$ & 99 \\
\hline
\end{tabular}




\section{INTRODUCTION}

\section{STATEMENT OF THE PROBLEM}

Shifting demographics and renewed investment in inner city neighborhoods in the United States generated a dialogue between citizens, politicians, academics, and practitioners. After several decades throughout twentieth century of discriminatory lending practices including redlining, white flight and settlement of suburbs, and an ever widening gap between household incomes the urban landscape was described as a brownfield frontier for creative pioneers. Before the real estate bubble burst in the U.S. in 2008, speculative house flipping became a common parlance. The urban housing market, after years of disinvestment, was prime for buying low and selling high.

With the influx of reinvestment in urban housing markets also came a resurgence of neighborhood retail and services. Like the housing market, disinvestment over the decades made for ripe economic opportunity for entrepreneurs to service new residents. Larger trends in the economy, including the outsourcing of manufacturing and the rising number of service sector employment translated into the notion of the creative economy. Creative good and services helped to redefine consumption patterns for the average American household. Urban centers, with their dense and affordable real estate opportunities, gave way to creative clusters. 
The language of academia began to permeate the general dialogue, with much of the urban reinvestment being labeled gentrification. At its most elementary foundation, the term describes to the process of affluent households displacing low income families from inner city housing as a result of rising pricings, taxes, and rent gap. Hamnett (2003) suggests that Glass (1961) was being ironic and tongue-incheek when she first coined the term gentrification to describe the influx of a new class of Londoners, yet the term came to the forefront in the US beginning in the 1980s as urban neighborhoods began to revive after several decade of disinvestment.

A footnote of residential phenomena, neighborhood retail change has been positioned in the literature as proof of gentrification; the boutiques, upscale bars and coffeehouses represent a visible symptom of shifting demographics and, as a result, a changing socio-economic landscape. As opposed to planned retail development, market driven commercial corridor change has been relied upon to provide the semiotic hallmarks of gentrification. However, despite the dependence upon these neighborhood commercial corridors, the actual processes by which they change in time and space has been relatively untouched by the literature. As a result, assumptions about the process have inflated anxieties about displacement and exacerbated emphasis on human agency as a catalyst for commercial change.

This dissertation, first and foremost, is interested in understanding the way in which urban neighborhood commercial space has changed over time. Given the volatile and dynamic nature of small businesses that gravitate to lower rents and 
smaller foot prints of neighborhood commercial corridors, a longitudinal approach to how the corridors change was developed to overcome gaps and individual business death. By looking at the aggregated history of commercial corridors over time, the goal was to discover any emergent patterns.

The central question of this work is first, do neighborhood commercial corridors demonstrate spatial configuration patterns? Based on the literature, it was believed neighborhood commercial corridors, despite unique characteristics, would demonstrate similar spatial clustering patterns related to centrality. More specifically, the research was interested in, when examining retail businesses by type, whether patterns of dispersion or clustering had an impact on the success, or tenure, of business types. The hypothesis was that only through an explicit framework of centrality would clear characteristics of neighborhood commercial change become apparent, and therefore useful, to further research and policy.

Neighborhood commercial streets not only have an impact on the perceived quality of life for residents, but also offer employment opportunities for entrepreneurs, professionals, and hourly wage workers. To large extent the type of businesses determine choice and economic viability for workers and nearby households alike. Within the literature on neighborhood commercial change, the chief concern has been in the succession of shopper goods over convenience goods. Similar to displacement issues within the housing market as ownership succeeds historic rental properties, the death or replacement of existing businesses as a 
commercial corridor experiences investment is seen as a threat to small business owners and, more generally, convenience goods that serve residential populations.

The second question of research was then, are historic businesses displaced by new businesses development and does business type have an impact on business death? Implicit within much of the commercial gentrification literature is the ecological invasion succession model of change, whereby traditional businesses are eventually displaced by new businesses catering to lifestyle consumption of new residents. By looking at business birth and death over time, and seeing how total counts of businesses related to average tenure, it was believed research could begin to test the theory that neighborhood commercial change patterns mirror shifts occurring in the residential areas.

Despite anxieties over business displacement and commercial gentrification within the dialogue, little research on the actual patterns of neighborhood commercial change has been conducted. In developing this research, resistance represented a broader emphasis on causality over morphological or spatio-temporal realities. It is my assertion that, before a clear and productive path to understanding the causes of neighborhood commercial development it is first critical to understand what, in fact, is occurring.

Because research on neighborhood commercial change is limited, this study utilizes an interdisciplinary and experimental approach. The strength of an experimental method is that it allows for emergent patterns without preconception bias. While there is a clear guiding hypothesis that convenience goods are a vital 
part to maintaining economic sustainability/viability of neighborhood commercial districts and that spatio-temporal patterns support and help to produce/reproduce this relationship, the theoretical framework does not define what the relationship looks like in time and space.

\section{OUTLINE OF CHAPTERS}

In the second chapter, I will outline the foundation for research based on the literature. Specifically, I have identified differing perspectives on centrality as it relates to space and time, and will explore how a movement-focused, dialectical basis of centrality is useful for understanding the patterns of neighborhood commercial change.

The problem heretofore with the bulk of literature on neighborhood commercial change has been an underlying assumption of centrality as an exclusionary process. In looking at neighborhood retail, descriptions of investment cycles by in large revolve around one primary cluster of social and economic activity. A demand side, agency driven approach has rationalized anxieties about businesses displacement to the exclusion of understanding recurrent patterns of socio-economic activity that occur in space, over time, in different areas. Because the literature has emphasized the role of actors, any patterns which occur according to various market forces across commercial corridors have not been identified in support or contradiction of this narrow definition of centrality.

I propose that by conceptualizing centrality as 1) dialogical, 2) movement based and 3) creating multiple centers better describes the process of neighborhood 
commercial change. The literature will demonstrate how identifying complex socio-temporal relationships provides a firm basis for further research issues including causality.

The literature review will also consider previous studies on urban commercial change and how a variety of disciplines consider some of the critical issues. Economics provides an interpretation of variable factored in location choice, for example, while geography helps unpack concepts of sense of place. A synthesis of relevant literature will demonstrate the significance of space and time as related to neighborhood commercial change.

The third chapter will describe the research methodology, including detailed examination of the approach as guided by the literature. I will provide a rationale for examining commercial corridors as the primary unit of measurement and outline how data was collected to provide detailed information about business change in several identified case studies. Because time is as a critical to the theoretical framework as space, data was collected over a twenty year period in yearly increments to neutralize influence of any extreme external forces and naturally occurring rates of business death. Historical data, collected to maximize interest in time and space, will help to develop the picture of the movement dialogue presented in the literature.

As business type is critical for approaching the second research question, I will present how distinctions of business types were made with available data and how typology was operationalized for analysis. Early on, I identified a strong 
concern within the literature that shopper good stores invaded and eventually succeeded convenience based businesses. Guided by these concerns, I developed both detailed and high level ways to parse businesses to understand the interaction of type within agglomerations; in order to understand the impact of clustering shopper good based businesses, it was necessary to tease out any relationships within broader categories of service versus goods. By analyzing according to several categorization methods, in addition, it is my hope to present a reproducible methodology that can be utilized by other research.

Finally, according to the development of movement economies within the literature, maps were generated to provide clear comparisons within time and among case study areas. The product of historical data, the maps represent spatial patterns throughout time and in space, of how businesses cluster. Although one-dimensional by nature, maps help to represent graph theory which supports the more complex concept of centrality.

The fourth chapter discusses research findings including an overview of the historical data, interesting observations and results from data collection and analysis, and finally an overview of research products. Through research findings, I anticipate first being able to identify any patterns in space and time, and between case study areas, that support the hypothesis neighborhood commercial corridors experience change in a recognizable way. With tenure serving as a proxy for stability for business success, it will become clear that businesses appropriate a 
center by which future activity responds to reproduce densities. Using a detailed analysis of two case studies, I will discuss the findings.

I also anticipate, after initial observation, that business types will demonstrate the concept of movement economies. By their very definition, shopper and convenience businesses have different orientations when considering competing businesses. Convenience businesses generally are more successful when dispersed and located within proximity to other attractions (including clusters of shopper businesses) whereas shopper goods, owing to comparison shopping and trip chaining, are more successful when clustering.

It is my hope that these findings will support the hypothesis that, contrary to the invasion succession assumed by gentrification literature, the reality of neighborhood commercial change relates more strongly to structural forces which help to produce and reproduce socio-economic conditions.

Finally, the conclusion will include the limitations of research, possible avenues for future study and recommendations based on findings. Constraints of available data, limited research precedence, and an experimental framework have narrowed the scope of research. Future research should necessarily look at neighborhood commercial change in a variety of cities in order to avoid criticisms of regional or local influence. A more robust quantitative methodology could also be developed to test statistical significance of patterns, thereby making strong conclusions about correlations of spatio-temporal variables. 
Because causality is an identified area of interest for academics and practitioners, I will conclude with suggestions for how my research lays a foundation for understanding the variables that contribute to neighborhood commercial change, implications of my research, and way in which spatio-temporal patterns can provide a clear and concise rationale for recognizing the need to make centrality an implicit issue in both research and practice. 


\section{LITERATURE REVIEW}

Identified within the literature is a significant gap of research focused on change patterns in urban neighborhood commercial corridors. Previous research has emphasized the role of the actor in determining change, whether changing mix of residents or entrepreneurial influence (Webb and Brown, 2012). This research is focused on the appearance of shopper goods which replace long-standing convenience goods businesses (Henig, 1982; Hardyman, 1992; Clemmer, 2000; Kim, 2012). This emphasis suggests an increasing homogeneity of business types and relied on ecological models of neighborhood commercial change (Aldrich and Reiss, 1976). However, predominant models of retail geography, specifically centrality, suggest heterogeneity helps to stimulate movement of individual shoppers within a commercial area, and thereby, consumption.

Considering current literature on centrality, I hope to demonstrate that theory advocates for a three dimensional approach to retail change, embracing the spatiotemporal process as a lynchpin to development. Then, using this framework, I endeavor to demonstrate that neighborhoods as a micro-scale representation of retail provide an opportunity to explore empirically the idea that centrality is dynamic, interacting with space as well as business type.

\section{CENTRALITY, SPACE AND TIME}

Density and centrality have long been understood as critical to retail development and sustainability as businesses stimulate shopper presence and 
activity, increasing accessibility to customer base (Hotelling, 1929; Bromley and Thomas, 1993; Scott, 1997; Gospodini, 2005; Ferrell, 2005; Ren and Kwan, 2009; Huang and Levinson, 2009; Glaeser, 2010; Sevtsuk, 2010; Dearden and Wilson, 2011). The literature suggests that even in a linear commercial corridor, certain spaces have more intrinsic value than others. Traditionally, the theoretical deconstruction of these phenomena has relied on the principle of centrality to explain why business flourish or prefer certain spaces over others. Porta et al (2008) argues that "accessibility may be transformed to visibility and popularity. Therefore, a central place tends to attract more customers and has a greater potential to develop into a social catalyst" (Porta et al, 2008, 451).

Oinas (2002) suggests that economic geography has largely depended on the assumption that "economic success requires clustering" (Oinas, 2002, 65). In these spaces of economic activity, the center is the optimal location for maximum market capture. Mullingan (1982) characterizes agglomeration at the local scale as clusters of economic activity in space, and central place theory as the framework for understanding economic agglomeration. According to his review of the economic geography literature, he posits the major theme of central place theory is that different points in a location have varying levels of centrality, producing a hierarchal structure of goods and services. Businesses are expected to locate as closely to consumer demand as possible, while simultaneously locating in close proximity to retailers who also attract a similar customer base while not directly competing (Stahl, 1987). When considering multi-good and services clusters, a 
behavioral theory of agglomeration most appropriately describes the dynamic relationship of centrality.

Crucitti et al (2006) identify centrality as a shared resource within a network that hinges on homogeneity and/or heterogeneity of distributions. Centrality is based on the structure of the city (Porta and Latora, 2008) with influence on both a macro and micro scale, particularly in the formation of "spontaneous" or "organic" cities (Porto, 2008, 451; Jacobs 1961). Lefebvre (1991) calls centrality a logical form that has both a mental and social centrality requiring definition. To paraphrase, the mental form is essentially an objective principle of centrality, while the social is the dynamic process which interacts in time over space to temporarily shape the centrality into a recognizable form.

Lefebvre (1991) also identified centrality as a movable form whereby time and space interact to shift the abstract and real center. This dialectical quality of centrality, Lefebvre argues, is often spurned by practitioners and thinkers in favor of centralization or a totalizing mission which expel peripheral elements. In this sense, centrality refers to density of like items whereby concentration is defined by the homogeneity of objects (Tannier and Pumain, 2005). In reality, the urban morphology is one of discontinuities and heterogeneity following socio-economic trends.

The dialogue, Lefebvre continues, between center and periphery is highly complex and presents itself as conflict and contradiction in space, derived by time. This relationship between time and space make centrality a moving target which 
cannot be contained through centralization. It also underscores the difficulties with identifying causal relationships in time and space. Without a clear empirical framework that acknowledges the interaction between time and space, characterizations of spatial processes like neighborhood commercial change are likely to lead to the conclusion that phenomena is subjective and actor driven.

Centrality, when used as a theoretical framework, requires a diligent understanding of how time impacts space. Sevtsuk (2010) demonstrates that, one and two dimensional models of retail store location assume all land is of equal quality and would allow for perfectly uniform spatial distribution of retail centers. Even in a perfect grid city, where there are no irregular connections, the principle of centrality would favor proximity to the CBD in a linear street segment.

Furthermore, the one dimension theory assumes all retail stores offer the exact same products. Two dimension models structure the location choice as related to range, or the maximum distance a customer will travel, and threshold, or the minimum demand for products necessary for a business to be sustainable (Sevtsuk, 2010). This results in a hexagonal pattern of retail development where range and threshold reproduce. This pattern, Sevtsuk argues, also assumes a uniform plane where all other factors are equal. In the case of the one and two dimensional models of centrality, time is an implicit, rather than explicit, variable which would appear to be subservient to an anchored center. Typically, it is coupled with distance to measure the impact on location. 
Walden (1990), in an analysis of urban retail food markets, illustrates that in time and space a one-dimensional model discounts the unique characteristics of a specific site which cannot exactly be duplicated, therefore creating unequal access from identical firms to a specific retail market. While there may be some theoretical value to Hotelling's theory, Walden argues, it essentially is a spaceless principle which does not account for externalities. Intuitively, we know that retail location choice does not occur or reproduce in a vacuum, nor are all products, customers or sites created equal. Therefore, while there is value in understanding the principles of one and two dimensional location theory, for the purposes of empirical research it is generally found to be inadequate for developing methodology or hypothesis testing.

Walden's research points to a layered approach of retail pricing whereby certain products are manipulated according to competition as attractors while other, non-food goods demonstrate fixed cost related to the assumption that these items will be complementary to the purchases determining store choice. In other words, stores use a strategy of competing based on demand and increasing their threshold, or market capture, through additional supply. In fact, other research has demonstrated that distance will be overcome by shoppers in order to seek out specific products or reduce overall shopping time (Bartlett, 2003; Arentze and Timmerman, 2005; Ferrell, 2005; Brooks et al, 2008; Clifton et al, 2012). For stores that do not offer a multitude of products, like grocery stores analyzed by Walden, 
they can recreate the strategy through proximity to complementary and competing businesses. In other words, eclectic or mixed clustering.

This interplay between individual businesses, whereby a second function of clustering serves to act as a multiplier, helps to reinforce the idea that urban settlements form according to a movement economy. It is perhaps easiest to illustrate when considering disinvested neighborhood commercial corridors. With low land occupancy rates, surviving businesses must rely solely on their own strength (either as convenience to adjacent households or by fulfilling a regional niche need/desire) to acquire and maintain business. This added cost of doing businesses necessarily factors into sustainable rent or tax assessment. By comparison, heavily invested areas allow businesses to benefit from spillover of nearby businesses, increasing quantity and quality of shoppers which helps to offset higher rents or taxes.

In this regard, density can serve as a proxy for the variable of movement. The framework of movement as intelligible predictor of spatial patterns has its roots in centrality. Specifically, urban geographers have recently been experimenting with fractals as a system for understanding spatio-temporal morphology (Tannier and Pumain, 2005). Essentially, fractal structures share distribution principles at a multitude of scales; the distribution principle means repetition of elements while not necessarily producing the same form (Tannier and Pumain, 2005). This process of production and reproduction of space supports a generative model of the built environment whereby time and space determine the iteration of built environment 
depending on the initiator (Arlinghaus, 2012). Arlinghaus tells us that "the strategy that underlies the physical development of fractal curves involves replacing, successively, the edges of a given regular polygon with a pre-determined pattern" functioning to generate a dynamic center of development through its relationship to the periphery. In applying this logic to the problem of neighborhood commercial corridor change, the pre-determined pattern is analogous to causality and outside the realm of research. What is more critical to understand is that first, the center is dynamic and simultaneously dependent and independent of adjacent polygons.

In the model developed for research, individual units (or businesses) interact according to a generative process for self-survival. If the center is the most ideal location, is would stand to reason that businesses naturally aspire to generate activity at their periphery, thereby gaining centrality within the system. As the literature informs, the most significant mechanism for ensuring this process is a balance of self-differentiation and self-similarity. In a dynamic system, with all businesses being equal it would stand to reason that all businesses are simultaneously jockeying for central place helping to increase overall density of a commercial corridor.

Furthermore, these principles suggest that development patterns will naturally occur within clusters. In contrast, reliance on invasion succession models of neighborhood commercial change make implicit, rather than explicit, the spatiotemporal context (Aldrich and Reiss, 1976; Heywood, 1989; Macdonald et al, 1990; Hobbs and Humphries, 1994; Cronk and Fuller, 1995). As Svetsuk points out, this 
assumes all space and time are equal resulting in a random pattern of development based on external socio-economic factors. Al_Sayed and Turner (2012) read these principles as occurring during an evolutionary process which tends to reproduce or eliminate street elements according to their spatio-temporal configurational properties. Those likely to reproduce encourage connectivity and accessibility relative to the broader structure while weak elements that don't function as a generative syntax to the broader structure will disappear. Again, the element of time is critical in articulating spatial relationships so that it becomes evident the two are not mutually exclusive and thereby cannot be analyzed separately.

The second problem with applying the invasion succession model to neighborhood commercial change is that its primary principle is the eventual succession or displacement of native businesses by invaders. Based on principles of centrality and the generative process of density, succession would be self-defeating; if the intuitive goal of businesses is to increase opportunity and access, eliminating other business would decrease density rather than preserve it.

Research conducted by Peter Johnson and Simon Parker (1996) examined the relationship between firm births and deaths in a spatial determinant context. In their review for Regional Science they review similar studies in what they categorize as "a small but growing literature on the interdependence between births and deaths" (Johnson, 1996, 681). Based on their literature review and empirical research, they develop a model that teases out the impact of variables on business births and deaths. Their conclusion is that external economic variables have a 
significant impact on business activity; however there is evidence to suggest an interdependence of firm birth and death specifically when considering growing sectors, like the service industry.

The invasion succession model when applied to business change does not successfully consider the importance of differentiation. As Logan and Zhang (2010) suggest, diversity is a by-product of external forces rather than initiator of activity. Displacement models also emphasize homogeneity as a mechanism by which individuals establish stability, and in fact stability is often defined by some research traditions as fundamentally a product of homogeneity (Betancur, 2011). While Betancur's analysis of displacement models is specifically applied to residential phenomena, within the context of the neighborhood it is often held to be indistinguishable from retail. As later review will demonstrate, the intertwining of commercial and residential at the neighborhood level has been customarily a product of data limitations. However, it also finds its roots in the assumptions underlying the application of ecological models to urban neighborhood transformations. An element of this application is the supposition that success, or stability, relies on the marshalling of resources through self-similarity.

This is partially due to the assumption that invasion succession necessarily is an exclusionary process. However, recent research (Webb and Brown, 2012) into neighborhood residential change demonstrates that there is a pronounced trend towards diversity and this, in turn, delimits actualization of invasion succession. A higher level of mobility across individual households, whether physically or 
virtually enabled through technological advancements, reduces the dependence on proximity to community and other resources and can even benefit households through exposure to culturally new resources and opportunities (Miller, 2012).

If a diversity index is decreasingly linked to volatility of a neighborhood, heterogeneity among businesses may also trend towards elasticity. Multi-cultural residential populations necessarily demonstrate different preferences and shopping behaviors, opening the market for additional opportunities for both similar and different types of businesses. And, as Miller (2012) research indicates diversity among residential populations serves to further expand market capture through education and access by previously untapped populations.

In the next section, the fundamentals of neighborhood commerce will elaborate on the benefits of eclectic clustering with an eye towards demonstrating the idea of the movement economy and generative centrality.

\section{THE SIGNIFICANCE OF NEIGHBORHOOD COMMERCE}

It may not be immediately evident why research on neighborhood commercial corridors matters. After all, they are typically not regionally significant employment centers or even primary distribution sites of consumer goods.

Neighborhood business districts do not contain significant resources impacting state or regional economy, and are considered to provide services and amenities to adjacent populations with little broader impact on the city. Rhetorically, we may understand that a neighborhood with a friendly coffee house is much more 
appealing than one adjacent to an abandoned building or an industrial site. But short of sense of place, it is not intuitively a game changer for cities.

The gentrification literature is perhaps the most accessible or explosive because it juxtaposes extremes of disinvestment and investment. Zukin et al's (2009) description of the "boutiquing" of neighborhood retail districts conjures pictures of exclusivity and privilege. Concern over the displacement of older economic activities including manufacturing and their subsequent replacement of cultural commodification has implications not only for consumption patterns within a neighborhood, but also the occupational opportunities of residents (Lloyd, 2002). As Lloyd suggests, on the scale of neighborhood transformation, shifting economies become a spatial phenomenon rather than a state of mind. Inevitably, it is the production of boutiques and cultural commodities within time and space of neighborhoods that represent the broader urban economy (Lloyd, 2002).

Storper and Venables (2008) speak more broadly of the need of economic agents to congregate, pointing to the continued trends of geographical density of employment and residence. Socio-economic benefits to face to face contact, they argue, reproduce spatio-temporal forms that otherwise seem restrictive and exclusive. In other words, dense investment is healthy because it avoids the distance and isolation of disinvested and sparse development. Redding and Venables (2002) argue that spatial clustering is a product of economic forces. Albeit on a much smaller scale, the neighborhood commercial corridor can be a prime example of spatial clustering. As Lloyd suggests, it is much more a function 
of spatio-economic phenomenon than style or preference, as cultural creative theorists suggest.

The literature suggests that retail has exerted influence on morphology and functionality of cities (Bromley, 1993; Dearden and Wilson, 2009; Cachinho, 2012). Like employment, retail sites are a primary destination of households. Location is one mechanism by which individual businesses compete. Small businesses, a stalwart unit of neighborhood commercial areas, have a stronger dependency on location by virtue of scale. In this way, they provide a case study of retail where location, it can be argued, is almost as critical as products or services being traded. It is also important that retail follows population (Bromley, 1993) so that in areas of urban renewal retail will mirror changing densities.

Basic elements of the neighborhood include people, places, public symbols and interaction systems that help situate the neighborhood within the broader context of the city (Schwirian, 1983). Research on creative culture economies in global cities has used neighborhoods and commercial districts to exemplify change and competition among counterparts (Sassen, 1994; Zukin, 1995; Scott, 1997, 2000; Pratt, 1997; Crewe and Beaverstock, 1998; Sassen and Roost, 2000; Hall, 2000; McNeil and While, 2001; Hollands and Chatterton, 2003; Hutton, 2004a; Gospodini, 2005). Globalization has changed the distribution of goods and services on a neighborhood scale (Sassen, 1998 and Zukin, 1989). Its impact on the urban landscape has created, the literature argues, communities catering to lifestyle and quality of life in order to attract corporations; place identity becomes the impetus for 
urban redevelopment centered on cultural, leisure and consumption spaces

(Gospodini, 2005; Clark et al, 2002; Storper and Scott, 2009). This, in turn, has

resulted in in "eclectic clustering" of new urban economic activity, whereby identity is formed through the aggregation of like type businesses (Scott, 1997; Gospodini, 2005; Zukin, 2009).

In the urban environment this is most evident on inner city areas where "economic activity becomes a dynamic element of the culture-generating and innovative capacities" of the overall city (Scott, 1997, 2005). These demand-driven explanations of urban commercial change follow a propensity of research to focus on causality and the actor, without making distinct conclusions about the actual spatio-temporal processes (Lloyd, 2002; Ley, 2003; Searle and Byrne, 2002; Fernandes and Chamusca, 2012).

Cities have always had complex economies; dense urban economic activity supports local, regional, national and global production and consumption patterns. In the postfordist city, Scott (1997) argues, well-developed urban identities are a result of agglomeration and locational specialization. Fernandes and Chamusca (2012) posit that an urban system's resilience is indicated by the reaction of urban retail to socio-economic forces. This literature clearly supports spatio-temporal theories of elasticity and the processes by which self-similar businesses operate to establish a clear sense of place, and more significantly, a generative center of economic activity. 
Although the functionality of retail is stressed in the research on urban sustainability and retail resilience, the spatial elements to resilience cannot be undervalued. The resilience of urban retail is necessarily dependent on its ability to adapt to changing patterns of consumption, while maintaining market capture through adjacency to viable retail. In a complex relationship with space and time, individual units must produce and reproduce a broader network of movement and retail while competing for resources and optimal market conditions, including centrality.

Zukin (2009) examines the role of the resident pioneer entrepreneur, who seizes economic opportunity by investing in adjacent commercial corridors while they are still disinvested, thus attracting similar businesses to the area. This dichotomy of the cultural economy, where the widening of spatio-economic network and mobility of households requires stronger place identity as a marketing asset for businesses, results in the aggregation of specialized economic activity; cultural creativity is the landscape of agglomerated stimuli (Jacobs, 1969; Scott, 1997; Butler and Robson, 2001; Smith, 2003; Rofe, 2003; Gospodini, 2005). Agglomeration is typically the language of knowledge based economic literature which seeks to understand synergy and impact of clustering on innovation (Audretsch, 1998; Hutton, 2000). However research on the artistic occupational group demonstrates their tendency to be concentrated in specific metropolitan areas (Menger, 1999). As Menger argues, the creative cultural economy relies on the dynamic relationship of individual actors with the economy; he posits "an artist's 
success often goes along with increasingly strategic choices and, by contrast, less successful careers mean entrapment in constraining contractual formulas." A diversity of opportunity for artistic employees support and reproduces the cultural creative economy, naturally spawning secondary or supporting economies.

This is a critical linkage because, as Menger notes, the underemployment tendencies of the artistic occupational group necessarily translate into household financial instability when compared with more traditional professional counterparts. Whereas the landscape of "boutiquing" (Zukin et al, 2009) characterized by gentrification literature emphasizes the displacement of commercial activities supporting low income residents, the reality is much more complicated, and less polarized. Successful neighborhoods, with strong "eclectic" economic identities not only have to contend with residents but also workers who, contrary to the traditional labor force, may have less discretionary spending for goods and services. Markusen and Schrock (2005) suggest that beyond considering the artistic earners as local actors, they should also be considered as producers of exports by which they earn incomes "spent in support of local-serving businesses" (Markusen and Schrock, $1663,2005)$.

While Markusen and Schrock's research focuses on the scale of cities, the same principles can be applied to the neighborhood unit. Previous research considering "commercial gentrification" has focused on displacement to the exclusion of considering the impact employees of new businesses have on supporting other adjacent economic activities. Although Zukin's (2009) research 
highlights entrepreneurial activities of new residents, there is still the assumption that new retail activity is at the expenses on long-term locally owned businesses.

Neighborhood commercial centers that prosper, in reality, have to accommodate a variety of constituents including visitors (regional and tourists), immediate residents, employees (including self-employed entrepreneurs like professional services), all the while developing a distinct enough niche to compete with other urban neighborhood commercial centers. Schueltz et al (2010) identify potential customer base for local retail services as residents and employees at nearby businesses. Research generally considers employees another type of resident (Scheultz et al, 2010; Zukin, 1997, etc). However, the range of employees is as diverse as the given set of businesses in a neighborhood commercial center.

Coupled with economic advantages of centrality, and thereby its generative process which is always aiming to expand its periphery, the demand for diversity from a broad base of customer populations suggests neighborhood commercial corridors will experience trends towards density and infill in lieu of simple displacement. The ability to accommodate heterogeneity, it is evident, has manifold benefits for individual businesses regardless of the commodity they trade upon.

Therefore, it is to be expected that this logic will demonstrate itself in the spatio-temporal landscape through intense clustering of different business types. For the temporal aspect, it is predicted business birth exponentially correlates to total businesses, with the birth rate gaining momentum as the total number of businesses reach maximum capacity for the neighborhood. For the spatial aspect, 
this new business development is expected to favor dense, uneven development along the corridor, taking advantage of proximity to both similar and different business types.

Finally, there is some nuance in how different types of businesses engage with this paradigm of development. In part, it is because individual businesses are not catering to the same populations and therefore perceive and respond to adjacent businesses differently, and according to their own individual engagement with demand and centrality. The next section will highlight the specific retail types evaluated by research and position how they are expected to function within these eclectic clusters.

\section{RETAIL TYPES IN TIME AND SPACE}

Shopping behavior can vary widely from individual to individual and moment to moment (Goldsmith et al, 2011). Kim et al (2011) investigates the modern approach to shopper motivation which has identified four principle shopper types: hedonic shoppers, utilitarian shoppers, demanding shoppers and apathetic shoppers. In many of the cases, convenience or time savings is a factor in determining shopping destinations despite motivation perspective of the shopper (Kim, 2011). In fact, it is the convenience of proximity for comparison shopping which drives the clustering of shopper goods businesses. Therefore, the element of convenience is relative to a customer's relationship to the business in space and time. 
Historically, retail businesses were classified according to effort (Bucklin, 1963) as follows:

Convenience Goods: Those consumers' goods which the customer purchases frequently, immediately, and with the minimum of effort.

Shopping Goods: Those consumers' goods which the customer in the process of selection and purchase characteristically compares on such bases as suitability, quality, price and style.

Specialty Goods: Those consumers' goods on which a significant group of buyers are habitually willing to make a special purchasing effort.

In this respect, the concept of effort serves to combine both time and space relative to the consumer. While Bucklin's article argues the semantics of defining retail business types, essentially the conclusion remains the same; convenience business rely on their proximity to consumers and the quantity of consumers, while shopper goods businesses rely on their proximity to similar businesses and the quality of shoppers (customers who are attracted to their location by comparison shopping, as well as other unique merits).

Similarly, Berry et al (2002) evaluated schemas of defining service convenience to align with goods related businesses. While convenience with service sector businesses is relative to an individual's perception in space and time, and in fact a variety of unique differentiators, essentially convenience is also tied up in space and time.

The main framework for understanding retail goods and services since the 1920s has been a scale of risk and effort, with convenience products at the bottom, shopper goods in the middle and specialty goods at the top (Murphy and Enis, 
1986). Brown (1994) argues that at the micro-scale, agglomeration becomes the primary spatial arrangement by which similar retail business types cluster to create distinctive sub-areas. However, competing economic forces of agglomeration and dispersion complicate centrality.

Brown evaluates the impact of attractor, or magnet, stores on shopper circulation patterns and concludes empirical evidence supports the conclusion the majority of shoppers gravitate towards these destinations. Linkages between similar and dissimilar retail business types can exploit these magnet stores by capturing densities of movement. The primary principle of minimum expenditure of effort, on the part of the consumer, suggests that the closer businesses are to magnet stores the greater the likelihood of patronage (Brown, 1994).

Understanding that shoppers have different motivations, destination retail is relative. In the case of neighborhoods, it is evident that convenience goods are magnets to residential populations (including employees) while shopper goods may attract broader regional populations. In this respect, retail type in space helps to determine shopping behavior. Over time, destinations may change according to movements of other businesses which may enhance or detract from attractor, and similarly destinations may be overcome by broader consumption patterns.

Empirically, Clarke et al (1997) suggest that proximity to customers is the most important variable for consumer goods, whereas comparison and financial savings are the principle motivators for shopper goods consumption. Comparison goods outlets benefit from clustering, whereas convenience goods stores generally 
tend towards dispersion; research on the aggregation of retail stores hypothesized that some businesses cluster (specifically shopper goods) while others (convenience goods) "tend to be uniformly distributed over the entire urban zone" (Jensen, et al, 2010).

\section{IMPACT ON RESEARCH}

Based on the literature, it is hypothesized that patterns will demonstrate these trends with a broader structure of centrality influencing the ultimate stability and success (in this case tenure as a proxy) of a neighborhood commercial corridor. Specifically, it is anticipated that neighborhood commercial corridors will display the following key characteristics: diversity of and among business types; density and infill clustering rather than even, linear development; and that within a commercial corridor morphologically, or structurally, similar clusters will develop over time.

The first point of diversity of and among business types addresses concerns of homogeneity in neighborhoods experiencing change. Considering trends towards heterogeneity, and its manifold economic benefits to individual businesses as outlined by the literature, it was expected that there was be a mix between convenience and shopper goods. Furthermore, the total number of businesses would correlate to a diversity of business types and be comparable across case study areas. Contrary to emphasis on "boutiquing" or descriptions of commercial gentrifications, it was hypothesized that analysis would demonstrate stability, or a high level of tenure combined with overall high total of businesses, corresponded to an optimal 
level of business mixture. This business mix is the "eclectic" portion of eclectic clustering as identified in the literature.

Second, research anticipated neighborhood commercial change would be spatially expressed in terms of clustering. While one and two dimensional models, invasion succession in particular, undervalue the inherent hierarchy of space, a complex framework of centrality as understood by fractal economics and movement economies suggested the generative properties of space will develop according to uneven, dense agglomeration. Following previous studies, principles of central place necessarily encourage development to optimize where businesses can be in close proximity to other businesses.

Finally, over time it was predicted neighborhood commercial corridors would develop multiple centers to increase cluster viability through proximity to other clusters. In advanced stages of development, with increased number of businesses and relative stability of businesses, decreased location opportunities necessarily limit where entering businesses can be established. Limited location choice, however, does not exclude a business from generative central place principles thereby resulting multiple centers. In this way, neighborhood commercial change is inherent dialogical and dynamic, responding to existing urban fabric to produce and reproduce profitable spaces. 


\section{RESEARCH DESIGN AND METHODS}

This chapter reviews the research design and methods, including a discussion of case study selection, time period, and analysis method. Using an interdisciplinary foundation, the research design focuses on a heuristic approach. Because the main contribution of the research is to understand spatio-temporal patterns, rather than test specific hypotheses, the methodology supported inductive analysis and observation. This was designed to provide an opportunity for future research and evaluation of patterns without issues of theoretical bias.

Economic geography and sociology literature recommend an exploratory/experimental research design that considers spatial and temporal processes to be the most promising strategy for understand phenomena at the neighborhood level (Sampson et al, 2002; Yeung, 2003). Because research on neighborhood commercial change is limited, precedents for methodology are also limited. Informed by the literature and lack of previous empirical work, a heuristic approach was developed.

Borrowing from several mixed methods of empirical research, the end goal of the research design was to allow for flexible, simple null hypothesis for the invasion succession model.

Research Questions:

1. Do neighborhood commercial corridors display trends of displacement, over time, of certain business types? 
2. Is development even and linear or do neighborhood commercial streets develop in uneven, dense spatial clusters?

3. Do business cluster according to type? How do business clusters change? Are there similarities of clusters from corridor to corridor and within corridors? Differences?

The first research question addresses the perspective within literature and policy that neighborhood commercial redevelopment involve displacement, where new, shopper goods oriented businesses catering to a changing residential population appear in the disinvested corridors and eventually replace preexisting, convenience goods businesses. The implication of this model on policy and theory would be to suggest that safeguards are needed to protect ownership and operation of businesses, which are displaced by reinvestment in a commercial district. Conversely, new evidence that heterogeneity is increasingly prevalent in neighborhoods of change coupled with benefits of diversity advocate for a business mix which includes a variety of types including specialty, shopper, and convenience goods and services. Essentially, are these developments eclectic?

The second research question speaks to the need to make spatio-temporal variables explicit by identifying whether or not there is a hierarchy of place. If development follows an even pattern or location sites do not display trends of agglomeration, and therefore cannot be correlated, then it is likely centrality is insufficient for understanding location choices in neighborhoods commercial corridors in change. 
The final research question addresses another commonly held perspective in the literature that retail location is based upon the central place theory, as represented by Hotelling. In other words, businesses locate according to variables of cost and proximity to the urban center, or population densities. What I am specifically interested in is whether densities reflect the premise that shopper goods tend to cluster, while convenience goods and services disperse along the aggregate. By distinguishing type of businesses, commonalities and differences in how business located in relation to each other allowed for insights that may help to advance theoretical work.

\section{METHODS}

The first step of research was to identify several case study areas that represented neighborhood commercial corridor change. Based on previous research (Hardyman, 1998; Sullivan, 2000; Curran, 2004), newspaper reports, government plans, and local knowledge several areas were selected according to the following criteria:

1. Relative proximity (within 5 miles) to the CBD

2. Locations adjacent to residential densities

3. Areas with identified commercial corridors

4. General sense of place/distinctiveness

In addition, two areas were chosen as control studies to compare patterns. These two areas were chose because of their lack of general sense of place. The 
next section reviews case study areas and general approach of using commercial corridors as the primary unit of analysis.

\section{UNIT OF ANALYSIS AND CASE STUDY APPROACH}

The fundamental unit of analysis for research was the aggregate of the street, rather than the individual businesses. For the purposes of this dissertation, streets were characterized by: business mix and types; compounded changes to the tenure of businesses; rates of change at the street scale; streetscape changes and design character; and range of prices of retail goods. The street is a critical unit for analysis because it served as the basis for the model of the spatio-temporal change curve and allowed for small errors assumed to be present in notably imperfect data sets.

The street allowed a more objective examination of trends free from bias of actor driven change or sampling issues related to determining analysis segments based on site specific characteristics.

The first step of research was to analyze the city as a whole and identify areas that popular knowledge states have experienced significant commercial change. The primary method for identifying these areas was a review of local publications from the 1990 s to the present day that featured stories on changing neighborhood districts and cultural "hot spots." Essentially, because the purpose of research is to establish patterns that occur in areas despite local conditions or characteristics, any gaps, biases or insufficiencies that may have occurred as the result of this method will have a minimal impact on conclusions. The small scope 
was felt as the most manageable way to conduct exploratory analysis. Future research testing findings and patterns would need to be increased in the number of case studies, incorporating similar sites within a variety of other US cities.

However for the purposes of the heuristic methods, considerations to a variety of local conditions including economic trends and demographic shifts should be evaluated as having an impact on change patterns.

Research identified several neighborhood commercial corridors in various stages of change throughout the City of Portland. Based on conclusions by Clemmer, and early research conducted by the author, case studies areas were identified as: the Hawthorne District (from 21st to 50th), the Alberta Arts District (from MLK to 33rd), NE 28th from Sandy to Stark, and NW 23rd and 21st (or commonly called the NW District). In trying to formulate a true test of invasion succession model on neighborhood commercial change, it was felt these case study areas best represented change in different time periods, with different characteristics, and different actors. It was felt that a diversity of variables strengthened the case for patterns of similarity that are uncovered by research and provided an optimum sample to test correlations.

To support findings, two additional case study areas that were observed to have less significant change, SE Belmont and NE 42nd, were also analyzed. These two corridors have historically been subservient to nearby commercial districts, and therefore essentially act as entry opportunities markets or spillover cachements for those districts. 
The first two areas considered, NW 21st and NW 23rd, are generally considered to be the Northwest District. This area has a mix of single family homes, apartment buildings, duplexes, town homes and condominiums. Contained by Burnside on the south side, industrial land to the north, a freeway to the east, and a hill to the west, this area is considered a haven for young urban professionals.

The Northwest area is considered to be, in part, transformed by active neighborhood organization and participation in city government. Broadly considered to be the first gentrified neighborhood in Portland's inner city, the Northwest has a variety of restaurants, bars, cafes and retail shops. The area is notoriously inhospitable to the automobile, as parking is predominantly limited to on street spaces. Compared to traditional malls or suburban retail, the lack of designated parking would suggest the majority of patrons are commuting to the location via means alternative to the automobile. However, as a regional destination, the NW District does attract a variety of populations to the area for shopping and work. Therefore the area was identified by early research as an ideal basis for the study of neighborhood commercial change.

According to the US Census, the NW District has one of the densest populations per square mile within the central city, increasing from several thousand in the 1980 s, to well over 9,000 in 2010 . Median household income increased most significantly in the residential area east of NW 21st between 1990 and 2000, rising from an average household income of $\$ 15,000$ to over $\$ 25,000$. The percentage of households with children remained consistently under 5\% over the last several 
decades and the percentage of individuals with a college degree remained between 30 to $40 \%$.

Another significant shift was the percent of white individuals decreased from over $90 \%$ in the 1980 s to fewer than $75 \%$ in the year 2000 .

SE Hawthorne has also been identified as one of the central examples of gentrification in the inner city of Portland. It is typically described as a bohemian area, and has a mix of brew pubs, pizza places, bars, cafes, restaurants, vintage clothing stores and other supporting retail. It has some apartment buildings, but is largely dominated by single family homes. Homes are predominantly larger, rehabilitated Craftsman, Victorian, Arts and Crafts, and Bungalow. The area is popular with both young individuals and couples and families with children. Before gentrification it was considered a mainstay area for hippies. Hawthorne Blvd. is a hub for multi-modal transportation, including buses, automobiles and bicycles.

The residential area around SE Hawthorne has enjoyed steady population since the 1980s, between the ranges of 5,000-9,000 people per census tract. Median household income also remained steadily in the $\$ 30,000$ to $\$ 45,000$ range (in 2000 dollars) with the exception of the tract between Hawthorne and Stark (to the north) and 30 th to 27 th which was consistently $\$ 15,000$ to $\$ 10,000$ behind adjacent tracts. The 2000 Census demonstrates this area has a larger percentage of multi-family dwellings, with $15-20 \%$ of people living in group quarters.

Running parallel to SE Hawthorne, SE Belmont does not have a firm identity. Redevelopment along the commercial corridor beginning in the late 1980s 
created opportunities for major anchors, like Zupan's market, but has been slow to spur significant change. The main commercial section of SE Belmont, from SE 21st to the major intersection at SE 39th, still retains many long standing businesses mixed with newcomers. Bars, restaurants and café dominate the landscape, with fewer retail establishments. Specialty niche retail and professional services appear in pockets along SE Belmont, but the lack of observable clustering make it an interesting foil for more cohesive neighborhood commercial corridors like Hawthorne or NW 23rd Ave. Belmont shares several census tracts with Hawthorne Blvd, so demographics are not surprisingly consistent. Income increased over $\$ 10,000$ from 1990 to 2000 in several tracts to the north of SE Belmont. The percent of owner occupied housing in these areas experiencing median household income increases were consistently between 20 to $30 \%$ from 1980 until 2000, with renter occupied units staying between 75 and 90\%. Interestingly, the area adjacent to SE Hawthorne that was consistently $\$ 10,000$ below adjacent tract median household income experienced a shift in the age of population between 1980 and 1990 , from a $30-40 \%$ of individuals between $18-24$ to $10-15 \%$. Within the span of ten years, the population shifted from $18-24$ years to $20-30 \%$ from $35-44.0$ Alberta (now branded as the Alberta Arts District) lays at an interesting intersection of neighborhoods. Between historically African American neighborhoods, historically older, working class neighborhoods, and close to a traditionally high income neighborhood, a boom in housing and commercial investment and appreciation during the late 90s to early 2000s resulted in a 
strengthening of identity along the commercial corridor. Alberta provides a particularly interesting dimension to research, because early investigations suggest that minority businesses have recently been displaced.

According to US Census tract data, tracts adjacent to Alberta saw an overall population decrease from the 1980 s to the 1990 s. Between the 1980 s to 2010 , percentage of owner occupied housing has remained around the 60 percent range. The most significant demographic shift between 1980 and 2010 was an increase in overall household income from nearby tract averages of $\$ 35,000$ (in year 2000 dollars) to $\$ 50,000$. Between 1990 and 2000, the percentage of white (nonHispanic) individuals increased in at least one adjacent census tract by at least 20 percent, with others remaining relatively the same.

The commercial area, while trying to maintain its branded identity as a haven for arts and diversity, appears to be following similar patterns of change to the Hawthorne area. Professional and personal services, non-profits, and a mix of convenience and shopper businesses are concentrated between approximately NE 12th and NE 29th.

NE and SE 28th, recently branded Restaurant Row, saw more shopper goods and services appear in previously residential or industrial pockets in the late 1990s and early 2000s. Largely a site of professional and commercial business services, a few anchors like Wild Oats market on Burnside helped to generate localized activity. In addition to being a relatively new location of business change, the corridor is also of interest because of land use constraints. One block north of 
Burnside is dominated by the second run movie theater wall, which is a blank façade. The block next to that also houses a large distribution center which also is unavailable for development. This has limited opportunities for business change or development on one side of the commercial corridor, near the anchor tenant. This unique characteristic has the potential to act as a strong external force on business change.

Finally, NE 42nd is ten blocks east of NE Alberta running from the Beaumont village commercial district north to industrial land uses by Columbia Blvd. Despite changes in residential demographic, the commercial corridor has remained underdeveloped. Like many of the other case study areas with pockets of industrial or commercial activity, the north end of the street is dominated by light industrial or commercial businesses. Convenience goods and services have cycled through the corridor and remained, while more shopper type goods and service oriented businesses have experienced short lives on the street before either dying or moving to another commercial corridor. NE 42nd Ave was selected as a case study area to serve as a comparison to other corridors where invasion succession was identified as an observable phenomenon. It was not expected that NE 42nd would undergo much change, and indeed the results bear this out.

In preparation for research, historical data of several neighborhood commercial districts was collected and analyzed. Using cross-reference directories, which list businesses by address and are supplemented by additional information 
(such as birth of business at the address, new businesses, and a change from commercial to residential).

As an exploratory exercise, historical data was collected on these neighborhood commercial districts from the 1970s until present day. This research revealed that major commercial change did not occur in these many of these districts until the 1990s. This may or may not be related to the significant changes in residential populations and patterns that occurred in Portland in the 1990s in response to the high tech boom.

The data from the 70s and 80s was useful in testing the final conclusions of research, particularly since it provided some idea of the background of the neighborhood commercial district; historical data allowed a good idea of total tenure, business type, and spatial changes that preexisted in case studies. The next section explores how historical data was utilized to understand spatio-temporal patterns and provide a framework for research questions.

\section{THE NEIGHBORHOOD: HISTORICAL DATA}

Historical data from the main case study areas was collected from 1980 until 2011. Although the 1980s were not used in the analysis, the data used to help inform change that occurred in the 1990s, and ensure that business birth and death in 1990 was accurately accounted for.

The main resource for historical data was cross-reference city directories. Cross reference directories give listings of residence and businesses, like a phone book, by address. In the case of business listings, cross reference directories also 
include notations which indicate the birth, tenure, and any changes to the listing. The cross reference directories are issued annually and are publicly available, allowing for ease of access and use. Their value as a historical research tool has precedence in similar studies on local business change.

Hardyman employed Cole's Cross Reference City Directories in a 1992 thesis that looked at commercial gentrification in Portland. Although her research was limited to one street, SE Hawthorne, and from the 1980s to the early 1990s, her research demonstrated the validity of using cross reference directories as a historical research tool for the purposes of this research. Similarly, Curran (2004) used Cole City Directories to examine the issue of industrial displacement created by gentrification in Williamsburg. Like Hardyman, Curran catalogued businesses by year and address to demonstrate change from one business type, industrial, to retail use.

While both Hardyman and Curran address problems associated with using cross-reference city directories, they both also recognize its significance as a starting point for mapping and collecting data on business change. Business license data, although useful for quality control purposes, was not complete enough to demonstrate yearly change. Zip code data obscures the address sites, so would not demonstrate nuanced displacement. Therefore, problems with cross reference directory data were outweighed by its value as a historical research tool.

Hardyman discusses the problem that the annual nature of city directories does not capture businesses that lasted less than one year. She also suggests that 
some errors possibly exist in the information the directories provide. Hardyman reconciles these problems by suggesting that the Cole directories claim 85-90 percent accuracy in reporting, and also suggests inaccuracies, including the lack of reporting businesses that did not succeed for the year period do not affect the general profile of commercial change. Because the aggregate is the unit of analysis, it was also felt that despite gaps in data, it generally would provide a repeatable and consistent resource. Also, because the primary purpose of research was to evaluate the invasion succession model, it was more critical to understand the long term impact of new businesses on existing businesses; short lived business ventures arguably cannot, by definition, be considered as successors.

An earlier study on gentrification in the Adams Morgan neighborhood, in Washington D.C., conducted by Henig (1982) also used cross reference directories to understand business change after finding interviews an insufficient method in providing a comprehensive picture. Henig also recognizes some potential deficiencies in using cross-reference directories, but was able to reconcile the data in much the same way as Hardyman. Where noticeable flaws existed, additional research was conducted to reconcile data and ensure for accuracy.

For the purposes of this study, the total number of businesses within a commercial corridor served as a proxy for the density. Density was also examined over time, in relationship to individual blocks to understand clustering patterns.

To understand the impact of density on neighborhood commercial change, two main variables were considered a). The average tenure of businesses (to serve 
as a proxy for stability) and b). The percent mix between retail convenience and shopper goods. Evaluating the correlation between business births and business deaths was the first method for understanding neighborhood commercial change. The comparison between types also serves to examine the mix of businesses within an area and what impact the addition of shopper goods and services have on convenience goods and services.

Once individual segment and street analysis was conducted, it was possible to compare data sets with each other to discern any patterns recognizable within the analysis. Although the limited scope of previous business research by Hardyman, Curran and Hening, did not use comparison to support findings, when evaluating theory and looking for patterns of change it was critical to research to compare and contrast findings in order to let emergent patterns rise to the surface.

Type of business was recorded based on supplemental research, including historical newspaper advertisements, business websites, business review websites, and phone books. In some cases, names were obvious (e.g. Quick Mart, Coin Laundry) or franchises from national chains. The next section reviews classification methods and considerations while coding the data.

\section{DATA AND CLASSIFICATION}

The products of historical research were databases of case study areas that catalogued, by year and by address, businesses. In some cases, vacancies, residential presence or lack of available data were noted and checked against 
additional resources, including newspapers, phone books, individual business websites and other internet resources, including business review sites like Yelp!

Once data was cross referenced by each year against surrounding years, and verified by additional research, a series of steps were employed to classify businesses according to type. Where business names did not denote the type of business (most professional and personal services typically include the type within the business name), additional research was conducted. For historical data on businesses no longer in existence, business license data was researched which lists the NAICS grouping.

A common method for classifying businesses is the North American Industry Classification System, formerly the SIC system, that is developed and maintained by the federal government. This classification system is used in studies with broad research interests, including market research, statistical research, labor research, and national data.

According to Triplett (2002) the U.S. statistical system came under attack in 1990. The main criticism was that the SIC system was inadequate in its classification of industries. In response, the NAICS was developed to replace the outdated SIC system. The NAICS embraces a five digit level grouping of businesses with the same or similar production processes. Triplett states that the development this system made both theoretical, economic sense as well as was a more coherent system for understanding industries. 
While the NAICS is viewed generally as an improvement upon the SIC system, Triplett states that there are still gaps which have omitted whole industries or components of industries. Therefore, the NAICS is an imperfect classification system. Peck (1993), in an overview of industrial classifications, states that the industry codes allow the research to capture economic sectors. The contribution of the U.S. census is to present an even more disaggregated system that offers a high level of product detail. This data, state Peck, is largely used to understand broad national, economic trends. However, as it has been commonly used in other empirical research designs including (Muske, Fitzgerald, and Kim, 2002; Leduc, 2001; Wiegand, Patterson, Zhou, Ventura and Cruz, 2003; Mohr, 1998; Curran, 2004) it was a useful way to obtain historical typology information about businesses.

Using the NAICS as a framework for objectively separating businesses, contemporary research also used business license data, as any available research including product pages, newspaper articles or in some cases direct observation. This added layer of research was critical for understanding nuanced differences between businesses that, while selling similar products or services, targeted different populations. Restaurants, for example, were often ambiguous in their names and therefore required extensive research to evaluate price, niche, and level of service (table or counter, for instance) to determine whether they should be evaluated as a convenience or a shopper good. 
By no means is the mixed method of classification completely devoid of subjective assignment. However, consistency in classification, when businesses were particularly ambiguous, was seen as the ultimate safeguard against biased results. Classification of businesses represents a significant issue in the retail change literature (Hagberg, 2008). There has been some discussion throughout the literature, Hagberg suggests, that retail businesses types can be dynamic given external factors which influence its adaptability and competitive structuring. Hagberg's argument that if a priori classification precedes analysis of retail change, than analysis may miss critical components of the change process resulting from the fluid relationship between individual retailers and economic forces (Hagberg, 2008). Guy (1998) illuminated traditional retail use types as problematic when evaluating central place theory. Comparing UK government classifications between retail goods and retail businesses, it is clearly evident that businesses can sell a diverse portion of retail goods (Guy, 1998). Prompting the description of variety store or hybrid retailer, this can impact everything from the corner store to the large department store.

Guy also evaluates the use of classifying businesses by shopping trip purpose. Distinguishing between convenience and comparison shopping (I use the term shopper) become ambivalent when stores blur the lines as a competitive approach (Guy, 1998). Guy reconciles this issue by classifying businesses as either household shopping or personal/fashion shopping. 
Recognizing the various issues of classification, it was again felt the best course of action was to follow the Occam's razor approach; it was important to design research with an eye towards distinguishing business enough so that they were able to measured but not so much that any fluidity of retail form resulted in problematic results. Guy ultimately finds, in his evaluation of retail classification systems, a similar balanced approach is most likely the most accurate and thorough. He suggests that a compromise between "comprehensiveness and simplicity" strike the balance between ease of analysis and interpretation and clarity of results (Guy, 263). Furthermore, he suggests that research design should take in to consideration the broader retail setting. In the case of a neighborhood commercial district, the distinction between shopper and convenience goods was felt as well based method to classify businesses without eliminating potential emergent results.

Holton (1958) provided a distinction between convenience, shopping and specialty goods which has long served as a foundation for differentiation between retail business types. Although Holton noted individual preferences often determine the relative nature of goods (whether they are convenience or shopper goods), generally the probability of needing to compare price and quality with similar goods is an earmark of shopper goods.

Holton points out this general practice of distinction offers a concise and unambiguous means by which to understand the difference of retail businesses, allowing for individual motivations and market constraints. 
While shopping and goods have undergone significant change since

Holton's work was published, the principles remain relatively the same. Guy (1998)

provides a workable guide for the distinction between convenience and comparison

goods which, with the addition of professional services, can provide a clear and

concise method for representing different neighborhood business types. While

research recognizes this is a simplified, rather than nuanced, approach to

understanding retail differences, it provides the greatest depth of differentiation

without overwhelming scope or breadth of comparisons.

\begin{tabular}{|c|c|c|c|c|}
\hline & $\begin{array}{l}\text { Eating/Drinking } \\
\text { Establishment }\end{array}$ & Personal Goods & Household Goods & Services \\
\hline $\begin{array}{l}\text { Shopper } \\
\text { Goods }\end{array}$ & $\begin{array}{l}\text { Restaurants, bars, } \\
\text { specialty markets, } \\
\text { specialty eating } \\
\text { establishments }\end{array}$ & $\begin{array}{l}\text { Clothing stores, } \\
\text { Perfumeries, } \\
\text { accessories, specialty } \\
\text { gyms, toy shops, } \\
\text { imports or world } \\
\text { goods, sporting goods } \\
\text { stores, hobby }\end{array}$ & $\begin{array}{l}\text { Furniture, } \\
\text { appliances, } \\
\text { housewares, Misc. } \\
\text { niche or specialty } \\
\text { products, art } \\
\text { gallery }\end{array}$ & $\begin{array}{l}\text { Massage, } \\
\text { specialty } \\
\text { services, tattoo } \\
\text { parlors }\end{array}$ \\
\hline $\begin{array}{l}\text { Convenience } \\
\text { Goods }\end{array}$ & $\begin{array}{l}\text { Take out, diners, } \\
\text { fast food, cafes, } \\
\text { bakeries, mini- } \\
\text { markets, taverns, } \\
\text { delis, food carts }\end{array}$ & $\begin{array}{l}\text { Bookstores or } \\
\text { magazine stands, gift } \\
\text { shops, florists, } \\
\text { mail/stationary, video } \\
\text { stores, gym/fitness } \\
\text { center, medical } \\
\text { supply, thrift stores } \\
\text { (clothing), wine stores }\end{array}$ & $\begin{array}{l}\text { Hardware, misc. } \\
\text { household utility } \\
\text { and parts, auto } \\
\text { parts, } \\
\text { Cleaning supplies, } \\
\text { thrift stores } \\
\text { (household) }\end{array}$ & $\begin{array}{l}\text { Repair services, } \\
\text { auto services, } \\
\text { laundry, } \\
\text { banking, } \\
\text { locksmith, } \\
\text { beauty } \\
\text { salons/barbers, } \\
\text { business } \\
\text { services } \\
\text { (printing, } \\
\text { copying) }\end{array}$ \\
\hline $\begin{array}{l}\text { Professional } \\
\text { Services }\end{array}$ & Caterers & $\begin{array}{l}\text { Doctors, attorneys, } \\
\text { insurance, counseling }\end{array}$ & $\begin{array}{l}\text { Real estate, pet } \\
\text { grooming/sitting } \\
\text { architectural, } \\
\text { specialty craft, } \\
\text { skilled trade }\end{array}$ & nonprofits \\
\hline
\end{tabular}

Table 1 Business Type Classification

Assigning individual businesses to a category required, in some cases, additional

research. In the case of still existing businesses it was possible to use establishment

websites to identify the types of products and services offered or visit locations in

persons, and in some cases of out of operation businesses online reviews gave 
similar details. For older businesses, newspaper articles, print advertisements, and discussions with long time residents help provide a general picture of business type.

Using detailed information on products and services, the principles of effort were then applied to designate whether a business was convenience or shopper type. According to the classification system (Table 1), specialty and shopper goods were combined to streamline classification. Professional services for the FIRE categories were treated separately than convenience or specialty services, as were other professional businesses to distinguish them from more traditional retail oriented convenience and shopper goods establishments.

Convenience goods were those goods or services purchased with high level of frequency, offering immediate gratification and requiring minimal efforts. For food establishments, this included take out establishments with limited seating, cafes and coffeehouses, mini-markets, bakeries, and restaurants that offered an informal dining experience. By contrast, shopper goods establishments, which involved some level of comparison or consideration over time, price and quality, included restaurants primarily serving seated customers, bars which emphasized cocktails, and specialty markets (Pastaworks or Everyday Wine).

Similarly, retail stores were classified by the relative time and monetary cost to the consumer. Everyday items dependent on accessibility, like newsstands (Rich's Cigars) or video stores (Videorama), were classified as convenience goods while goods likely appealing to specialty or lifestyle consumption like boutiques or household shops (Kitchen Kaboodle) were classified as shopper goods. 
In some cases, it was evident that businesses could qualify for both convenience or shopper types, particularly when multiple items or services were offered. For example, Dosha Salon on Hawthorne offers both hair style and cutting and spa services, or non-profits like the Community Cycling Center on Alberta houses a retail component. In mapping, both were represented using different business types. When counting total businesses by type, the primary functional type for businesses crossing classification was used.

\section{HEURISTIC ANALYSIS}

Outside of business classification and hypothesis testing, the primary goal of research was to explore spatio-temporal patterns through historical aggregated data. Because precedent for empirical tests of theoretical basis are multi-disciplinary, research design relied on mixed methods pulling from a broad base of pedagogy.

Yeung (2003), in an evaluation of methodology of geographical studies, found that research methods remained underdeveloped and often relied on traditional methods. Based on a review of research design, he concluded that statistical analyzes were a useful tool for exploring broad pictures of economic landscapes, particularly when considering what he called the new economic geographies (Yeung, 2003). Yeung argues for abstraction as the first step towards conceptualizing and theorizing the causal relationships between actors. Because the relationships between actors are not readily available to empirical observation, abstraction as a methodological approach can help develop theory that can uncover 
relationships between empirically observable phenomena (like development) and generative mechanisms (Yeung, 2003).

Roberts (2001) defined the dangers in presuming to assume casual relationships from abstraction. However, because abstraction was employed for the purposes of solely understand the concrete mechanisms and patterns of change, there is little fear from the dangers of critical realism, which Roberts defines as a problem of static, non-dialectical assumptions (Roberts, 2001). While casual relationships may be the next step to understanding neighborhood commercial corridor change, research presented evidence that the picture was much more complex than can be explained by one set of actors. With identified gaps in the historical data, the level of accuracy required by a deep, multi method inquiry into competing external factors would be too incomplete and likely erroneous.

Mayer and Cukier (2013) argue that broader availability of big data have shifted focus from causality to answering other questions including how, where, when and who. The thrust of their book is to demonstrate that there is a global shift from causation to correlation as the accessibility of large, real time data sets transform research design. Because big data is a relatively new field of computational analysis, this shift is in many regards in its infancy. However, the principles of using correlation to solve problems formulates the basis of heuristic methodology.

Recognizing this, empirical tests were conducted against theoretically supported variables. First, to address the issue of invasion succession, analysis of 
the correlation between business birth and death was conducted; both predefined ten block segments and the aggregate of the street were units of analysis for birth-death correlation tests.

The ten block segments were developed to test correlations on a smaller scale; ten blocks roughly split corridors into three segments, and provided for an unbiased sample of businesses tending to cluster on a smaller, walkable scale. Koohsari et al (2012) produced a recent study examining the impact of perception and proximity on neighborhood walking trips, and defined a neighborhood walk as 10-15 minutes. Based on the Portland average block size, ten blocks is equal to roughly a ten minute walking, allowing an extra five minutes for traffic and additional distance from residents or origin point. Because the segmentation process was meant to serve as a test of correlation patterns, the origin points set to simplify segmentation and only represent a finite number of origin points for actual pedestrians.

The ultimate goal of research was then, to see what, if any correlations could first be made between business birth and death. Second, was to see if the total number of businesses had any impact on this relationship. Finally, it was of interest to see how type impacted business birth and death correlations, and whether the results supported the basic model of invasion succession. If birth and death displayed a strong correlation, with birth occurring after corresponding business death, the theory that businesses displace existing businesses would seem to be significant. If, however, correlation was minimal it would be determined that 
invasion succession was an unlikely descriptive process for neighborhood commercial change.

One of the main research questions and hypotheses proposes that birth will demonstrate a strong correlation with birth, increasing business density and resulting in business clusters. While some business death is expected as a natural economic condition of the retail market, research anticipated that patterns would demonstrate a higher tendency for growth rates would follow exponentially until the corridor reached a high overall number of businesses. Once at this tipping point for maximum density, it was anticipated that moderate birth and death rates would continue and show little correlation, instead being subject to regional, national or global economic trends.

\section{DATA TRANSFORMATIONS}

Correlation measures and total counts of businesses were used to develop a variety of charts and graphs used to illuminate patterns. As a first step, spreadsheets of the raw data was color coded to indicate type at various scales, from specific to broad. Spreadsheets of data were also used to tabulate birth and deaths through automated summations which could then be transformed into graphs, data charts, and input into formulas. Spreadsheets of data were maintained separately for each case study areas, and helped early on to identify needs for additional information, including type classification, obtained through mixed research methods.

The final step of research was to transform historical data into maps that explored issues represented in the literature. Specifically, maps showing patterns of 
change over time and space were the most accessible method to observe and explore general principles of centrality. Visual representation of location patterns could furthermore form a strong basis for specific comparison between case studies, allowing emergent patterns to be identified.

Maps were developed first to show changing densities of business in commercial corridors over time. Next, historical data and type classification was utilized to present a longitudinal picture of business location activity by type, including business death and birth. For the broader analysis, maps were compared based on five year increments across all areas.

\section{IN DEPTH CASE STUDY ANALYSIS}

Two areas were investigated in depth, Hawthorne and Alberta. These case studies were chosen based on the availability of previous research, similar morphological properties, most closely matched distance to the $\mathrm{CBD}$, and the characterization of each area as different and distinct places as found in mass media survey. Using maps, historical data, and previous studies, in depth comparisons were made about spatial clustering, business types, and the impact on tenure and mix.

As will be discussed in the next chapter, in depth analysis also revealed more nuanced data which aided interpretation of findings. Research looked at spatial clustering metrics, density measures, and observational data to compare patterns in both case study areas in five year intervals. Based on findings, recommendations 
were produced for further research including methodological considerations, theoretical implications, and potential causality issues. 


\section{DATA RESULTS AND FINDINGS}

This chapter will discuss observations during data collection, analysis and key findings with interpretations of results. By means of introduction, a review of totals and raw data will be presented. Initial observations will frame a broader discussion of analysis, highlighted by in depth analysis of SE Hawthorne and NE Alberta. Specifically, issues of tenure, correlations between business birth and death as a proxy measure of invasion succession, and relationship between totals of shopper and convenience businesses will be presented.

Finally, a discussion of results will be followed by an interpretation of data related to research questions. Analysis will address the data in relationship to the invasion succession model of change, spatial clustering as an indicator of centrality, and the relationship between business type and stability of a corridor.

\section{TOTAL BUSINESSES AND TENURE}

The first stage of analysis following data collection was to calculate total businesses by year in each corridor. These simple counts were used as a foundation for understanding peaks of change. Counts did not consider any other criteria like employment size, site size, or ownership as a way of avoiding bias or noise to data ${ }^{1}$.

\footnotetext{
1 During early data collection, alternative data sources for ownership and birth and death were evaluated. Business license data was obtained from the State of Oregon. The information, while useful as a secondary source, demonstrated too many gaps to offer a consistent method for understanding neighborhood business change. Similarly, the City of Portland's GIS mapping tool did not capture yearly snapshots of business change as assessor and permit information was based on ownership rather than occupancy. Because occupant businesses were the primary focus of research, other variables like employee numbers, retail square footage and ownership would have added unnecessary complexity to heuristic research design. Therefore, a simple count of business
} 
One of the principle interests during corridor selection of the case studies was to choose commercial streets that were different in location within the city, physical characteristics, and character. These differences were important to ensuring results capture the spectrum of change, while providing a real test for any temporal or spatial patterns, including invasion succession and clustering, that may arise.

Commercial corridors were distinct not only in character, but in total number of businesses (Table 2). In part this was related to the total length of the street; SE Hawthorne as analyzed consisted of over 50 blocks, NE $28^{\text {th }}$ and NW 21 st over 15 blocks, NE $42^{\text {nd }}$ and NE Alberta over 30 blocks, NE Belmont over 40 blocks and NW $23^{\text {rd }}$ over 20 blocks. Total numbers of businesses also related to the level of investment demonstrating in 1990; Hawthorne and NW $21^{\text {st }}$ demonstrate smaller total business increases over 1990-2010 as a result of earlier investments while NE Alberta, experiencing the most dramatic investment between 1990 and 2005 saw a greater net increase of the total number of businesses (Table 2).

\begin{tabular}{|c|c|c|c|c|c|}
\hline Commercial Corridor & 1990 & 1995 & 2000 & 2005 & 2010 \\
\hline NE $28^{\text {th }}$ & 30 & 53 & 59 & 48 & 31 \\
\hline NE $42^{\text {nd }}$ Ave & 78 & 79 & 78 & 75 & 51 \\
\hline NE Alberta & 50 & 62 & 98 & 168 & 160 \\
\hline NW 21 $1^{\text {st }}$ & 81 & 96 & 119 & 118 & 82 \\
\hline NW 23rd & 121 & 151 & 189 & 112 & 119 \\
\hline SE Belmont & 148 & 150 & 173 & 216 & 165 \\
\hline SE Hawthorne & 287 & 278 & 301 & 329 & 261 \\
\hline
\end{tabular}

Table 2 Total business numbers for street in five year increments

was utilized as the most effective and repeatable method for understanding basic spatial and temporal patterns. 
What was interesting, considering differences phases of investment for each street was that all experienced peaks in total number of business between 2000 and 2005. Decline by 2010 in total business counts across areas likely resulted from 2007 to 2009 US recession which led to significant unemployment in the PMSA (Figure 9). Over the twenty year period analyzed, significant external economic forces including several recessions undoubtedly impacted birth and death rates for businesses within each corridor. The evidence of these individual corridor peaks suggested structural influences on micro economies of corridors are significant enough to demonstrate patterns beyond the neighborhood.

The next step of data collection was to examine the birth and death cycles of individual businesses. The cross reference directories provide notations on a business's birth year, however in order to ensure accuracy of data, information was collected by year for each address. This allowed missing data to be tracked and corrected through yearly listings. In some cases, information had to be reconciled with external research including newspapers and business websites.

In cases where a business relocated within the individual street, a death for the location and birth for the new location was not counted. However, for businesses which relocated to another location within the city or region, their disappearance from the corridor was treated as a death. Because displacement has been raised as a significant concern for neighborhood commercial change, it was felt treating displacement from the corridors as deaths when aggregated with other data (including businesses relocating from other areas to the corridors treated as a 
birth) would allow for the strongest analysis of change impact on existing businesses.

By the same token, in the case where businesses expanded into adjacent sites, displacing previous businesses, (Powells on SE Hawthorne for example), the expansion or annex property was treated as a birth. Although not a common occurrence, when businesses expanded it was important to represent that one business (or a vacancy) was being replaced by the birth of another. This was the only case where size of a business had a potential impact on the analysis.

Another observation during the data collection phase were changes to addresses or conversion between residential and commercial uses. When new addresses or changes to addresses appeared, they were incorporated into the spreadsheet with notations. During counts of totals, births and deaths, these properties were treated as if they had been long standing. The main complication this presented to analysis was it eliminated potential of placing a maximum capacity on possible business locations, as it was evident the dynamic relationship of investment made the capacity inestimable. Tracking change over a longer time period might potentially offer a valid scale to evaluate totals by, however minimum and maximums calculated in the analyzed two decade time period could have opened analysis up to sample bias.

Births and deaths were tabulated for all years, with data from previous decades to calculate any activity in 1990 or capture potential missing data. A broad look at births and deaths began to provide information about business tenure in the 
corridors. Tenure, as a proxy for stability, was considered against birth and death rates to evaluate any correlations which would suggest an impact on longevity of businesses.

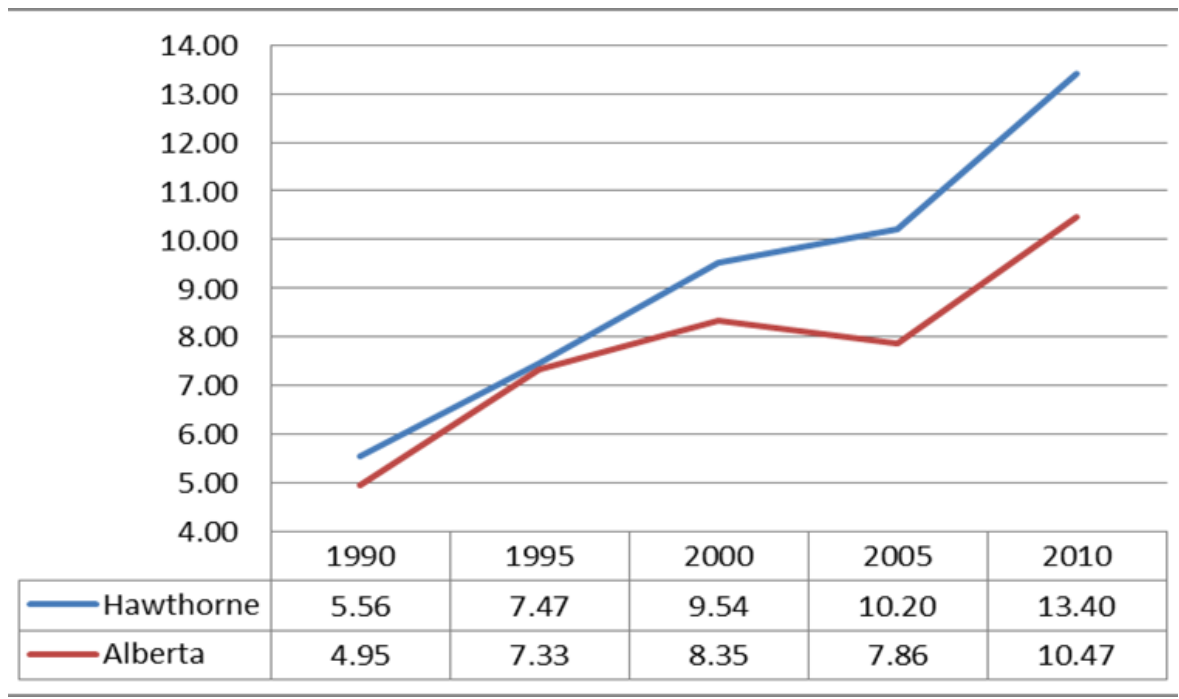

Figure 1 Average Tenure for Hawthorne and Alberta by five year increments rounded two decimals

Evident from initial analysis of tenure was that the relative stability of neighborhood commercial corridors increased over the last twenty years. Figure 3 demonstrates, for the two in depth case study areas, that average tenure for SE Hawthorne and NE Alberta more than doubled between 1990 and 2010². Hawthorne experienced a deviation from a steady slope of tenure between 2000 and 2005, while Alberta saw a dip in average tenure during the same years, echoing trends of business density (Table 2) that reached a peak in 2005. When comparing the two data transformations, it was interesting to note that a decline in total number

\footnotetext{
2 Tenure was calculated using business birth information prior to 1990 . For instance, several businesses in the $30^{\text {th }}$ blocks of SE Hawthorne originated in the early 1980s and mid 1970s.
} 
of businesses between 2005 and 2010 did not impact the trend of increasing average tenure, indicating a continued stability of businesses in both corridors.

\section{BUSINESS TYPES}

The final stage of initial data collection was to classify businesses according to type. As noted in the previous chapter, in cases where business names did not make it obvious how to classify ${ }^{3}$ it was necessary to follow up with mixed method research to identify the main type and separate according to convenience or shopper goods. Resources including newspaper archives, websites, review sites like Yelp! and Google, Google Maps, and informal interviews with Portland residents were used to help evaluate primary goods or services of non-operational businesses. For current businesses, informal in person visits were also used to investigate primary goods or services of each establishment. Detailed information was collected in spreadsheets, which were then color coded using several different classification systems from specific to general.

An interesting observation from data was the level of diversity among business types within individual segments. Even in dense shopper type retail centers, the presence of professional, government, non-profit and convenience activities are noticeable. Although this does not occur in all areas, in the main case

\footnotetext{
${ }^{3}$ Businesses which included indication of goods or services within the company name in some cases still required further investigation, particularly for restaurants and retail goods where assumed consumer effort was main distinguishing feature. However, obvious business names (Random Order Coffeehouse, Earl's Barbershop, Vian's Automotive) or corporate franchises (Ben \& Jerry's, Subway Sandwiches) were classified with the assumption their name appropriately identified their type.
} 
study corridors diversity is a common feature. The primary exception to business mix are NE $42^{\text {nd }}$ and SE Belmont, the two areas chosen as less successful sites of commercial redevelopment and development.

Over time, there was also a demonstrable diversity of the density of clusters across segments within individual case study corridors. The whole length of case study streets did not experience rates of change at equal volumes or within similar time periods; clusters began to be evident with analysis of totals by segment. This suggests that redevelopment and neighborhood change does not uniformly impact neighborhood commercial corridors. Rather than even development and redevelopment, it is apparent that some segments have more dense and diverse business activity than other segments. It was evident that within each commercial corridor, intense activities centered near residentially dense areas.

It is important to note that even in highly developed commercial corridors that have been pronounced commercially gentrified by researchers like Hardyman (1992) and Clemmer (2000), when considered as a total street or parsed by random intervals reveals a much more complex relationship with other segments, adjacent neighborhoods, and the city at large. This was a significant finding, as even in areas with long term dense retail, like NW $23^{\text {rd }}$, there was an evident hierarchy of space. This supported hypothesis of clustering and furthermore helps to challenge concerns that gentrification results in "boutiqued" streets devoid of original businesses. It also lends strong support for the inclusion of employees as a significant class of 
consumers, with residents and visitors, which should be considered as helping to sustain commercial areas.

Apparent in the graphs and maps, the trend towards diversity and density is typically connected to the total volume within the segment of shopper goods. Those non- convenience retails goods and services (like restaurants and boutiques) most commonly cluster in specific areas, buffered by less dense segments mixed with professional, government, industrial, commercial and convenience business activity. An overabundance of one type of use generally discourages future development of other types of use. This follows economic principles, and therefore would appear to be intuitive. However it runs counter to the landscape suggested by the literature of culturally commodified neighborhood commerce; the process appears more inclusionary of business types than rhetoric has recommended.

Part of the diversity, and apparent clustering, of business types is related to the location within the larger system of spaces. Perceptive boundaries, helping to strengthen a hierarchy of space, appeared to stimulate the generative model of development by devaluing peripheral spaces that could be used for businesses requiring less visibility or density for comparison shopping purposes.

Longer streets, like SE Hawthorne and SE Belmont, actually run through a series of neighborhoods. At their west most sections, both transect the Central Eastside, an industrial landscape that also contains main north south arterials, Martin Luther King Blvd and Grand Ave. Similarly, NE Alberta is bound to the west by Martin Luther King Blvd, and NW $21^{\text {st }}$ and NW $23^{\text {rd }}$ Ave are contained at 
their boundaries by Burnside, a major east west arterial, and by an industrial area to the north. NE/SE $28^{\text {th }}$ included Burnside in the studied segments as commercial activity occurred in densities on either side of the major arterial. However, NE $28^{\text {th }}$ is bound to the north by Sandy Blvd, also a major arterial that runs diagonally through the eastside of the city.

The characteristics of boundaries created by grid characteristics helped to identify perceptive boundaries. What was evident, by including long sections of the streets in the data collection process, was that all commercial use is not evenly or regularly distributed.

The peripheral sections of corridors appeared to support pockets of professional services. These included doctors, lawyers, accountants, and other small offices of professionals working both as individual and cooperative firms. Professional services appeared resilient, in many cases, to changes within the retail goods and services clusters; many of the professional services are still present and had their birth during the 1980s. No doubt, the nature of owner operator businesses allows for more flexibility to contend with broader economic constraints while lower rent costs at the periphery helped reduce overhead.

The same was also true for government and non-profit organizations located near changing retail clusters. In several of the areas, government offices and nonprofit organizations pre-dated the time period of the research, or arrived in neighborhoods prior to periods of high investment. It can be assumed this enabled such offices and services to secure low rents while gaining access to adjacent and 
city wide populations services by these business types. Non-profits and government locations at the edges of the corridors had greater longevity than those within the core, however there were exceptions; Sabin Community Development Corporation and the Community Cycling Center on NE Alberta were located at the core of dense activity and able to sustain their location for over a decade even during the height of business change between 2000 and 2005 .

It is worth noting that in the less successful case study areas of NE $42^{\text {nd }}$ and SE Belmont, there was a lower quantity of professional services, government offices, and non-profit organizations than in counterparts. NE $42^{\text {nd }}$ has a high density of industrial and commercial services, most likely because of its proximity to Columbia Blvd in the north, which is a major transportation and distribution route. In denser neighborhood sections of this corridor, convenience businesses tend to cluster around other commercial services. Unlike other case study areas, there is a marked lack of doctor offices and FIRE professionals. There are a handful of nonprofit or government establishments, but these also tend to cluster near other office buildings and at a distance from convenience business clusters.

By comparison, SE Belmont has more shopper goods establishments. However, FIRE and other professional establishments tend to cluster rather than disperse. The impact on the ground of this would be to create greater distance between convenience and shopper goods and densities of employees, minimizing opportunities for market capture of visitors. 
The densest section of commercial activity on SE Belmont is enhanced by a narrower street and small scale buildings that are anchored by major grocery retailer Zupan's Market. New developments to the east of this segment might potentially help to strengthen SE Belmont as a shopper destination, but its limited diversity of business types within segments reduces the potential for additional draw from employment densities. SE Belmont has traditionally maintained convenience and shopper businesses, with a particularly strong density of eating and drinking establishments. During week days, when the majority of working residents are away, many of the eating establishments are closed. Other corridors, with a higher number of professional services, typically have eating establishments which serve during both lunch and dinner hours, and there is a broader variety of both convenience and shopper type eateries.

The other case studies demonstrate a much stronger interplay between uses and a wider dispersion of non shopper establishments along segments which, undoubtedly, allows for improved capture of both convenience and shopper spending. I think this is a critical connection to make, which is so often neglected in the literature or in planning; an over emphasis on residents or visitors neglects the purchasing power and daily interaction employees have with neighborhood commercial corridors.

Employees occupy a unique position between residents and visitors, with a different set of routines and behaviors that impact their relationship to businesses in the neighborhood commercial corridor. Like residents, they may run convenience 
or personal errands throughout the day at nearby businesses. Likewise, they may also visit nearby retail establishments to compare with similar businesses near their own residence or to connect with other employees for social reasons. Their regular presence in the neighborhood commercial corridor creates an added population for both convenience and shopper goods stores and in turn may have benefits of also creating a sense of community, continuity, and even diversity to a neighborhood commercial corridor.

This is especially true for commercial corridors when businesses are successful and employ larger numbers of people. A corridor consisting primarily of owner-operator businesses reduces opportunities to help support adjacent businesses.

In many of the case study areas, professionals appear to operate individually within a community of like professionals. This was most commonly found with the medical profession, where doctors, counselors, and other health professionals cooperated to share space. Agglomeration for professionals, most likely resulting from cost saving measures, typically related directly to the specific type of service. In this way, these agglomerations were similar to shopper goods which allow consumers to comparison shop among like goods.

Other professions, insurance or real estate agents, for instance, tended to behave more like convenience businesses and disperse across the corridor. In the more dynamic case study areas, these professional services tended to appear, 
intermixed with other types, as a sort of buffer between dense commercial activity and more commercial or industrial uses.

This recommends to practitioners the importance of considering these business functions when developing or redeveloping a commercial area. Anecdotal evidence from other neighborhood commercial corridors in Portland that have struggled with reinvestment also suggest that they suffer from a similar lack of presence by professional, government and non-profits organizations and services.

Planning for these functions by creating sanctuaries for rent control or spaces that are flexible for these types of uses are one example of how research may guide the application of theory to the built environment. It also recommends that not all professional services be clustered in one area, but be mixed with other uses.

\section{BIRTH, DEATH AND UNEMPLOYMENT}

The next step of research was to begin to analyze observable patterns to clearly delineate relationships between business types. The end goal was to understand whether increased development necessarily involved an exclusionary process akin to the ecological model of invasion succession. First, general patterns of birth and death were considered.

Across case study areas, there were a few discernible patterns. High levels of business death occurred in 2009, while higher levels of business births occurred in 1994. (Figures 2-8). When compared with annual unemployment rates for the Portland Metro Statistical Area (PMSA), 2009 was also a period of high 
unemployment while unemployment was on a downward slope during 1994 (Figure 9). High death rates also mapped to high unemployment rates in 1991 and 1992, reflecting the economic recession that occurred nationally during these years. Not only is unemployment a good measure of general economic conditions, it also suggests that businesses are most likely to flourish during a strong economy.

While this may appear intuitive, there has been some research to suggest that entrepreneurial activities increase during unemployment as a response to decreased job opportunity (Storey, 1991). Qualitative research may still bear out this as a cause for entrepreneurial activity, but aggregate data of Portland neighborhood commercial corridors suggests that more small business entrepreneurship occurs during a strong economic climate.

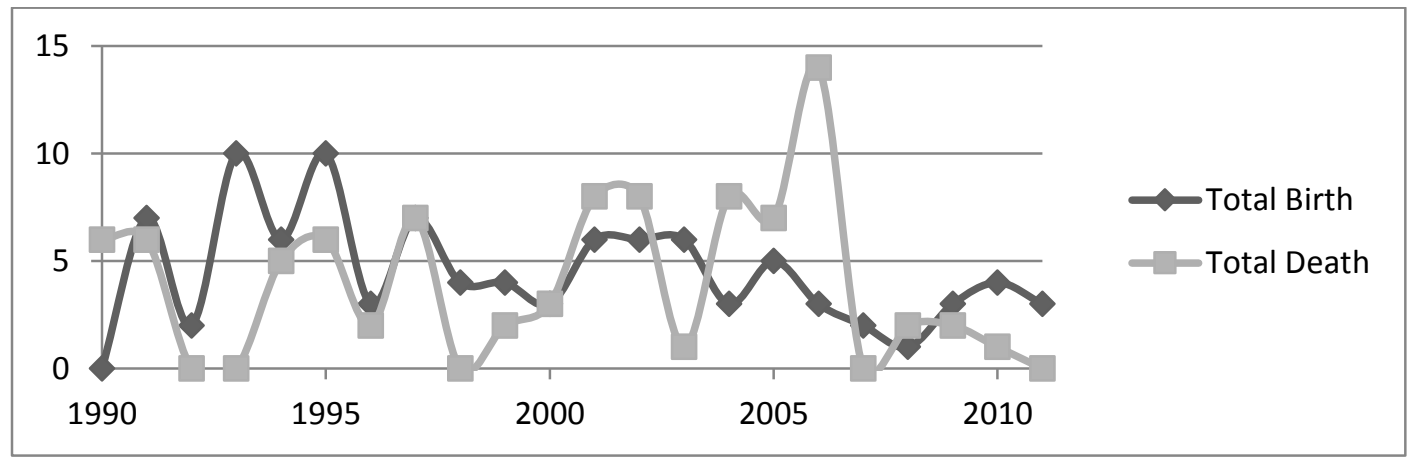

Figure 2 NE \& SE $28^{\text {th }}$

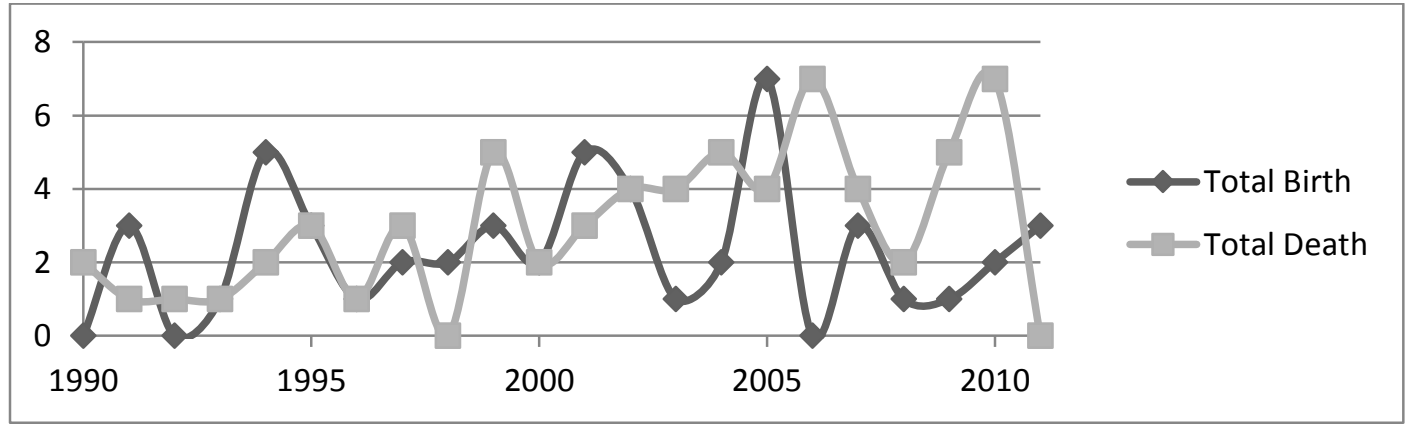

Figure $3 \mathrm{NE} 42^{\text {nd }}$ 


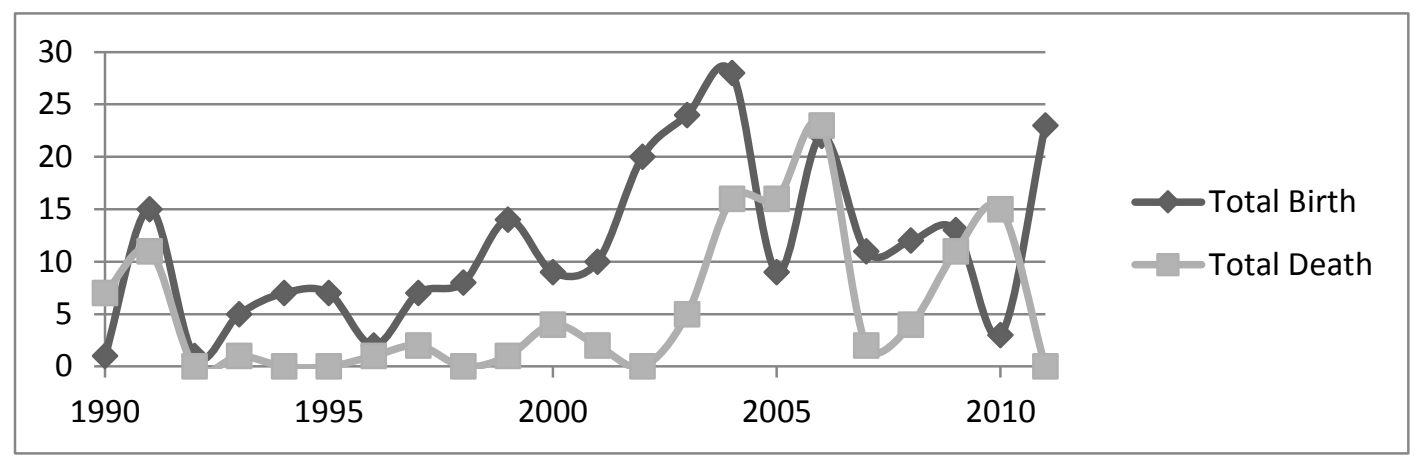

Figure 4 NE Alberta

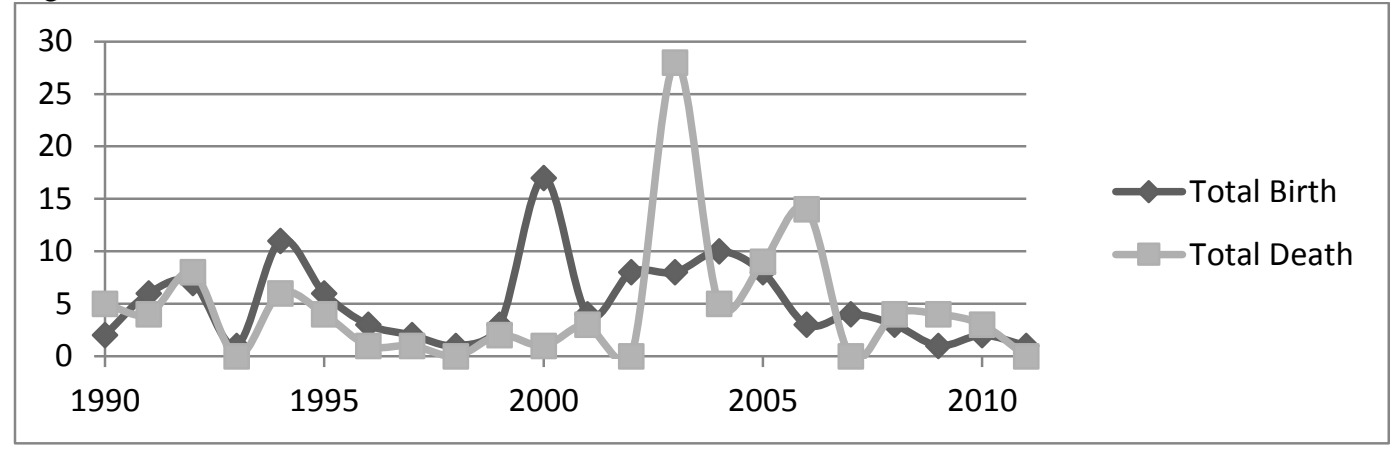

Figure $5 \mathrm{NW} 21^{\text {st }}$

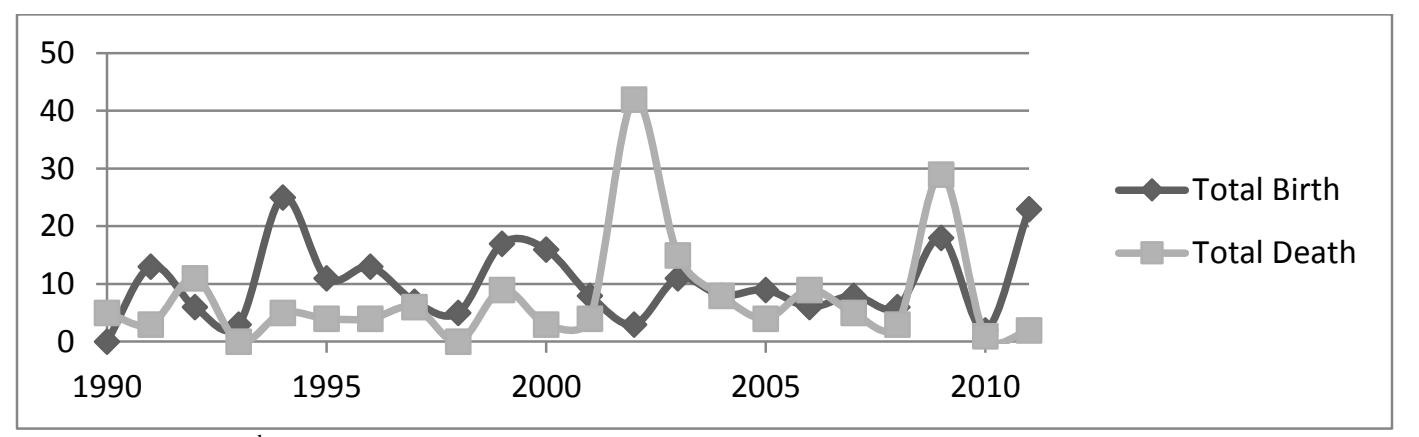

Figure $6 \mathrm{NW} 23^{\text {rd }}$

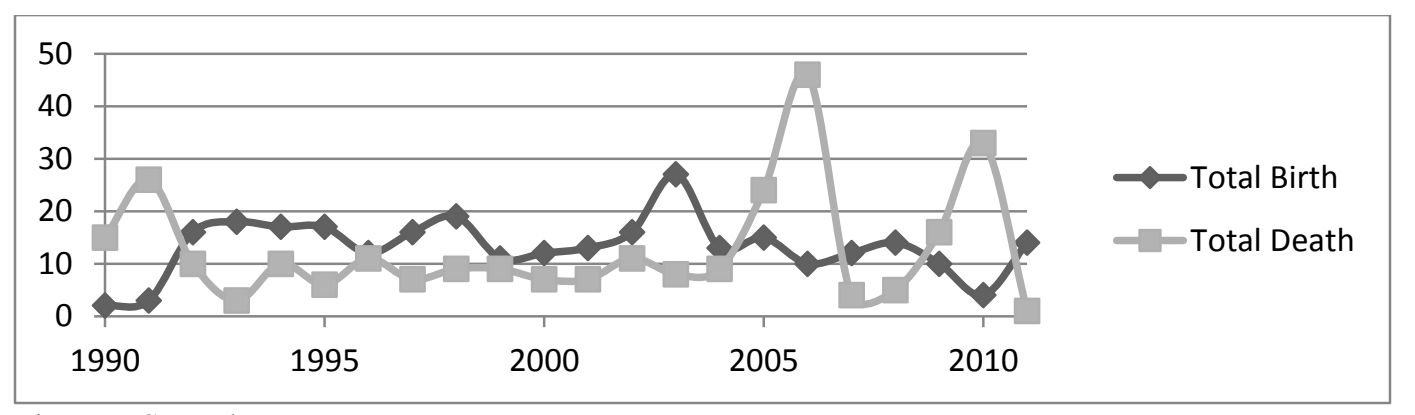

Figure 7 SE Belmont 


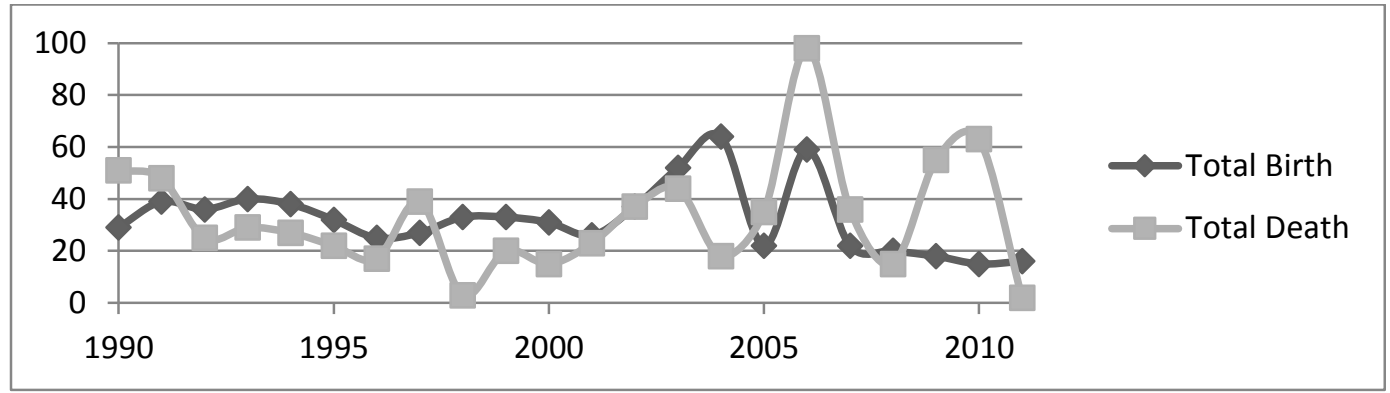

Figure 8 SE Hawthorne

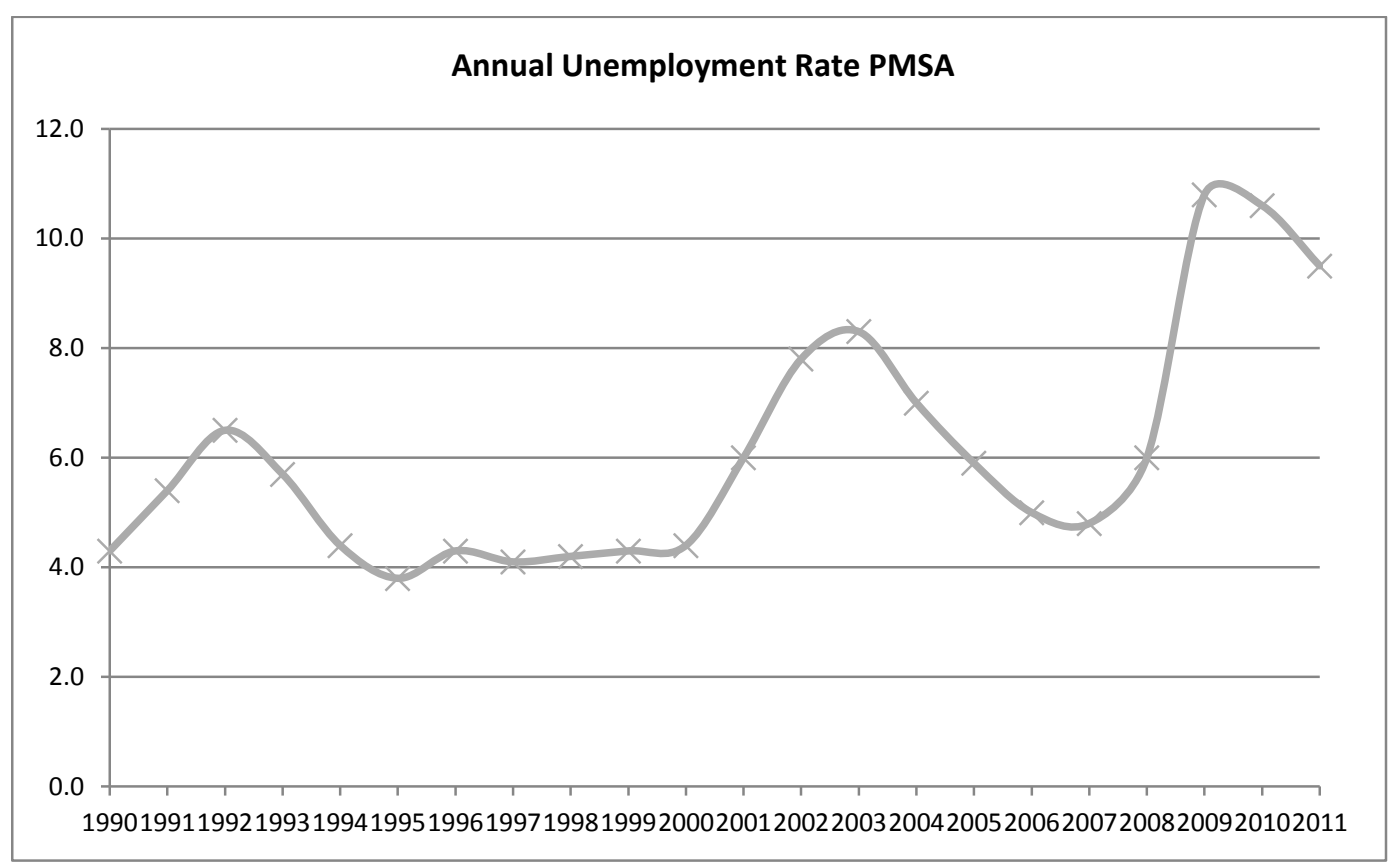

Figure 9 Annual Unemployment Rate PMSA 


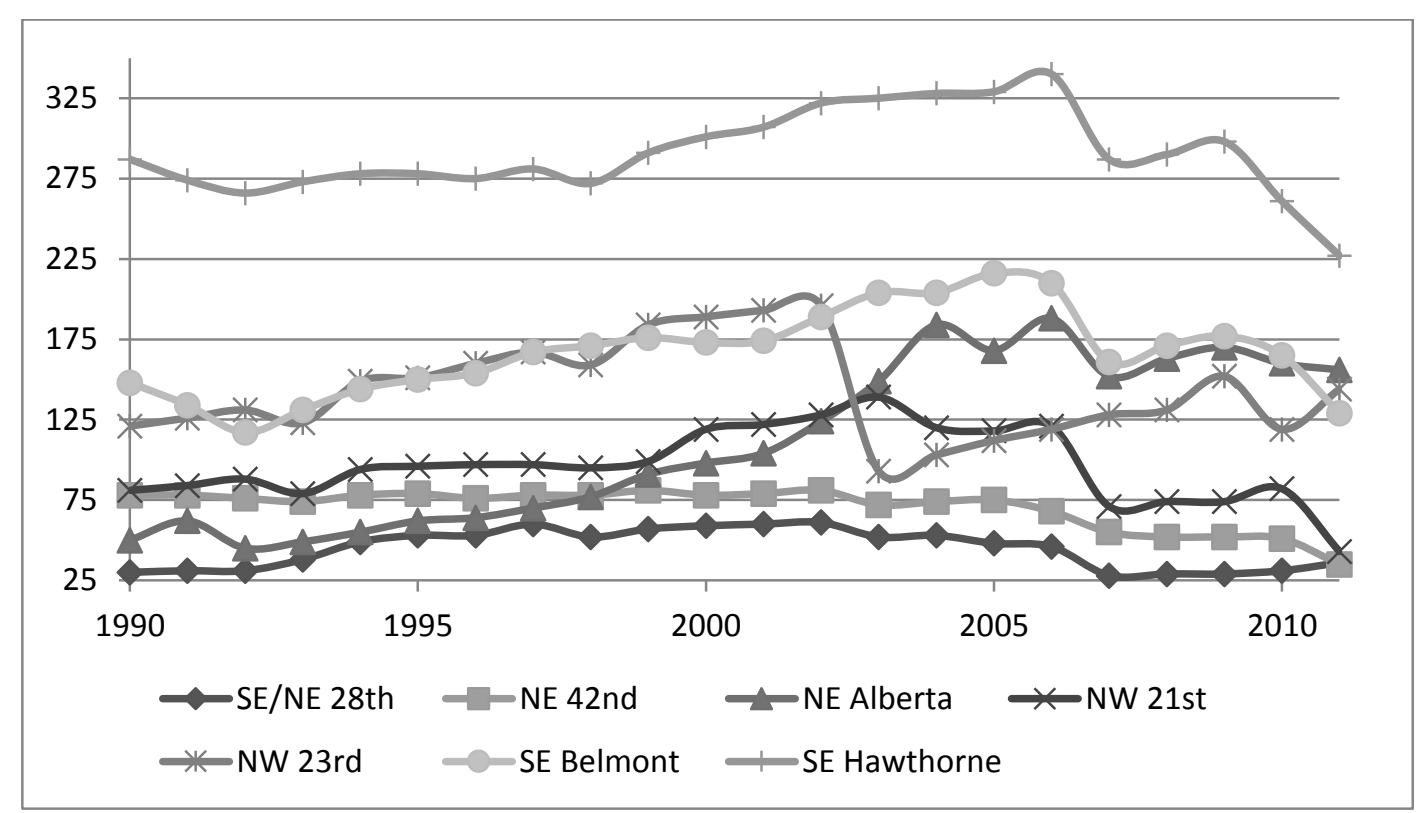

Figure 10 Total Businesses by Street

Comparing the total number of businesses for all case study areas across the twenty one year period further bear out the impact of economic conditions on neighborhood commercial corridor density (Figure 10). The total number of businesses in the majority of case study areas peaked around 2006, when unemployment hit a low. The only exception was NW $23^{\text {rd }}$, which saw a spike of convenience businesses in 2003-2004 which was followed by a steep decline in following years.

Across case study areas, another trend showed death rates had greater hills and valleys, or extreme variations between years, than birth rates (Figures 2-8). Some of this, most likely, is related to normal turnover that occurs in the retail and commercial sector. Birth rates, on the other hand, appear to have much more regular states of incline and decline. This begins to suggest that rather than in direct 
response to each other, birth and death rates are likely influenced by external factors including economic conditions as represented by unemployment rates.

Data strengthened observations that displacement was most likely not a real pressure on neighborhood commercial corridors; external factors including the regional and national economy appeared to have the greatest impact on cycles of change. This suggested that invasion succession most likely was not an effective model for understanding neighborhood commercial corridor change. The next step was to test the model against data, using methodology from similar studies.

\section{INVASION SUCCESSION AND THE PEARSON PRODUCT MOMENT CORRELATION COEFFICIENT}

Ecological studies of invasion succession typically use the Pearson Product Moment Correlation Coefficient to demonstrate the relationship between invading and native species. Kahmen \& Pochlod (2004) used the Pearson Correlation Coefficient to demonstrated grassland succession of native plants, demonstrating high correlation scores of woody plant succession over time, which precipitation when compared against succession showed a negative correlation. Figuero (2003) used the Pearson Correlation Coefficient to understand the impact of environmental variables on species succession in salt marsh environments. Meiners (1994) used the correlation coefficient to understand heterogeneity in a forest field gradient during succession.

In general, the Pearson Correlation Coefficient (PCC) has been an invaluable way to understand correlation between variables as they interact in time and space. 
Applying the foundation to the research, the Pearson Correlation Coefficient (PCC) was used to demonstrate correlation or anticorrelation between business birth and death in case study areas. The simplicity of this method was seen, for the purposes of exploratory research, to be an invaluable tool for recognizing emergent patterns.

In the equation, a perfect correlation results in a score of 1 while a perfect anti-correlation is represented by a negative 1 . The variation between the scores is broken out in increments equal to a standard of interpretation of correlation.

\begin{tabular}{|l|l|l|}
\hline Correlation & Negative & Positive \\
\hline None & -0.09 to 0.0 & 0.0 to 0.09 \\
\hline Small & -0.3 to -0.1 & 0.1 to 0.3 \\
\hline Medium & -0.5 to -0.3 & 0.3 to 0.5 \\
\hline Strong & -1.0 to -0.5 & 0.5 to 1.0 \\
\hline
\end{tabular}

Table 3 Standard Interpretation of Pearson Correlation Coefficient

Scores were compared against a standard interpretation of correlation available in the literature (Table 3 ) which vary from strong negative to strong positive correlation. For the purposes of this research, a high standard for PCC values was set to interpret a significant positive or negative correlation between variables. The first step of analysis was to take total business birth and death (count of businesses in year of first appearance or disappearance at address) along the street and analyze to see the strength of the linear correlation. In these tests, births of businesses were treated as the $\mathrm{X}$ variable and deaths of businesses as $\mathrm{Y}$. As birth and death were also proxies for stability of neighborhood commercial corridors, results would also shed light on whether the correlation between the two had an impact on stability. 
Analysis was conducted for all case study areas, both for individual segments and for the street as a whole, across the twenty one year period resulting in one score per segment and one score per street. Scores were then assigned the standard interpretation of correlation to demonstrate any patterns of covariance. Scores varied on the scale of possible correlations from medium negative to medium positive, with no strong negative or positive results. In two cases, $\mathrm{NE} 42^{\text {nd }}$ and $\mathrm{NW}$ $23^{\text {rd }}$ the correlation between business birth and death was negligible and warranted a zero score. Three of the case study areas, SE Hawthorne, NE/SE $28^{\text {th }}$ and NW $21^{\text {st }}$ revealed a small positive score. Finally, SE Belmont achieved a medium negative score which contrasted with NE Alberta's medium negative score.

The correlations were not calculated using any normalized function, and with a high standard for positive or negative correlation, were used as a foundation for future research. Without providing context or normalizing variables, the primary purpose of correlations functioned as the most direct approach for addressing a null hypothesis of invasion succession.

Given the stages of redevelopment of each of the case study areas, the correlations were not far from conclusions reached by observation. Later stages of change, as represented by the NW District case study areas and SE Hawthorne, showed minimal correlation because existing businesses, for the most part, now enjoyed tenure started in the 1970s or 1980s. This didn't mean static business birth and death, only that there was less dramatic activity than areas that were less densely populated by businesses. 
The two cases, SE Belmont and NE $42^{\text {nd }}$, that were selected because change on those streets has been slow to occur, demonstrated that displacement was a nonissue as business seemed to be born and die without influencing each other. SE Belmont showed a medium negative correlation between business birth and death, the highest anti-correlation value from case study areas. In reviewing data, the main difference between SE Belmont and other case study areas was the low level of birth rate throughout the time series. Although spikes in business death occurred during similar periods to other case study death rates, there were no peaks of increasing businesses throughout the twenty one years.

With only minor business gains, and dramatic losses, it is evident that SE Belmont did not see density increases common in other urban neighborhoods of change. $\mathrm{NE} 42^{\text {nd }}$ showed no correlation or anti-correlation between business births and deaths, likely attributed to both low birth and death rates over the twenty one year period. This neighborhood commercial corridor was chosen specifically for the observed lack of change, and results from correlation scores supported observations.

NE Alberta, on which change did not start to dramatically occur until the 1990s, showed the highest level of correlation. Based on the scale of interpretation, it was still at the low end of medium correlation and suggests that business birth and death may have some influence on each other. However, because correlation was not on the high end of the medium scale or at the strong positive level, it would be overstating to suggest the two were dependent variables of change. 
During popular conversations about gentrification and displacement in the 1990s and 2000s in Portland, Alberta was commonly a cited case. Business change was seen as a symptom of inmovers changing the neighborhood according to their lifestyles and choices. While the correlation between birth and death does recommend that, in part, this may have occurred in some instances, it is by no means the only explanation of business change along the street. Many of the long standing businesses that have been on Alberta since the 1980s, and even earlier, were still present at the time of data collection; the Appliance Refrigeration Hospital, Vian's Auto Service, and Courtesy Janitorial Services are just three examples of businesses that have existed until at least the 1980s.

\begin{tabular}{|l|l|l|}
\hline Commercial Corridor & PCC & Interpretation of Correlation \\
\hline NE 28th & .132 & Small Positive \\
\hline NE 42nd Ave & .026 & None \\
\hline NE Alberta & 0.323 & Medium Positive \\
\hline NW 21st & 0.21535 & Small Positive \\
\hline NW 23rd & -.0221 & None \\
\hline SE Belmont & -0.500 & Medium Negative \\
\hline SE Hawthorne & 0.242 & Small Positive \\
\hline
\end{tabular}

Table 4 Pearson Correlation Coefficient of Total Birth and Death per Case Study Area with Standard Interpretation

Initial correlation coefficients suggest that invasion succession is not an efficient framework for understanding neighborhood commercial corridor change. While business births and death may display some dependency, data suggests that their trajectories are not direct influencers of each other. It is also significant that despite unique characteristics and time periods of change for each case study area 
(or even, for that matter, within each individual street) the coefficients were within relatively close range; the small range of coefficients, given the large scale of possibility, suggests there is some commonality between the processes of change (Figure 11b).

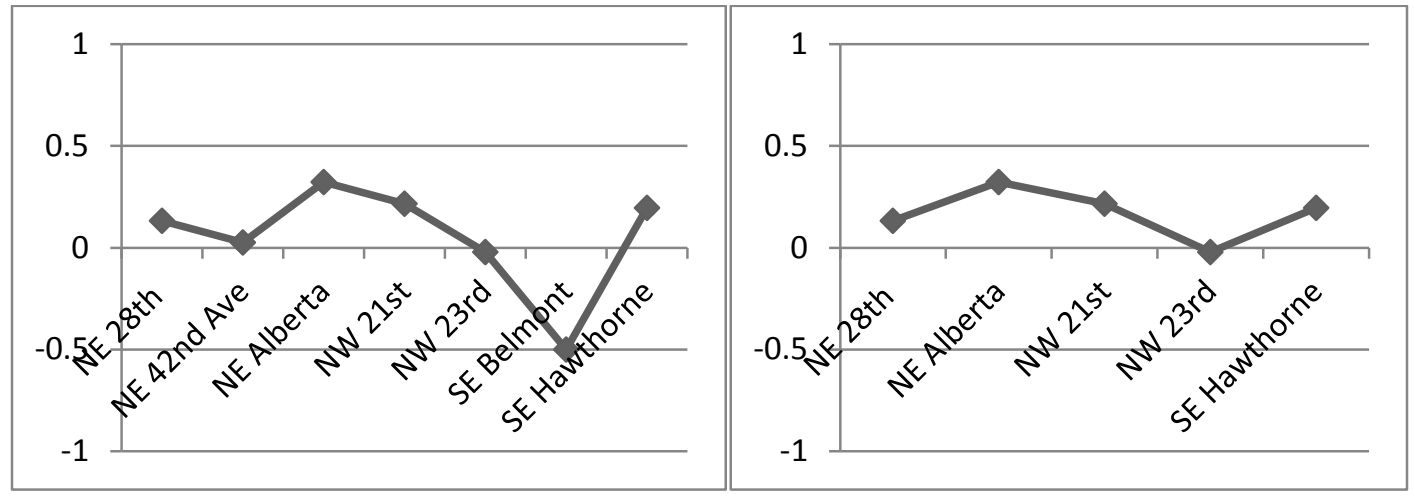

Figure 11a Graphic Version of Table 11 total Pearson Correlation Coefficient Scale Figure 11b with $\mathrm{NE} 42^{\text {nd }}$ and SE Belmont (control cases) removed

To strengthen results, and also identify any problems or issues of weight on data, the correlation coefficient was also applied to the ten block segments within a case study area. Because segments were parsed based purely on block order in an effort to reduce sampling bias, it was significant that results mirrored street findings; analyzing commercial corridors as a whole and in ten block increments demonstrated varied medium positive to medium negative correlations according to the Pearson Coefficient. Regardless of whether streets were analyzed as a whole or in aggregate blocks, the correlation between business birth and death remained consistent across case study areas (Table 5). 


\begin{tabular}{|c|c|c|c|c|c|c|c|}
\hline $\begin{array}{l}\text { Commercial } \\
\text { Corridor }\end{array}$ & $\begin{array}{l}\text { Segment } \\
1 \text { PCC }\end{array}$ & $\begin{array}{l}\text { Segment } \\
2 \text { PCC }\end{array}$ & $\begin{array}{l}\text { Segment } \\
3 \text { PCC }\end{array}$ & $\begin{array}{l}\text { Segment } \\
4 \text { PCC }\end{array}$ & $\begin{array}{l}\text { Segment } \\
5 \text { PCC }\end{array}$ & $\begin{array}{l}\text { Segment } \\
6 \text { PCC }\end{array}$ & $\begin{array}{l}\text { PCC } \\
\text { Total } \\
\text { Street }\end{array}$ \\
\hline NE $28^{\text {th }}$ & -0.0836 & 0.102 & & & & & 0.132 \\
\hline $\mathrm{NE} 42^{\text {nd }}$ Ave & 0.205 & -0.287 & -0.125 & -0.177 & & & 0.0264 \\
\hline NE Alberta & -0.0522 & 0.198 & 0.358 & 0.183 & & & 0.323 \\
\hline NW $21^{\text {st }}$ & 0.1776 & 0.0793 & & & & & 0.215 \\
\hline NW 23rd & -0.0813 & -0.2427 & -0.104 & & & & -0.0221 \\
\hline SE Belmont & -0.1602 & -0.0799 & -0.493 & -0.170 & -0.323 & & -0.500 \\
\hline $\begin{array}{l}\text { SE } \\
\text { Hawthorne }\end{array}$ & 0.2078 & 0.244 & 0.2421 & 0.1510 & 0.259 & -0.072 & 0.241 \\
\hline
\end{tabular}

Table 5 Total Birth and Death Correlations by 10 block $\leq$ Segments

\begin{tabular}{|l|l|l|l|l|l|l|}
\hline Commercial Corridor & $\begin{array}{l}\text { Segment } \\
1 \text { PCC }\end{array}$ & $\begin{array}{l}\text { Segment } \\
2 \text { PCC }\end{array}$ & $\begin{array}{l}\text { Segment } \\
\text { 3 PCC }\end{array}$ & $\begin{array}{l}\text { Segment } \\
4 \text { PCC }\end{array}$ & $\begin{array}{l}\text { Segment } \\
5 \text { PCC }\end{array}$ & $\begin{array}{l}\text { Segment } \\
6 \text { PCC }\end{array}$ \\
\hline $\begin{array}{l}\text { NE Alberta Same Year } \\
\text { NE Alberta Death Year }\end{array}$ & -0.0522 & 0.198 & 0.358 & 0.183 & & \\
$\begin{array}{l}\text { Later Than Birth } \\
\text { NE Alberta } \\
\begin{array}{l}\text { Death Year Earlier Than } \\
\text { Birth }\end{array}\end{array}$ & 0.20272 & 0.4237 & 0.3152 & -0.107 & & \\
\hline $\begin{array}{l}\text { SE Hawthorne Same } \\
\text { Year }\end{array}$ & 0.2078 & 0.244 & 0.2421 & 0.151 & 0.259 & -0.072 \\
\hline $\begin{array}{l}\text { SE Hawthorne Death } \\
\text { Year Later Than Birth }\end{array}$ & 0.0306 & 0.019 & 0.2356 & -0.1926 & 0.1319 & -0.0759 \\
\hline $\begin{array}{l}\text { SE Hawthorne Death } \\
\text { Year Earlier Than Birth }\end{array}$ & -0.0772 & 0.3323 & 0.1931 & -0.2521 & -0.1484 & 0.0073 \\
\hline
\end{tabular}

Table 6 NE Alberta and SE Hawthorne Pearson Correlation Coefficients by 10 block segments staggering variables

Considering the potential time lag of impact between business birth and death which may influence correlations, the correlation coefficient was also run staggering death the year after business births. The variables were also calculated with death a year before birth to consider where availability of sites may potentially increase opportunities for new businesses, capturing the external market forces on neighborhood commercial change. Table 6 demonstrates the respective calculated values for ten block segments for both NE Alberta and SE Hawthorne.

In the majority of ten block segments, the impact of staggering death and birth was minimal in shifting the interpretation of the correlation. The exception, 
producing one of the highest correlation values for all analysis, was the second segment of NE Alberta considering death a year after birth. While the result was still a medium positive correlation, it represented potential confirmation that invasion succession might be in some part responsible for change patterns in this part of Alberta. The most obvious culprit for the dependence between the variables was the decade with the highest volume of activity, 2000-2010.

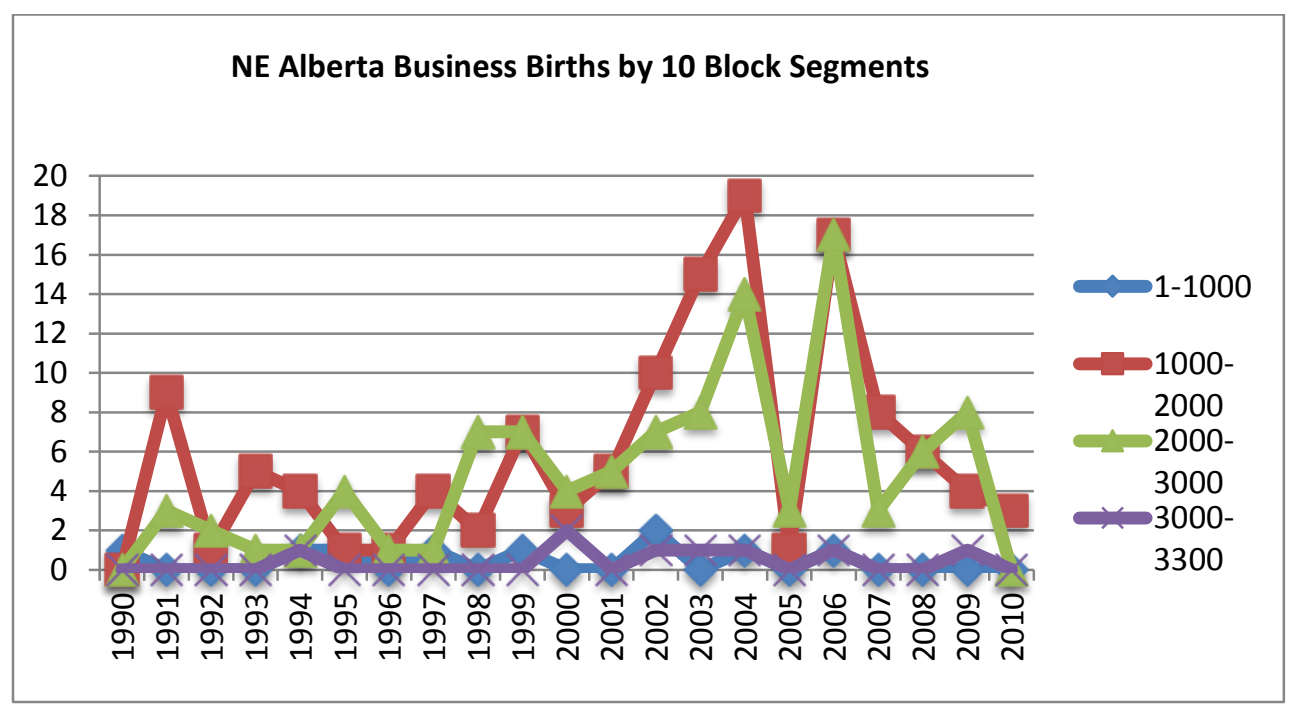

Figure 12 Total Business Births NE Alberta By 10 Block Segments

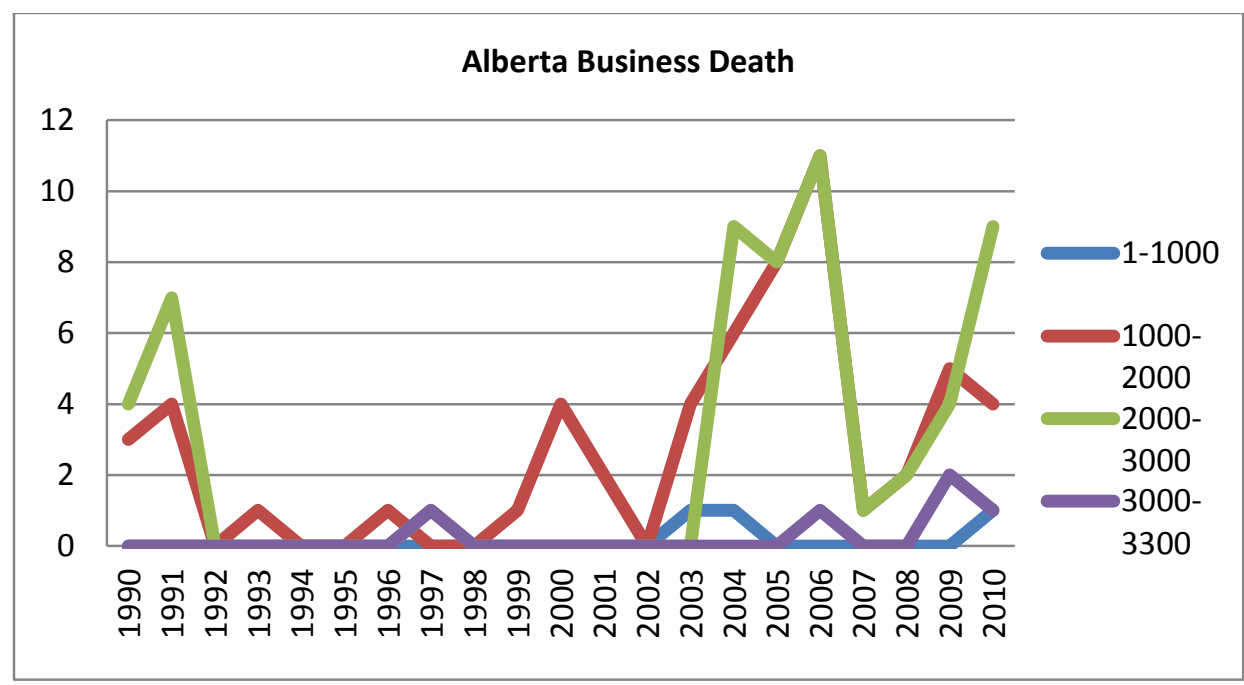

Figure 13 Total Business Deaths NE Alberta By 10 Block Segments 

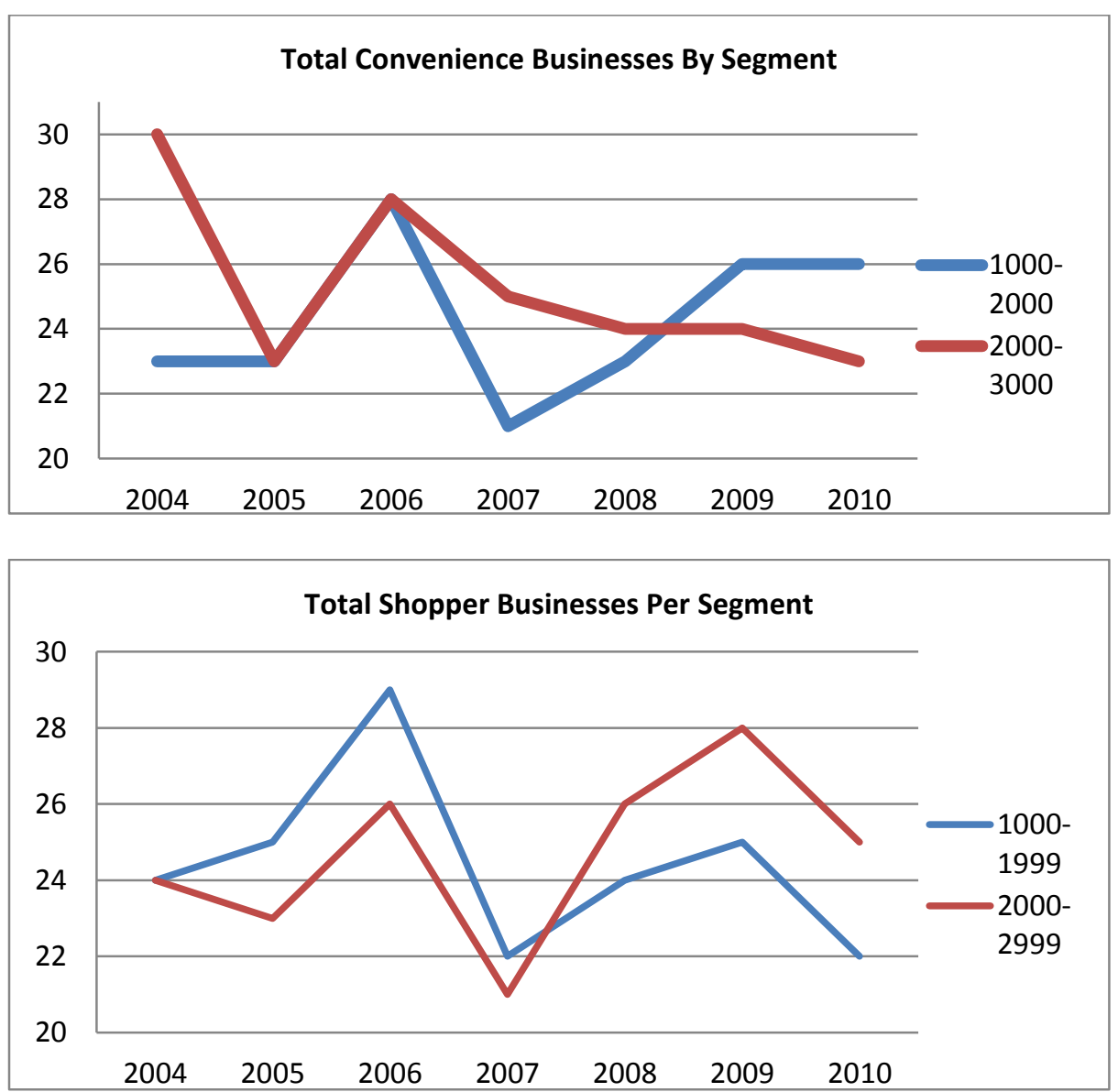

Figures $14 \mathrm{a} \& 14 \mathrm{~b}$ Total convenience and shopper businesses for $2^{\text {nd }}$ and $3^{\text {rd }}$ segments of NE Alberta over time

Detailed analysis of NE Alberta reveals that there were large spikes in birth and deaths for the $2^{\text {nd }}$ and $3^{\text {rd }}$ segments $\left(10^{\text {th }}-29^{\text {th }}\right)$ in 2006 (Figures $12 \& 13$ ). This 
suggested both turnover of existing businesses and an influx of new businesses.

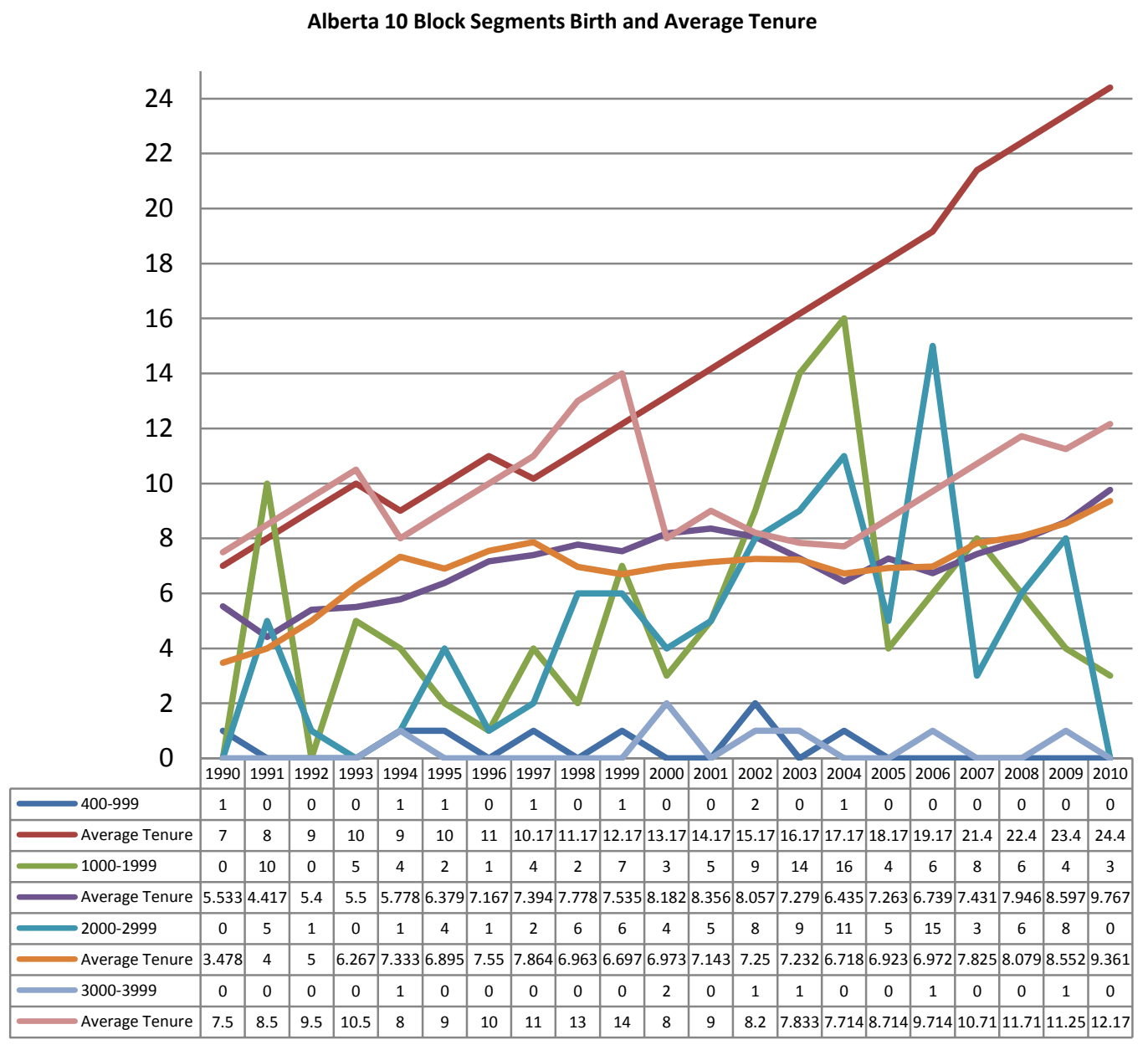

Figure 15 NE Alberta Total Birth and Average Tenure by 10 Block Segments

During 2006, total numbers of both convenience and shopper goods

businesses spiked for both segments (Figures 14a \& 14b). It was also in this year, within both segments of the corridor, that average tenure began an incline after several years of fluctuation (Figure 15). Based on additional analysis, it appears that this year was a critical tipping point for development, which would lead to increased stability in subsequent years. The correlation likely showed medium 
positive relationship between birth and death due to the overall high volume of activity occurring

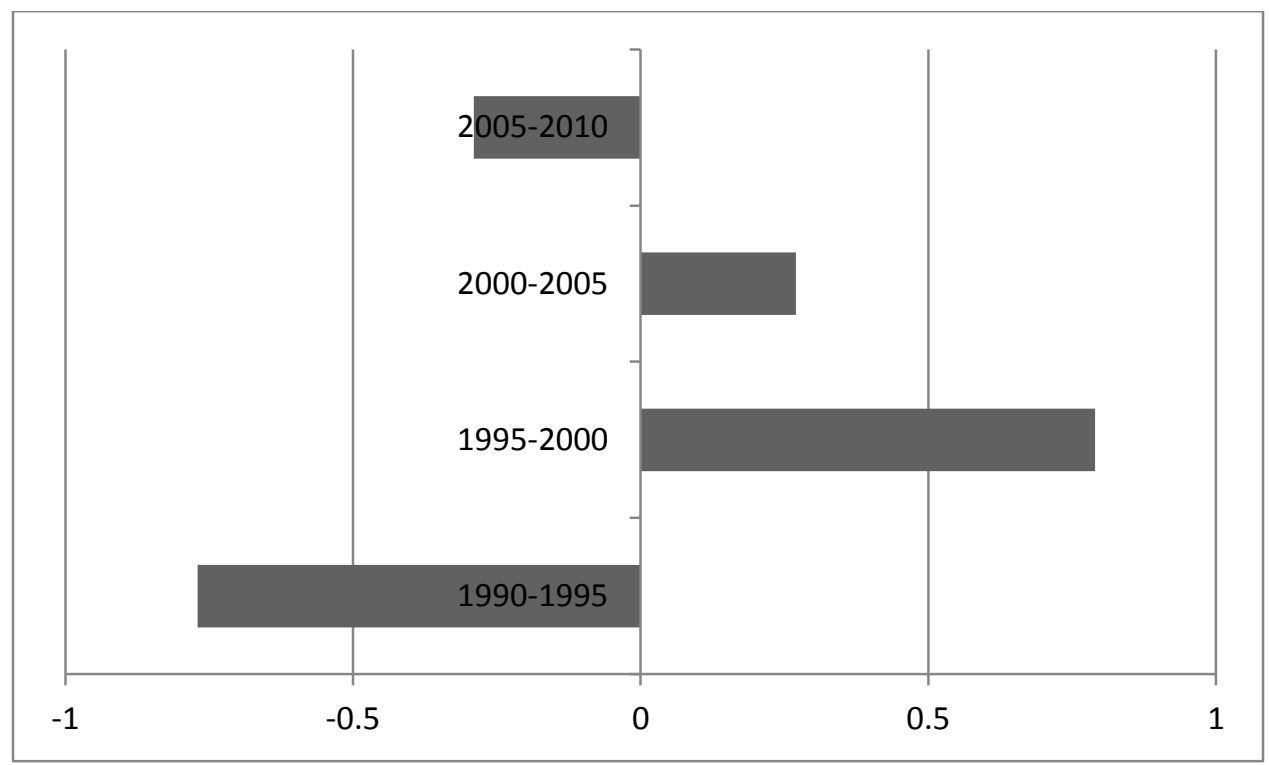

Figure 16 PCC Segment 2 NE Alberta By Five Year Increments with Death Year After Birth

To isolate the time period most critical in creating a medium positive correlation score for NE Alberta's 20-29 $9^{\text {th }}$ blocks, the Pearson Correlation Coefficient was calculated in five year increments with death of businesses a year after birth (Figure 16). As other data indicated, the years following 2005 had a weak to negative relationship between birth and death rates. In fact, it was the time period between 1995 and 2000 that showed a strong positive correlation between birth and death, at over .78. Further isolation showed the years 1999 and 2000 (with death occurring a year following birth) had a perfect score of correlation, 1 .

In 1999, seven new businesses appeared on Alberta and four disappeared in 2000, a year later. Two of those businesses were located on the southeast corner of 
$15^{\text {th }}$, a building that was redeveloped in 2000 for mixed use, with the Alberta Cooperative Grocery locating in 2001 in the ground floor. The other two business deaths in 2000 were Vices, which had been at 1011 since 1981, and Provvista Specialty Foods, an importer and wholesale distributor of food stuffs, which had been at $1401 \mathrm{NE}$ Alberta since 1997. Provvista located to an industrial location to accommodate their expanding business and distribution needs.

In 2001, the two businesses that disappeared from NE Alberta were located towards the $10^{\text {th }}$ street block, at the opposite end of the segment where the three births in 2000 concentrated. When the segment is reduced in half, the correlation mimics the small positive finding from running death and birth in the same year. While these two years were no doubt significant as indicators of commercial corridor changes, detailed analysis demonstrates that across the aggregate evidence does not support an interdependence between birth and death.

More broadly, variations in correlations within segments in all areas related to the overall number of businesses; stronger positive correlations corresponded to a greater density of businesses. The first segment of case studies including NE Alberta, SE Belmont and SE Hawthorne are primarily light industrial, and professional and commercial services. These showed low to negative correlation scores, mirroring trend of segments 3 and 4 of $\mathrm{NE} 42^{\text {nd }}$, which is consists predominantly of industrial and commercial service uses.

It is not surprising that industrial business types showed low to negative correlation scores in these locations. Proximity to major city arterials suggest these 
businesses are less reliant on adjacency to resident populations and have regional or other distribution and sales methods. Loose spatial network motivations naturally would decrease economic impact of nearby businesses. In essence, these business types are not directly engaged in neighborhood commercial dialogue.

Based on overall densities along corridors, it would also appear these areas are not in danger of encroachment from convenience and shopper business types. In most cases these light industrial areas are at least ten blocks away from retail business densities, and outside of significant land use interventions, unlikely to be attractive to businesses catering to residential populations.

For NE $28^{\text {th }}$, industrial business types are by in large embedded in the fabric and not front facing to the convenience and shopper businesses. Instead, industrial uses (like the syrup manufacturing company on NE $28^{\text {th }}$ and Couch) are oriented towards major arterials. For the most part, SE/NE 28th houses retail goods and services with a mix between convenience and shopper types. These also showed negative to low correlation scores between business births and deaths within segments, suggesting patterns of business birth and death were influenced by external factors. Significantly, the SE portion, which demonstrated a low correlation score, had one block demolished and redeveloped as mixed use, creating a significant impact on data as overall it is the low density portion of the corridor. While redevelopment of sites through demolition of pre-existing structures is not unique, in a commercial corridor in early stages of redevelopment its statistical impact is potentially anomalous. 
What is not anomalous about this particular instance is the tendency for sites in redeveloped corridors to be converted over to higher density retail.

To tease out this observation, the total number of businesses was analyzed for both segment and street data (Appendix C). This result supported theoretical conclusions that clustering or densities of businesses would create more opportunities for change, and be a necessary by product of the retail law of gravitation.

Analysis of the birth of shopper goods and service businesses against the death of convenience businesses within individual segments or the street as a whole supported the idea that the linear relationship between birth and death was typically minimally to negatively correlated (Table 5). In the only instance where birth and death showed a medium correlation, NE Alberta, results from the coefficient measuring correlation between shopper birth and death showed a small positive correlation.

\begin{tabular}{|c|c|c|c|c|c|c|c|}
\hline $\begin{array}{l}\text { Commercial } \\
\text { Corridor }\end{array}$ & $\begin{array}{l}\text { Segment } \\
1 \text { PCC }\end{array}$ & $\begin{array}{l}\text { Segment } \\
2 \text { PCC }\end{array}$ & $\begin{array}{l}\text { Segment } \\
3 \text { PCC }\end{array}$ & $\begin{array}{l}\text { Segment } \\
4 \text { PCC }\end{array}$ & $\begin{array}{l}\text { Segment } \\
5 \text { PCC }\end{array}$ & $\begin{array}{l}\text { Segment } \\
6 \text { PCC }\end{array}$ & $\begin{array}{l}\text { PCC } \\
\text { Total } \\
\text { Street }\end{array}$ \\
\hline SE/NE $28^{\text {th }}$ & 0.1793 & -0.0517 & & & & & -0.0220 \\
\hline $\mathrm{NE} 42^{\text {nd }}$ Ave & -0.0690 & -0.0819 & -0.0562 & 0 & & & 0.159 \\
\hline NE Alberta & -0.0867 & 0.1941 & 0.1935 & 0.3382 & & & 0.2503 \\
\hline $\mathrm{NW} 21^{\mathrm{st}}$ & -0.1398 & 0.1945 & & & & & -0.046 \\
\hline NW 23rd & -0.2378 & -0.0140 & 0 & & & & -0.177 \\
\hline SE Belmont & -0.1634 & -0.0918 & -0.5883 & -0.3127 & -0.1087 & & -0.5075 \\
\hline $\begin{array}{l}\text { SE } \\
\text { Hawthorne }\end{array}$ & 0.0046 & 0.4490 & -0.2285 & 0.1942 & 0.4676 & -0.0651 & 0.2327 \\
\hline
\end{tabular}

Table 7 Total Shopper Birth and Death Convenience by 10 Block $\leq$ Segments

Although the results of shopper birth and convenience business death correlations fairly support the idea that invasion succession is an ineffective model, research 
next extracted professional and personal convenience services from the death rates to see how that might influence correlations. Because professional services seemed to have resilience in tenure along all case study areas, it was necessary to see if by removing them from the equation if it would impact the correlation scores.

\begin{tabular}{|c|c|c|c|c|c|c|c|}
\hline $\begin{array}{l}\text { Commercial } \\
\text { Corridor }\end{array}$ & $\begin{array}{l}\text { Segment } \\
1 \text { PCC }\end{array}$ & $\begin{array}{l}\text { Segment } \\
2 \text { PCC }\end{array}$ & $\begin{array}{l}\text { Segment } \\
3 \text { PCC }\end{array}$ & $\begin{array}{l}\text { Segment } \\
4 \text { PCC }\end{array}$ & $\begin{array}{l}\text { Segment } \\
5 \text { PCC }\end{array}$ & $\begin{array}{l}\text { Segment } \\
6 \text { PCC }\end{array}$ & $\begin{array}{l}\text { PCC } \\
\text { Total } \\
\text { Street } \\
\end{array}$ \\
\hline $\begin{array}{l}\text { SE Hawthorne With } \\
\text { Professional } \\
\text { Services }\end{array}$ & 0.0046 & 0.4490 & -0.2285 & 0.1942 & 0.4676 & -0.0651 & 0.2327 \\
\hline $\begin{array}{l}\text { SE Hawthorne } \\
\text { Without } \\
\text { Professional } \\
\text { Services }\end{array}$ & -0.2118 & 0.1565 & -0.3379 & 0.1442 & 0.4526 & -0.0985 & 0.2335 \\
\hline
\end{tabular}

The impact of removing professional and personal convenience services tests was minimal; with a difference in most cases of between .1 and .01 , the results are that specific types do not generally influence the equation.

Intuitively, it is natural that there will be some correlation between births and deaths as a result of time and space constraints. This was evident in higher correlation scores for Alberta, which otherwise may have been misleading. It is also conceivable that external forces and distinct identities result in varying patterns of correlation. However, in none of the cases is there a significant relationship between business or shopper business birth on the displacement, or death of convenience businesses. What results suggest, instead, is that convenience businesses tend to support the birth of shopper businesses. It is fair to interpret this 
as a function of a multiplier on activity and shopper traffic; optimal business districts have a mix of business types to help maximize market capture.

Contrary to anecdotal reporting, the data suggests that invader businesses, particularly shopper goods, are a poor predictor of the displacement of pre-existing businesses. There was no evidence to suggest, either as a whole aggregate or in individual segments, that the linear relationship between business birth and death was, at its highest point, anything greater than moderately correlated. Moderate to small correlation, giving finite business location opportunities, is logical and supports broader economic theory. In this way, the economy at the neighborhood scale seems to mirror trends at a city, regional or national level.

In the case of the highest correlation, NE Alberta data suggested change reached a tipping point in 2006, preceded by instability. This provided more opportunities for businesses present in the first decade to be displaced by more aggressive densities. Observation of change in case study areas points to complete redevelopment of whole city blocks, which often included demolition and construction to form new spaces of commerce. In the case of NE Alberta deaths in 2000, two businesses were replaced by redevelopment of a site which would eventually house the Alberta Cooperative Grocery. Similar intervention occurred on the corner of SE $28^{\text {th }}$ and Burnside, with impact occurring after 2010. Such a dramatic change of land use and business space created distinctly new opportunities for businesses which may have not occurred in older, existing buildings. 
Therefore, the Pearson Correlation Coefficient was an efficient test of invasion succession as a null hypothesis. If invasion succession was a valid model for understanding neighborhood commercial corridor change, results would show strong correlations and not have so much variation between case study areas. As anticipated by research, invasion succession presents an incomplete and ineffective framework for understanding how business corridors change in neighborhoods experiencing residential population shifts.

To understand if business type, as suggested by the literature, demonstrated patterns of displacement the birth of shopper businesses were compared with rates of death of convenience businesses. Examining birth by segment and type, in compared with total birth rates by segment, the shopper type of business had a strong correlation with overall birth rates. The correlation between convenience goods and overall birth rates by year was less.

This supports the hypothesis that shopper type businesses rely on proximity and presence of other, similar, types of businesses to appeal to consumer behavior patterns. Convenience businesses, it would appear, are less reliant on the other business activity although do show a positive correlation.

Taking data a step further, total businesses by type were evaluated and compared against the total number of businesses to look for thresholds during times of stability and times of change. Within the most densely populated segments, the total number of shopper goods increased exponentially, but ultimately during times of low net change both convenience and shopper retail and personal services varied 
between a scale of $20-45 \%$, for a sum of between $60-80 \%$ of total businesses (Table 17a-h). This left between $40 \%$ and $20 \%$ of businesses during those years of stability to be accounted for by commercial and professional services, non-profit entities, and government bodies.

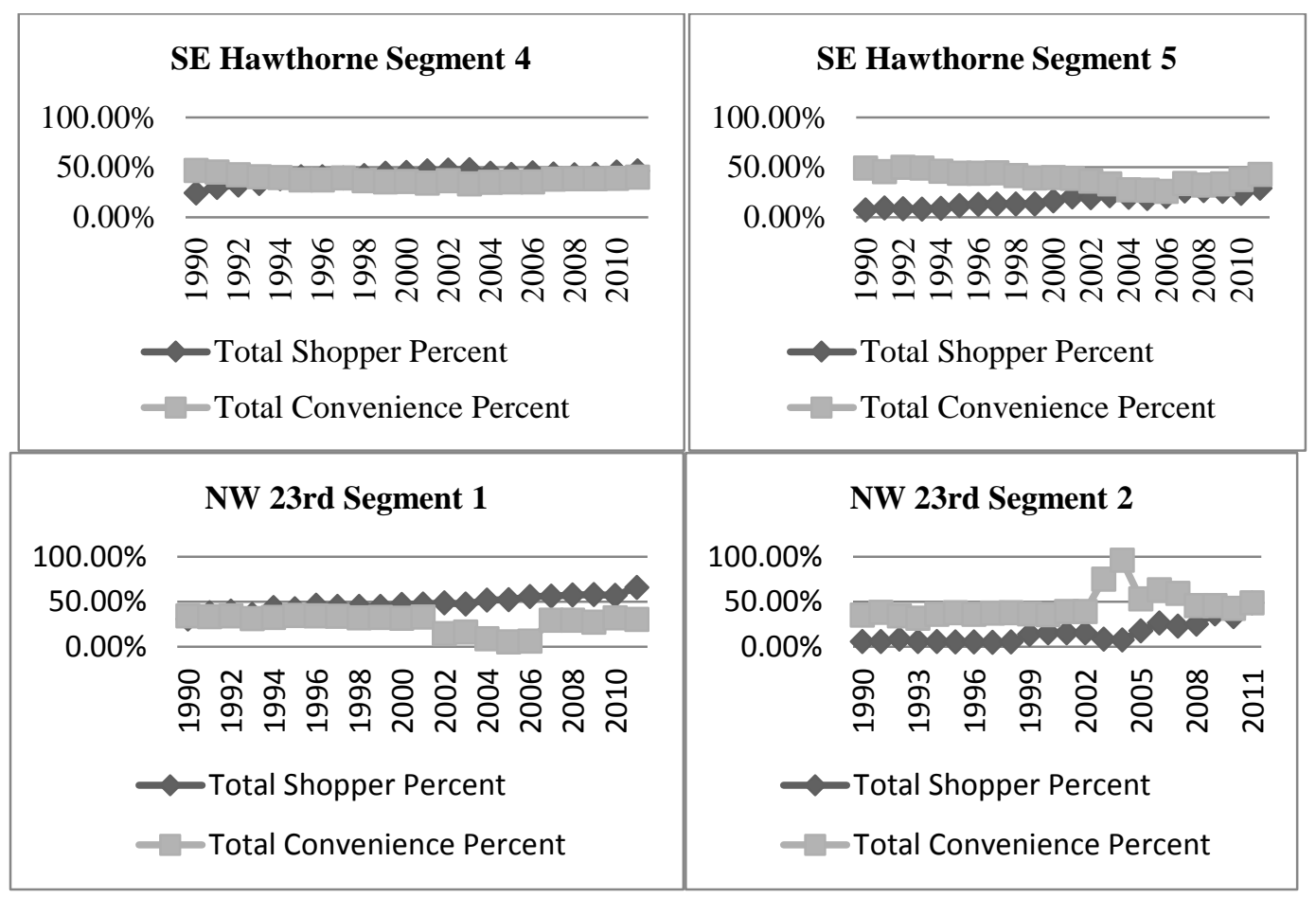




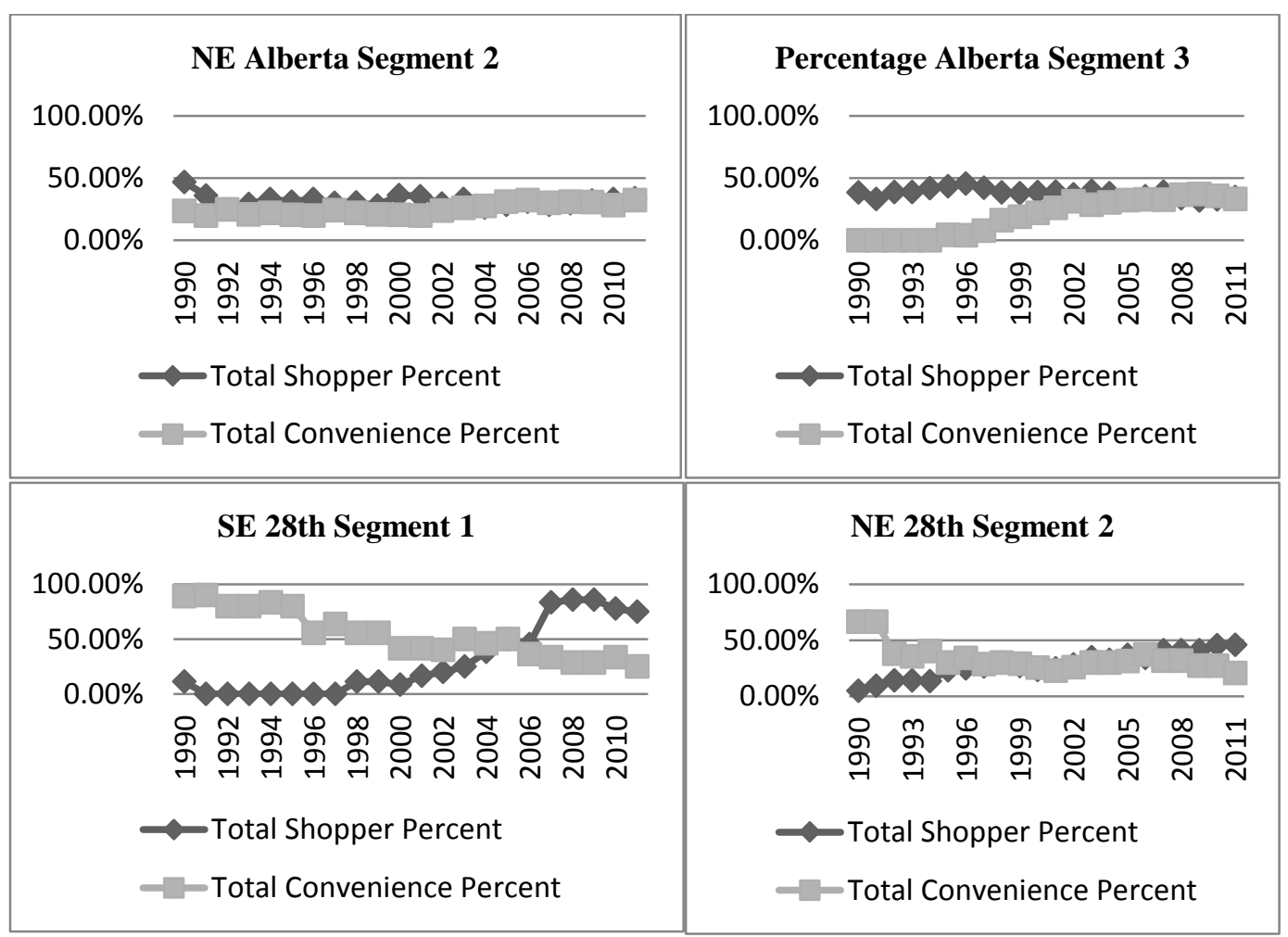

Figures 17a-h-Total Shopper and Convenience Businesses (Excluding Professional and Commercial Services)

When total shopper and total convenience, excluding professional services, businesses are compared in the densest portions of main case study areas, and results add another dimension to neighborhood commercial corridor change. Comparing percentage mixes of total businesses, the most dense segments (SE Hawthorne 4, NW $23^{\text {rd }} 1$, NE Alberta 3, and NE $28^{\text {th }}$ Segment 2) demonstrate that during the times of greatest economic stability both in terms of Metro unemployment rates and total number of businesses (approximately from 19952002) that the percentage mix is close to equal.

The second densest segments, adjacent to most dense segments, show much more erratic patterns. With the exception of NW $23^{\text {rd }}$, the percentage mix on these 
segments comes close to equal during a high point of unemployment (2006) after preceding years showed a gap between business types. The similarities between case study areas seem to end there.

The NE and SE portions of $28^{\text {th }}$ mirror each other in decline of total number of convenience businesses and a rise of shopper goods. As the reputation of the street as "Restaurant Row" began to build around 2007-2008, it seems businesses began to follow suit. The addition of several eateries and upscale dining options, as well as new mixed use development on the corner of SE $28^{\text {th }}$ and Burnside can be traced by following the significant increases in shopper goods establishments in both segments after 2006.

Alberta's most dense segments would appear to be shifting towards spreading the density of convenience and shopper goods across twenty blocks. Segment 3, once being completely devoid of convenience goods and services, now appears to balance this business type with shopper goods. The same is true in the most dense ten block segment, Segment 2. The trends of diversity and stabilization on Alberta correspond with a large increase business births around 2004. According to an Inside Prospects study of 2002-2003 cited by the City of Portland (2004) in their commercial corridor's study, Alberta had a -52 percent difference from the average of employees per square mile within Portland commercial corridors. Compared with average, Alberta had 12 percent more employment in the retail category, with smaller establishment sizes reducing overall purchasing power of employee population. 
Following the spike in overall increases in businesses along Alberta in 2004, it is then significant that (Figures $12 \& 13$ ) by 2006, convenience and shopper goods began to stabilize at an even split. This further supports the importance of considering multiple populations, including commercial corridor employees, as potential customer bases for adjacent businesses.

SE Hawthorne demonstrates a similar relationship between segments, with the 5 segment showing less density of shopper and convenience goods as a result of higher presence of professional services. For more retail oriented segments (Figure 12 \& 13) a large number of business death between 2008 and 2010 resulted in an increasingly even share of market between convenience and shopper businesses, as convenience businesses dropped.

The Alberta and Hawthorne cases demonstrate that over-representation by one business type typically results in instability followed by an evening out of business type distribution. In 2002, NW $23^{\text {rd }}$ saw a significant number of business deaths across segments, the highest total over the twenty year period. As a result, preceding years demonstrated uneven representation by convenience businesses with minimal shopper goods establishments. Slowly, since 2004, shopper businesses on NW $23^{\text {rd }}$ have been on the incline dropping total birth and death activity to the lowest over the twenty year period, increasing overall business tenure.

The critical percentage of business mix made up by professional, commercial and other services strengthened observations that the presence of these business types lend themselves to dense, stable business environments. While the 
gentrification literature has hypothesized that neighboring residential change results in an exclusionary process in adjacent commercial corridors, in fact it would appear that the importance of diversity among business types increases as overall development density increases. This suggests that the invasion succession model, with emphasis on displacement, is an insufficient, if not dangerous characterization of neighborhood commercial corridor change.

As the free market responds to economic stimulation in previously disinvested areas, assumptions that preclude inclusion of convenience goods and services potentially may result in creating markets of volatility and diminishing elasticity of small businesses to respond to a demand placed by a broad base of consumers and consumer types.

\section{RETAIL LAW OF GRAVITATION}

Having made the case for eclectic business mix, the next step of research was to identify whether or not businesses has the tendency to cluster or whether development was primarily even and linear. There is some abstraction implicit within the question of site selection, therefore it required significant experimentation and observation within data sets.

First, the total number of businesses was evaluated against the neighborhood populations for each decade (Tables $15 \& 16$ ). To create continuity across analysis, businesses totals were calculated within ten block segments based on addresses. The first obvious conclusion from total numbers of businesses is that densities vary 
throughout the corridor. The second is that the overall total number of businesses influence individual segment densities; the oldest districts, NW $23^{\text {rd }}$, NW $21^{\text {st }}$ and SE Hawthorne, have the highest level of densities within a given segment.

Another observation is that NE Alberta almost doubled its total number of businesses in two segments in 2010, from 2000, whereas other case study areas lost businesses or made very minor gains. This supports the conclusion that the medium positive correlation score demonstrated by total births and deaths of Alberta is likely as a result of an overall increase in density.

With the exception of the NW District case study areas, the greatest number of businesses appear to concentrate in the middle segment of case study corridors. As these segments also tend to correspond with neighborhood borders and higher neighborhood populations, it suggests that these areas benefit from the retail law of gravitation. In other words, they are the shortest point between all neighborhoods with the greatest proximity to larger residential densities. 


\begin{tabular}{|c|c|c|c|c|c|c|c|}
\hline $\begin{array}{l}\text { Commercial } \\
\text { Corridor }\end{array}$ & Date & $\begin{array}{l}\text { Segment } \\
1 \text { Pop. }\end{array}$ & $\begin{array}{l}\text { Segment } \\
2 \text { Pop. }\end{array}$ & $\begin{array}{l}\text { Segment } \\
3 \text { Pop. }\end{array}$ & $\begin{array}{l}\text { Segment } \\
\text { 4 Pop. }\end{array}$ & $\begin{array}{l}\text { Segment } \\
5 \text { Pop. }\end{array}$ & $\begin{array}{l}\text { Segment } \\
6 \text { Pop. }\end{array}$ \\
\hline $\mathrm{NE} / \mathrm{SE} 28^{\text {th }}$ & 2000 & 5,095 & 5,095 & & & & \\
\hline $\mathrm{NE} / \mathrm{SE} 28^{\text {th }}$ & 2010 & 5,340 & 5,340 & & & & \\
\hline $\mathrm{NE} 42^{\text {nd }}$ Ave & 2000 & 5,332 & 12,833 & 12,833 & 12,833 & & \\
\hline NE $42^{\text {nd }}$ Ave & 2010 & 5,346 & 13,209 & 13,209 & 13,209 & & \\
\hline NE Alberta & 2000 & 5,938 & 2,924 & 2,924 & 2,924 & & \\
\hline NE Alberta & 2010 & 6,149 & 2585 & 2585 & 2585 & & \\
\hline NW $21^{\text {st }}$ & 2000 & 12,596 & 12,596 & & & & \\
\hline NW $21^{\text {st }}$ & 2010 & 13,399 & 13,399 & & & & \\
\hline $\mathrm{NW} 23^{\text {rd }}$ & 2000 & 12,596 & 12,596 & 12,596 & & & \\
\hline $\mathrm{NW} 23^{\mathrm{rd}}$ & 2010 & 13,399 & 13,399 & 13,399 & & & \\
\hline SE Belmont & 2000 & 7,923 & 7,923 & 7,923 & 7,155 & 7,155 & \\
\hline SE Belmont & 2010 & 8,472 & 8,472 & 8,472 & 7,354 & 7,354 & \\
\hline SE Hawthorne & 2000 & 7,007 & 7,007 & 7,007 & 11,245 & 11,245 & 9,982 \\
\hline SE Hawthorne & 2010 & 7,336 & 7,336 & 7,336 & 11,607 & 11,607 & 10,162 \\
\hline
\end{tabular}

Table 9 Segment Neighborhood Populations for 2000 \& 2010

\begin{tabular}{|c|c|c|c|c|c|c|c|}
\hline $\begin{array}{l}\text { Commercial } \\
\text { Corridor }\end{array}$ & Date & $\begin{array}{l}\text { Seg. } 1 \\
\text { Total } \\
\text { Business }\end{array}$ & $\begin{array}{l}\text { Seg. } 2 \\
\text { Total } \\
\text { Business }\end{array}$ & $\begin{array}{l}\text { Seg. } 3 \\
\text { Total } \\
\text { Business }\end{array}$ & $\begin{array}{l}\text { Seg. } 4 \\
\text { Total } \\
\text { Business }\end{array}$ & $\begin{array}{l}\text { Seg. } 5 \\
\text { Total } \\
\text { Business }\end{array}$ & $\begin{array}{l}\text { Seg. } 6 \\
\text { Total } \\
\text { Business }\end{array}$ \\
\hline $\mathrm{NE} / \mathrm{SE} 28^{\text {th }}$ & 2000 & 12 & 47 & & & & \\
\hline $\mathrm{NE} / \mathrm{SE} 28^{\text {th }}$ & 2010 & 9 & 22 & & & & \\
\hline $\mathrm{NE} 42^{\text {nd }}$ Ave & 2000 & 3 & 28 & 27 & 14 & & \\
\hline $\mathrm{NE} 42^{\text {nd }}$ Ave & 2010 & 4 & 19 & 18 & 10 & & \\
\hline NE Alberta & 2000 & 9 & 44 & 41 & 4 & & \\
\hline NE Alberta & 2010 & 6 & 78 & 70 & 6 & & \\
\hline $\mathrm{NW} 21^{\mathrm{st}}$ & 2000 & 88 & 31 & & & & \\
\hline NW $21^{\text {st }}$ & 2010 & 63 & 19 & & & & \\
\hline NW $23^{\text {rd }}$ & 2000 & 140 & 45 & 4 & & & \\
\hline $\mathrm{NW} 23^{\text {rd }}$ & 2010 & 84 & 33 & 2 & & & \\
\hline SE Belmont & 2000 & 15 & 14 & 43 & 63 & 38 & \\
\hline SE Belmont & 2010 & 13 & 9 & 50 & 57 & 36 & \\
\hline SE Hawthorne & 2000 & 40 & 55 & 41 & 151 & 90 & 14 \\
\hline SE Hawthorne & 2010 & 39 & 41 & 38 & 128 & 92 & 15 \\
\hline
\end{tabular}

Table 10 Segment Total Businesses for 2000 \& 2010

Applying Reilly's Law of Retail Gravitation to SE Hawthorne, for instance, the relationship between neighborhood populations at the western most point (segment 1) and the eastern most point (segment 6), and the distance between those segments to the most dense business activity (segment 4) demonstrate that the larger populations of the eastern most segments serve as an attraction. Similarly, for NW 
District densities tend to cluster closer to Burnside, a main arterial, which separates the NW District from adjacent neighborhoods.

Dense commercial development on Alberta capitalizes on the adjacent neighborhood population (segment 1 ) while still capturing its immediate neighborhood, as well as neighborhood populations to the north, south and east. NE $28^{\text {th }}$ demonstrates greater density than the SE $28^{\text {th }}$ portion, most likely due to its situation between Burnside and Sandy, both major arterials. NE/SE $28^{\text {th }}$ also has the large Laurelhurst neighborhood to the east.

To drill even further into understanding impact of agglomerations on commercial corridors, totals were looked at for five year segments for the two in depth case study areas (Alberta and Hawthorne). Analysis across time of block densities in both areas demonstrated uneven development. What is perhaps most indicative of the impact of agglomeration on businesses is that with few exceptions, densities remain relatively consistent over time within blocks.

Another interesting feature of block by block analysis, is that in looking at the horizontal axis as representative of the street, there are identifiable main clusters of activity with a strongly concentrated center supported by a gradually decreasing density along the periphery to either side. Furthermore, each street demonstrates several different concentrations of businesses at distances of more than ten blocks suggesting that commercial corridors, while maintaining a primary center, also have peripheral clusters which imitate spatial patterns in time. 


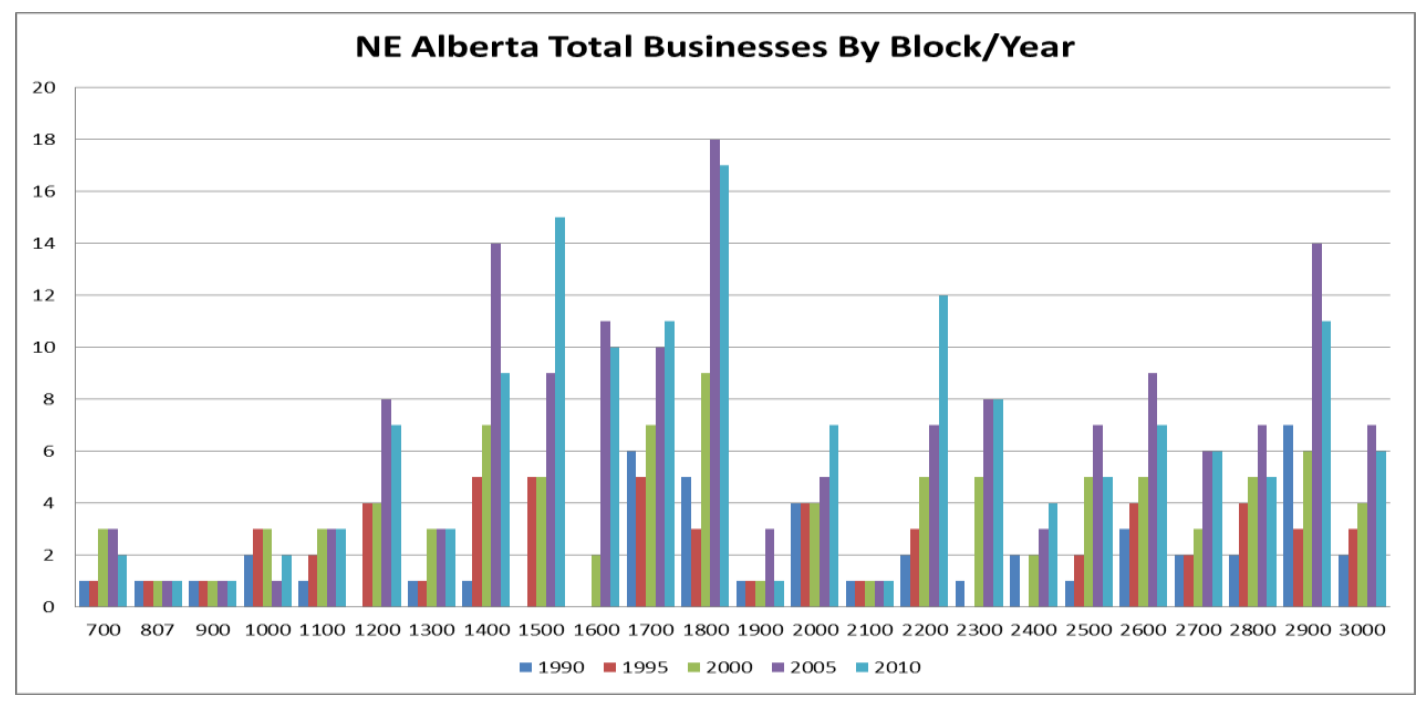

Figure 18 Total across five year increments by block on NE Alberta and $7^{\text {th }}-30^{\text {th }}$

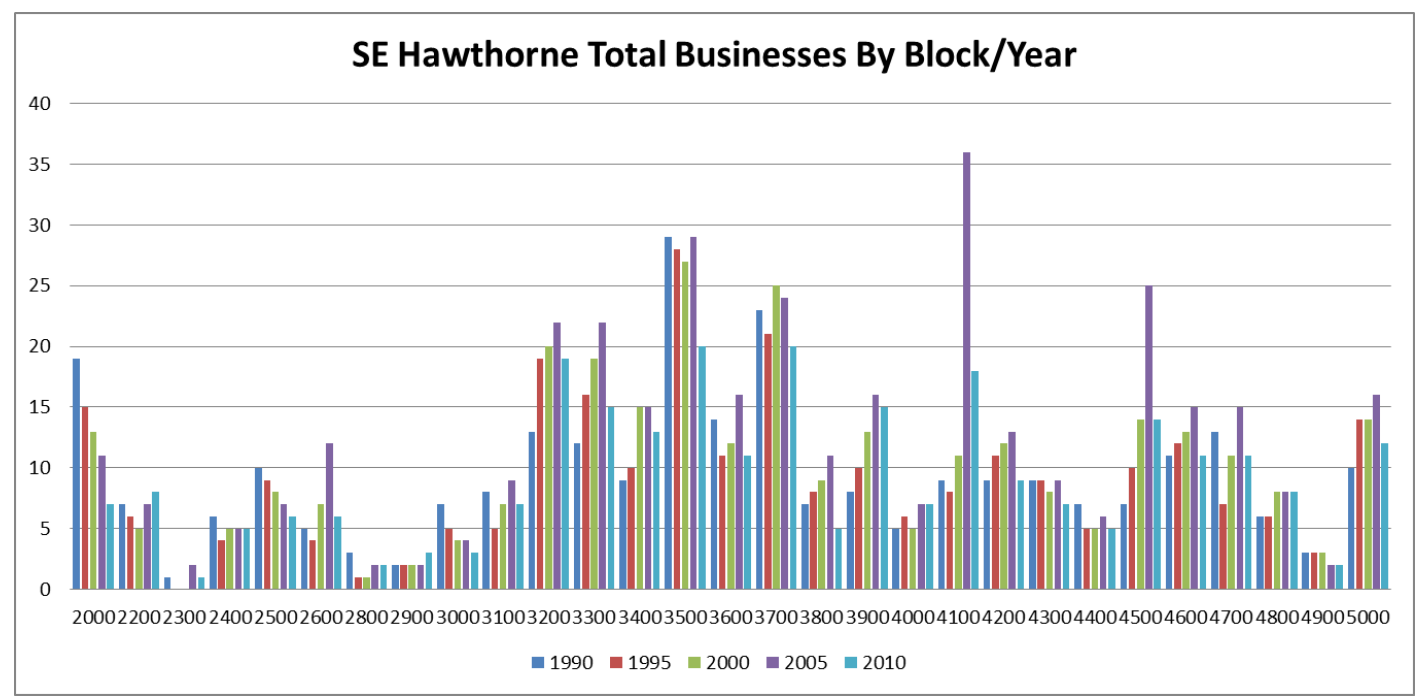

Figure 19 Total across five year increments by block on SE Hawthorne and $20^{\text {th }}-50^{\text {th }}$

While the scale of density is different across and within corridors, patterns

represent an intelligible spatio-temporal syntax that can be said to be fractal. Based on the literature, the spatio-temporal patterns are inherently generative and, regardless of unique conditions or characteristics, time, or intervention, serve to produce and reproduce socio-economic relationships. The similarities in clustering behavior across corridors advocates for a broader spatial logic of eclectic clustering. 
The maps (Appendix B) also demonstrate that the blocks with the highest density experience the most change, with peripheral elements operating like anchors. In some respects, the retail logic is similar to planned retail development, like malls, where anchored by large corporate department stores, the interior consists of smaller, mixed retail goods and services. Unique to the neighborhood commercial corridors are convenience services, like repair shops and laundry services, which depend on residential proximities.

Shopper goods, the subject of concern for displacement based models, appears to cluster nearby self-similar businesses, as predicted by the literature, to form specialty lifestyle enclaves. These are predictably located at the locus of clusters, and help support convenience goods and services oriented businesses by establishing a destination for specialty shopping which attracts a new customer base to the area. These specialty clusters are what have given more established areas including the NW District and SE Hawthorne their identities, as NW District supports a variety of small and large boutiques and home wares shops, while SE Hawthorne features both personal and household vintage stores.

Again, while the distinctiveness of these clusters is unique to each area and, in most cases the region, it is clear the generative spatio-temporal processes which maintain commercial viability. A complete picture of central place theory cannot be understood without delving into issues of causality, including land use patterns, employment numbers, retail sales, residential population shifts, and policy, it appears that densities of businesses do gravitate towards points that maximize 
customer base. It is also worthwhile to mention that convenience businesses, while dispersing along the streets, do seem to have longer longevity when they are also situated by small centers of employment, like clusters of professional or government services. 


\section{DISCUSSION AND RECOMMENDATIONS}

\section{LIMITATIONS}

There are several limitations of the presented research which should be identified before a discussion of findings and insights. Beyond constraints of scope and resources, intentional controls were developed through the research design to both allow for heuristic examination and to challenge assumptions of previous research through simple, concise mechanisms.

First, public policy influences and private interventions were not considered against birth and death rates. In essence, all birth and death rates of businesses were treated as equal to avoid any bias. Similarly, scale of individual businesses or ownership (small versus larger employer, local versus corporate ownership) were absent from research design to remove inherent bias or value judgment. In a more focused study on causality or individual corridors or specific industries scale, ownership and public/private influence should necessarily be considered. A nuanced study intending to understand unique characteristics of spatio-temporal processes in individual corridors, too, would want to consider these factors. For the purposes of identifying patterns and exploring the spatio-temporal phenomena, these considerations were treated as noise which would potentially derail any correlations between businesses when all other things were held equal.

Furthermore, because the research design was envisioned as a first step in developing a comprehensive agenda of research for neighborhood commercial corridors, 
it should not be treated as a micro-study of individual streets where unique change characteristics or nuances can be understood. Data was aggregated primarily to avoid such assumptions and to clearly delineate the purpose of the dissertation as heuristic.

Other constraints which existed at the onset of research, including time and monetary restrictions on data collection, may be alleviated in the future by continuing accessibility and advancements in digital data. However, at the time of data collection much of the material was not yet available online or in a comprehensive format. With investment trends in GIS datasets, it will likely be possible for future studies to increase the depth and breadth of similar research without similar obstacle. This could potentially extend itself to monthly change tracking, rather than year to year, capturing valuable information that can be compared to create a more comprehensive picture of change.

\section{DISCUSSION AND RECOMMENDATIONS}

Based on the findings of research, both statistical and observation, it is evident that although new businesses may be perceived as invaders, in most cases succession of pre-existing businesses appears to be related more to broader economic factors. In comparing neighborhood commercial corridor change against, for instance, unemployment rates for the PMSA it creates a much more complex picture of the relationship between individual businesses and the context of the street, city, region and even nation.

Evidence from data contradicts conclusions from similar studies conducted by Hardyman (1992), Henig (1982), and Clemmer (2000). As my own previous research 
(Howsley, 2001) also relied on assumptions within the gentrification literature I can offer several insights as to why there is a disconnect between the data and previous studies.

First, in most cases specific segments of neighborhood commercial corridors were analyzed. Essentially, this created a sampling problem whereby case studies were chosen based on an already evident fit with the model. Although the segments surrounding dense neighborhood commercial activity typically support other uses and other populations, they offer a context for the dense activity by which to understand patterns of development and density. Without the broader context of whole streets, it would have been impossible to understand issues of centrality, gravitation, and even how clusters of other business types may impact agglomerations of convenience and retail types.

The second problem with previous research is the lack of clear statistical hypothesis testing, which allowed for a standardized interpretation of the interplay between variables. Indeed, without the simple, yet efficient application of the Pearson Correlation Coefficient it would have been difficult to articulate the true relationship between business births and deaths.

The third problem with previous research, based on evidence and the literature review, is that there was confusion between causality and spatio-temporal patterns. Yeung (2003) demonstrates that traditional methodologies for understanding new economic geography are inherently flawed because they tend to produce ambiguous, irrelevant and weak results. New economic geographies, Yeung suggests, require an open methodology that allows for data triangulation which in turn can help develop solid theory. 
Previous studies on neighborhood commercial corridor change typically have relied on one to two methods of evaluating spatio-temporal processes. In most cases, the end game is to support the gentrification dialogue and emphasize sources of conflict and change. By contrast, my research design de-emphasized causality in order to develop greater depth and breadth of spatio-temporal processes. This allowed me to avoid sample bias and to make assumptions about findings had they been based solely on one model.

The lack of correlation between business birth and death confirms that these two variables, although not completely independent, cannot be said to be dependent. Correlation scores, reflecting medium to small covariance, suggest that business birth and death are not mutually exclusive. Evidence from business type comparison and correlation measures support the conclusion that the relationship, rather than direct, is indirect and complex.

Businesses behave, in time and space, according to governing economic principles which can either stimulate or retard growth potential. Comparing examples of significant change with more problematic case study areas, like NE $42^{\text {nd }}$ or SE Belmont, demonstrate the importance of a diversity of business types and their dispersion across segments. Comparison between segments within the street also demonstrates the balance achieved through business mix. Rather than an exclusionary process, commercial change and redevelopment appears to be inclusionary opening opportunities for a diversity of businesses which cater to a broad base of customers.

What cannot be excluded from this is the importance identified of corridor employee populations, which inhabit a street differently than residents or visitors. In part, this strengthens the need to safeguard location sites for professional services in 
neighborhood retail corridors. In several cases, professional services reflect some of the longest tenure and legacy of retail streets in transition and help to maintain stability while convenience and shopper goods experience growth or decline. The other significance of employees as a customer base is that it helps to maintain a diversity of business types, supporting convenience goods and services which might otherwise suffer from mobile residential populations.

Another conclusion from data is that by overemphasizing invasion succession, research avoids recognition of density increases in segments. Segments that contain more shopper goods increase in the total number of businesses without the replacement of preexisting businesses. This may be as a result of any number of factors including land use, rents, availability and infrastructure. What is evident, however, is that the creation of new spaces has a higher frequency of occurrence than the replacement or displacement of preexisting businesses. This is evident in business type graphs (Appendix A) by simply noting the amount of white space (vacancy, residential land use, or no previous address listing) that occurs before many of the businesses. Even in successful neighborhood commercial corridors, like NW $23^{\text {rd }}$, that began to transition as many as forty years prior this appears to be the case.

The sum total of research is that underlying assumptions of invasion and succession have resulted in bias. Null hypothesis testing suggests that invasion and succession is not an efficient model for understanding neighborhood commercial corridor change. To truly understand causality a robust study of potential variables would need to be evaluated to determine if there were any broader patterns which speak to the phenomena. 
These would, naturally, include land use, rents, social actors, networks, distribution patterns, residential demographics, infrastructure, and several layers of economic conditions including regional and national indicators including employment.

The purpose of research was to guide future research and planning/policy decisions towards a more efficient framework of understand neighborhood commercial corridor change. One of the biggest challenges facing research and planning/policy is the long held assumption that neighborhood commercial corridors followed the principles of invasion succession. Without rigid regulation, or even a suppression of change, this model would suggest that stakeholders are powerless to influence the process of change.

However, as my research suggests, invasion succession is an ineffective model for characterizing neighborhood commercial corridor change. While neighborhood businesses seem to interact with residential income shifts, it has not resulted in sweeping displacement of pre-existing businesses.

\section{COMMERCIAL GENTRIFICATION}

In the proposal stage of research, my premise was that commercial change may follow similar patterns of residential change. I think that research in the past, too, has been guided by loaded hypotheses framed by the literature of gentrification. Recent suggestions by Freeman and others that displacement may not be as serious an issue in gentrifying neighborhoods as once suspected, however, raised similar doubts with my own research foundations.

By examining the research design and even the literature review approach, I determined that an exploratory method was required to truly understand what spatio- 
temporal patterns of neighborhood commercial corridor change really looked like. The result was, with initial observation during the data collection phase, that rather than displacing businesses change in these neighborhood commercial corridors had more to do with clustering and density increases.

I also observed that convenience goods and services, like coffee houses and dry cleaners, were anchors for pockets of development along the corridor. In many ways, the patterns of neighborhood commercial corridor change are fractal in repeating similar expressions of business activity.

The evidence suggests that, while businesses do gravitate to neighborhoods that experience household income shifts, the process that follows neighborhood commercial change is vastly different than the more normative slope of change found in residential phenomena. Displacement, that thing that keeps well-intended activists, planners and academics alike awake, does not appear to an enduring problem for businesses along neighborhood commercial corridors; low correlation between business birth and deaths suggest that greater mechanisms of change influence these commercial centers.

Businesses flourish when there is a heightened amount of other businesses activity which attracts movement and allows for shopper behaviors, like comparison shopping and trip chaining. Walkability seems to influence the scale of activity, as densities tend to cluster within half mile segments; however pockets of activity throughout the street suggest that a neighborhood commercial corridor serves a multitude of functions heretofore missed by representations of commercial gentrification or invasion succession. 
The relationship between residential change and commercial change has always appeared to be a chicken or egg question. That the case study areas that flourish were once thriving streetcar routes, influencing land use patterns, cannot be ignored. However, it also must be significant that as a general rule of urban commerce, the greater the residential income the more likely to be an adjacent, thriving commercial street.

To categorize neighborhood commercial change in neighborhoods experiencing gentrification or gentrification like symptoms as commercial gentrification would be to mix the complex interplay of external forces that result in redevelopment of, in many cases, disinvested areas. By oversimplifying neighborhood commercial corridor change, it becomes impossible to identify the nuanced patterns that help to strengthen or weaken these service centers and potential sites of employment and wealth generation.

Broader changes in the global economy, regardless of lifestyle choice or household income, have continued to influence the ways and the what's of consumption. However, technology or cultural shifts change tangible goods, personal and professional services are evidently still the backbone of neighborhood commercial corridors. As the pressures of transportation, particularly gas prices, encourage consumption patterns closer to home it is natural to expect there will be entrepreneurial ventures also willing to offer shopper goods and services closer to home.

The two need not be mutually exclusive, as the concept of commercial gentrification implies. It is evidently possible, through examination of neighborhood commercial change, for a multitude of business types to coexist. In part, this is most likely because they target different populations. For every service sector business, with the exception of exclusively owner-laborer small businesses, there are typically hourly 
wage workers. Whether working at night, morning, or daytime, hourly wage workers also seek out places to meet, eat, and conduct other personal and professional business. While businesses that target higher income residential populations will likely not attract this population of workers, or even the employees of that business, opportunity to set up a competitive, adjacent business catering specifically to these populations exist if the density of similar workers is great enough.

\section{RECOMMENDATIONS FOR RESEARCH}

More research evaluating these principles, as well as considering external forces and causality, are necessary to completely capture the process of neighborhood commercial change. Comparative studies examining similar phenomena in other cities would also be useful to understand if concepts within research are universal.

There is still very little attention paid to small scale retail that develops within the urban landscape. This is unfortunate, because it has the potential to connect to both economic and quality of life issues, as well as helping to further understanding the ideas of "retail deserts."

The idea that neighborhood commercial change creates "retail islands" of privilege, however, seems far from the mark of what actually occurs. More comprehensive access to sales records, pricing sheets, and rent records would be helpful in demonstrating real cost issues that impact cycles of change.

Finally, I think it also is of interest to give more attention to the importance of professional, government, and non-profit businesses and organizations in helping to stabilize a neighborhood commercial area. This was one of the most fascinating and 
surprising pieces of research that cropped up at every stage, from data collection to data analysis. In many ways, these business types are the unsung heroes of successful neighborhood commercial corridors. Their resilience in the face of change, too, suggests that there can be mutual benefits to a co-existence of business functions.

\section{RECOMMENDATIONS FOR PRACTITIONERS}

Based on conclusions reached by research, there are several elementary recommendations that can be made to practitioners, whether revitalizing disinvested areas or attempting to identify problems when investment does not net results.

First, and for most, along with business funding entrepreneurs need to be equipped with similar knowledge available to corporations. Training or resources that explain trade areas, and principles like the retail law of gravitation, might help curb businesses from springing up in exactly the wrong site for their target audience. The adage that real estate's top most important features are location, location, location is not too far of the mark when considering all the multiple attractions and drawbacks a location can have for a business.

It also is important to note that, just as business change presents a variety of business types, so redevelopment of the sticks and bricks of a place should consider designing spaces flexible for a variety of uses. Often, new construction in these corridors consists of ground floor retail with housing above, or some variation of the mixed use model. For sustaining businesses, particularly with an eye to expansion and contraction of individual establishments, the ability to grow or shrink in place could ultimately help 
businesses stay put. With residential tenancies, flexibility may be limited or be a deterrent to certain types of businesses concerned about impact on neighbors above.

The presence of professional services, government office, and non-profit organizations in stable business corridors suggests that redevelopment should also consider traditional or non-traditional office space as a part of any redevelopment project. New models of business condos, ground floor office townhomes, and other similar projects are great examples of new ways to think about developing in neighborhood commercial corridors. There are also, throughout Portland, cooperatives and flexible office spaces that help share operating costs among individual entrepreneurs. Because research has illuminated the population of workers within neighborhood corridors as a natural, additional captive consumer creating spaces for these type of establishments will only continue to strengthen the success of convenience and shopper type businesses. 


\section{REFERENCES}

Abbott, C. (1983). Portland: Planning, Politics, and Growth in a Twentieth Century City. Lincoln: University of Nebraska Press.

Abbott, C. (2001). Greater Portland: Urban Life and Landscape in the Pacific Northwest. Philadelphia: University of Pennsylvania Press.

Al_Sayed, K., \& Turner, A. (2012). Emergence and self-organization in urban structures. In Proceedings of AGILE.

Aldrich, H., \& Reiss Jr, A. J. (1976). Continuities in the study of ecological succession: changes in the race composition of neighborhoods and their businesses. American Journal of Sociology, 846-866.

Alejandrino, S.A. (2000). Gentrification in San Francisco's Mission District: Indicators and Policy Recommendations. Mission Economic Development Association, Summer.

Alwitt, L. and T. Donley (1997). Retail Stores in Poor Urban Neighborhoods. The Journal of Consumer Affairs, 31(1), pp. 139-164.

Andreasen, A (1971). Inner City Business: A Case Study of Buffalo, New York. New York: Praeger Publishers. 
Arlinghaus, S (1985) Fractals Take a Central Place. Geografiska Annaler. Series B, Human Geography, Vol. 67, No. 2 (1985), pp. 83-88Published by: Blackwell Publishing on behalf of the Swedish Society for Anthropology and Geography. Stable URL: http://www.jstor.org/stable/490419.

Ashuri, B. (2008). A Real Options Approach to Modeling Investments in Competitive, Dynamic Retail Markets. Georgia Institute of Technology.

Atkinson, R. (2003). Introduction: Misunderstood Saviour or Vengeful Wrecker? The Many Meanings and Problems of Gentrification. Urban Studies, 40(12), November.

Betancur, J. (2011). Gentrification and community fabric in Chicago. Urban studies, 48(2), 383-406.

Berry, B. (1999). Comment on Elvin K. Wyly and Daniel J. Hammel's 'Islands of Decay in Seas of Renewal: Housing Policy and the Resurgence of Gentrification" Gentrification Resurgent?. Housing Policy Debate, 10(4), pp.783-788.

Berry, B. J. L. (2012). Shopping centers and the geography of urban areas; a theoretical and empirical study of the spatial structure of intraurban retail and service business (Doctoral dissertation). 
Berry, L. L., Seiders, K., \& Grewal, D. (2002). Understanding service convenience. The Journal of Marketing, 1-17.

Bostic, R.W. and R.W. Martin (2003). Black Home-owners as a Gentrifying Force? Neighbourhood Dynamics in the Context of Minority Home-ownership. Urban Studies, 40(12), November, pp. 2427-2449.

Bridge, G. (2001). Estate Agents as Interpreters of Economic and Cultural Capital: The Gentrification Premium in the Sydney Housing Market International. Journal of Urban and Regional Research, 25(1), March, pp. 87-101.

Bridge, G. (2003). Time Space Trajectories in Provincial Gentrification. Urban Studies, 40(12), pp. 2545-2556.

Bridge, G. and R. Dowling (2001). Microgeographies of Retailing and Gentrification. Australian Geographer, 32(1), pp. 93-107

Bromley, R. (1993). Retail change: contemporary issues. Routledge.

Brookings Institution. (2003). Portland in Focus: A Profile from Census 2000. www.brookings.edu. 
Brooks, C., P. Kaufmann, and D. Lichenstein. (2004). Travel Configuration on Consumer Trip-Chained Store Choice. Journal of Consumer Research. 31, September, pp. 241-248.

Brown, S. (1994). Retail location at the micro-scale: inventory and prospect. Service Industries Journal, 14(4), 542-576.

Bucklin, L. P. (1963). Retail strategy and the classification of consumer goods. The Journal of Marketing, 50-55.

Burger, M., \& Meijers, E. (2012). Form follows function? Linking morphological and functional polycentricity. Urban Studies, 49(5), 1127-1149.

Butler, T. and G. Robson (2001). Social Capital, Gentrification and Neighbourhood Change in London: A Comparison of Three South London Neighbourhoods. Urban Studies, 38(12), pp. 2145-2162.

Butler, T. and G. Robson (2003). Negotiating Their Way In: The Middle Classes, Gentrification and the Deployment of Capital in a Globalising Metropolis. Urban Studies, 40(9), August, pp. 1791-1809.

Butler, T. and Robson (2003) Plotting the Middle Classes: Gentrification and Circuits of Education in London. Housing Studies, 18(1), pp.5-28. 
Cachinho, H. (2012). Consumerscapes and the resilience assessment of urban retail systems. Cities.

City of Portland. (2004). Commercial Corridor Study. http://www.portlandoregon.gov/bps/index.cfm?c=38610\&

Chernev, A. (2004). Goal Orientation and Consumer Preference for the Status Quo. Journal of Consumer Research. 31, December, pp.557-565.

Clarke, I., Bennison, D., \& Pal, J. (1997). Towards a contemporary perspective of retail location. International Journal of Retail \& Distribution Management, 25(2), 59-69.

Clarke, I., A. Hallsworth, P. Jackson, R. de Kervenoael, R. Perez-del-Aguila, and M. Kirkup. (2004). "Retail competition and consumer choice: contextualising the "food deserts" debate", International Journal of Retail \& Distribution Management. 32(2), pp.89- 99

Clemmer, G. (2000). Quantitative Spatial Analysis Techniques for Analyzing Gentrification Patterns: Case Study, Portland Oregon.

Cohen,D., K. Mason, A. Bedimo, R. Scribner, V. Basolo, and T. Farley (2003). Neighborhood Physical Conditions and Health. American Journal of Public Health. 93 (3), pp. 467-471. 
Cortwright, J. (2006). Unpublished presentation available www.pdc.us/uraclassmaterials.

Courtat, T., Douady, S., \& Gloaguen, C. (2011, May). Centrality maps and the analysis of city street networks. In Proceedings of the 5th International ICST Conference on Performance Evaluation Methodologies and Tools (pp. 316-321). ICST (Institute for Computer Sciences, Social-Informatics and Telecommunications Engineering).

Crewe, L. (2000). Geographies of Retailing and Consumption. Progress in Human Geography. 24(2), pp. 275-290.

Crucitti, P., Latora, V., \& Porta, S. (2006). Centrality in networks of urban streets. Chaos: an interdisciplinary journal of nonlinear science, 16(1), 015113-015113.

Curran, W. (2004). Gentrification and the Displacement of Work: Exploring the Links in Williamsburg, Brooklyn. Dissertation.

Davidson, M. and L. Lees. (2005). New-build 'gentrification' and London's riverside renaissance. Environment and Planning. 37, pp 1165-1190.

Davies, R. L. (1970). Variable relationships in central place and retail potential models. Regional Studies, 4(1), 49-61. 
Dearden, J., \& Wilson, A. G. (2009). Exploring urban retail phase transitions.

Dearden, J., \& Wilson, A. (2011). A framework for exploring urban retail discontinuities. Geographical Analysis, 43(2), 172-187.

Dennis, C., Marsland, D., \& Cockett, T. (2002). Central place practice: shopping centre attractiveness measures, hinterland boundaries and the UK retail hierarchy. Journal of Retailing and Consumer Services, 9(4), 185-199.

Douglas, M. (1997) In Defense of Shopping. in The Shopping Experience. eds. P. Falk and C. Campbell. London: Sage Publications.

Farquhar, J. D., \& Rowley, J. (2009). Convenience: a services perspective. Marketing Theory, 9(4), 425-438.

Fernandes, J. R., \& Chamusca, P. (2012). Urban policies, planning and retail resilience. Cities.

Figueroa, M. E. (2003). "Facilitated invasion by hybridization of Sarcocornia species in a salt-marsh succession". The Journal of Ecology. 91(4), p.616 
Feser, E. (2002) Tracing the Sources of Local External Economies. Urban Studies vol 39, No 13 2485-2506

Freeman, L. C. (1977). A set of measures of centrality based on betweenness. Sociometry, 35-41.

Freeman, L. and F. Braconi (2004). Gentrification and Displacement: New York City in the 1990s. Journal of the American Planning Association, 70(1), Winter, pp. 39-53

Garber, M. (2000). Sex and Real Estate: Why We Love Houses. New York: Anchor Books.

Gaudio, R.P. (2003). Coffeetalk: Starbucks and the Commercialization of Casual Conversation. Language in Society, 32, pp. 659-691.

Getis, A., \& Paelinck, J. H. (2004). An analytical description of spatial patterns. L'Espace géographique, (1), 61-68.

Gieryn, T. F. (2006). City as Truth-Spot Laboratories and Field-Sites in Urban Studies. Social Studies of Science, 36(1), 5-38. 
Glaeser, E. (ed) (2010). Who Benefits Whom in the Neighborhood? Demographics and Retail Product Geography in Agglomeration Economics. Chicago: University of Chicago Press.

Goldsmith, R. E., Flynn, L. R., \& Clark, R. A. (2011). Materialism and brand engagement as shopping motivations. Journal of Retailing and Consumer Services, 18(4), 278-284.

Goodchild, Michael F. "ILACS: A location-allocation Model for Retail Site Selection.” Journal of Retailing 60, No. 1 (1984) 84-100

Guy, C. (1998). Classifications of retail stores and shopping centres: some methodological issues. GeoJournal. 45, pp.255-264.

Hagberg, J. (2008). Retail change and the practice of classification. Center for Retailing. Goteborg: Goteberg University.

Hammond, B. “Homeownership Rates Decrease.” Oregonian, March 16, 2001, p. 1 \& A1.

Hane, B., K. Jager and H. Drexler. (2005). The Pearson product-moment correlation coefficient is better suited for identification of DNA fingerprint profiles than band matching algorithms. Eltrophoresis. 14(1), pp. 967-972. 
Hardin III, W. G., \& Wolverton, M. L. (2000). Micro-market determinants of neighborhood center rental rates. Journal of Real Estate Research, 20(3), 299-322.

Hardin, W. G., \& Wolverton, M. L. (2001). Neighborhood center image and rents. The Journal of Real Estate Finance and Economics, 23(1), 31-46.

Harries, K. (1971). Ethnic Variations in Los Angeles Business Patterns. Annals of the Association of American Geographers. 61, pp. 736-743.

Hardyman, R. (1992). Hawthorne Boulevard: Commercial Gentrification and the Creation of An Image. Thesis.

Henig, J. (1982). Neighborhood mobilization: redevelopment and response. New York: Rutgers University Press.

Hillier, B. (1996). Space is the Machine. Cambridge: University Press.

Hillier, B. (2001). "The Theory of the City As Object: or How Spatial Laws Mediate the Social Construction of Urban Space.” Atlanta Space Syntax Symposium.

Hillier, B. and J. Hanson. (1984). The Social Logic of Space. Cambridge: University Press. 
Holt, D. (1998). Does Cultural Capital Structure American Consumption? Journal of Consumer Research. 25, June, pp. 1-26.

Holton, Richard H. (1958). The Distinction Between Convenience Goods, Shopping Goods, and Specialty Goods. Journal of Marketing 23(1): 53-56.

Howsley, K. (2001). Uncovering the Spatial Patterns of Portland's Gentrification: An Analysis of the Phenomena of Gentrification According to the Urban Grid Structure. Thesis. (short paper available at www.spacesyntax.net/symposia/ SSS4/fullpapers/ 76Howsleypaper.pdf -)

Jacobs, K. (2002). Subjectivity and the Transformation of Urban Spatial Experience. Housing, Theory and Society, 19, pp. 102-111.

Johnson, P. and S. Parker (1996). Spatial variations in the determinants and effects of firm births and deaths. Regional Studies, 30.7, pp. 679-686.

Jun, H. J. (2010). Diverging Paths: The Determinants of Neighborhood Change Across Space and Time (Doctoral dissertation, Ohio State University).

Kahmen, S. (02/2004). "Plant functional trait responses to grassland succession over 25 years". Journal of vegetation science(1100-9233), 15(1), p.21 
Kärrholm, M., Nylund, K., \& Prieto de la Fuente, P. (2012). Spatial resilience and urban planning: Addressing the interdependence of urban retail areas. Cities.

Karsten, L. (2003). Family Gentrifiers: Challenging the City as a Place Simultaneously to Build a Career and to Raise Children. Urban Studies, 40(12), pp. 2573-3584.

Kasarda, J.D. (1999). Comment on Elvin K. Wyly and Daniel J. Hammel's "Islands of Decay in Seas of Renewal: Housing Policy and the Resurgence of Gentrification". Housing Policy Debate, 10(4), pp.773-781.

Kennedy, M. and P. Leonard. (2001). Dealing with Neighborhood Change: A Primer on Gentrification and Policy Choices. The Brookings Institution Center of Urban and Metropolitan Policy, April.

Kim, E.. Mitigating Displacement due to Gentrification: Tools for Portland, Oregon. M.A. dissertation, Tufts University, United States -- Massachusetts. Retrieved February 20, 2012, from Dissertations \& Theses: Full Text.(Publication No. AAT 1495318).

Kim, Y. H., Lee, M. Y., \& Kim, Y. K. (2011). A new shopper typology: Utilitarian and hedonic perspectives. Journal of Global Academy of Marketing, 21(2), 102-113. 
Kloosterman, R.C. and J.P. Van de Leun (1999). Just for Starters: Commercial Gentrification by Immigrant Entrepreneurs in Amsterdam and Rotterdam Neighbourhoods. Housing Studies, 14(5), pp. 659-677

Koebel, C.T. (1999). Analysing Neighborhood Retail and Service Change in Six Cities Center for Housing Research Virginia Polytechnic Institute and State University.

Koohsari, M. J., Karakiewicz, J. A., \& Kaczynski, A. T. (2012). Public Open Space and Walking: The Role of Proximity, Perceptual Qualities of the Surrounding Built Environment, and Street Configuration. Environment and Behavior.

Krizek, K. (2003). Neighborhood services, trip purpose, and tour-based travel. Transportation. 20: pp. 387-410.

Lang, R. and J. LeFurgy. (2003). Edgeless Cities: Examining the Noncentered Metropolis. Housing Policy Debate, 14(3), pp. 427-460.

Leduc, J. (2001). SEPH Estimates Are Now Based on the North American Industrial Classification System (NAICS). SEPH Analysis and Dissemination Section, Working Papers.

Lees, L. (2000). A reappraisal of gentrification: towards a 'geography of gentrification'. Progress in Human Geography, 24(3), pp.389-408. 
Lefebvre, H. (1991). The production of space. Oxford, OX, UK: Blackwell.

Ley, D. (2003). Artists, Aestheticisation, and the Field of Gentrification. Urban Studies, 40(12), pp.2527-2544.

Leyden, K. (2003). Social Capital and the Built Environment: The Importance of Walkale Neighborhoods. American Journal of Public Health, September, 93(9), pp.1546-1551.

Lloyd, R. (2002). Neo-Bohemia: Art and Neighborhood Redevelopment in Chicago. Journal of Urban Affairs, 24(5), pp. 517-532.

Lockshin, L., P. Quester, and T. Spawton. (2001). Segmentation by Involvement or Nationality for Global retailing: A Cross-National Comparative Study of Wine Shopping Behaviours. Journal of Wine Research. 12(3), pp. 223-236.

Logan, J. R., \& Zhang, C. (2010). Global Neighborhoods: New Pathways to Diversity and Separation1. American Journal of Sociology, 115(4), 1069-1109.

Lovelock, C. H. (1983). Classifying services to gain strategic marketing insights. The Journal of Marketing, 9-20.

MacColl, K. (1979). The Growth of a City: Power and Politics in Portland, Oregon 1915 to 1950. Portland: Georgian Press Company. 
Marcuse, P. (1999). Comment on Elvin K. Wyly and Daniel J. Hammel's “Islands of Decay in Seas of Renewal: Housing Policy and the Resurgence of Gentrification”. Housing Policy Debate, 10(4), pp. 789-797.

Martinez-Fernandez, C., Audirac, I., Fol, S., \& Cunningham-Sabot, E. (2012). Shrinking cities: urban challenges of globalization. International Journal of Urban and Regional Research, 36(2), 213-225.

Mayer-Schönberger, V., Cukier, K., \& ebrary, I. (2013). Big data: A revolution that will transform how we live, work, and think. Boston: Houghton Mifflin Harcourt.

Mele, C. (1996). Globalization, Culture, and Neighborhood Change: Reinventing the Lower East Side of New York. 48(2), pp. 3-22.

Mian, S, Assessing value-added contributions of university technology business incubators to tenant firms. Research Policy, Volume 25, Issue 3, May 1996, pp. 325-335.

Mildner, G. (1998). "Growth Management in the Portland Region and the Housing Boom of the 1990's.” www.urbanfutures.org/wpgrowth.html Urban Futures Working Paper no. 98-1, May. 
Miller, M. J. (2012). Food availability in the heartland: effects of neighborhood race and income composition (Doctoral dissertation, Kansas State University).

Miranda, M. J. (2009). Engaging the purchase motivations to charm shoppers. Marketing Intelligence \& Planning, 27(1), 127-145.

Mohr, M. (2003). NAPCS Structure Illustration: Possible Product Groups, Sub-Groups, and Classes. Trilateral Steering Group Meeting.

Moorman, C., K Diehl, D. Brinberg, and B. Kidwell. (2004). Subjective Knowledge, Search Locations, and Consumer Choice. Journal of Consumer Research. 31, December, pp. 673-680.

Moudon, A, C. Lee, A. Cheadle, C Garvin, D. Johnson, T. Schmid, R. Weathers and L. Lin. (2006). Opertional Definitions Walkable Neighborhood: Theoretical and Empirical Insights. Journal of Physical Activity and Health. 3, Suppl 1, pp. S99-S117.

Mulligan, G. F. (1984). Agglomeration and central place theory: a review of the literature. International Regional Science Review, 9(1), 1-42.

Muniz, A. and T. O’Guinn. (2001). Brand Community. Journal of Consumer Research. 27, March, pp. 412-432. 
Murphy, P. E., \& Enis, B. M. (1986). Classifying products strategically. The Journal of Marketing, 24-42.

Muske, G., M. Fitzgerald, and J. Kim (2002). Copreneurs as Family Businesses: Evaluating the Differences By Industry Type. Cooperative Regional Research Project.

Naeem, Shahid (10/2000). "Plant diversity increases resistance to invasion in the absence of covarying extrinsic factors". Oikos(0030-1299), 91(1), p.97.

Nie, C. and L. Zepeda (2011). Lifestyle segmentation of US food shoppers to examine organic and local food consumption. 57(1), pp. 28-37

Nunn, S. (2001). Planning for Inner-City Retail Development: The Case of Indianapolis. The American Planners Association Journal. 67(2), Spring, pp. 159-172.

Oinas, P. (2002). Competition and collaboration in interconnected places: towards a researcj agenda. Geogr. Ann.. 84 B (2): 65-76.

Oliver, G. and S. Suo. "Population Changes." Oregonian, June 18, 2001, pgs. 1 \& A5. Peck, S. (1993). Testing the Advantages of Using Product level Data to Create Linkages Across Industrial Coding Systems. Center for Economic Studies. 
Pitkin, B. (2001). Theories of Neighborhood Change: Implications for Community Development Policy and Practice. UCLA Advanced Policy Institute, November.

Phillips, M. (2004). Other Geographies of Gentrification. Progress in Human Geography, 28(1), pp.5-30.

Porta, S., \& Latora, V. (2008). Centrality and cities: Multiple centrality assessment as a tool for urban analysis and design. New Urbanism and Beyond: Designing Cities for the Future, 140-145.

Porta, S., Latora, V., Wang, F., Strano, E., Cardillo, A., Scellato, S., ... \& Messora, R. (2009). Street centrality and densities of retail and services in Bologna, Italy. Environment and Planning B: Planning and design, 36(3), 450-465.

Portland Development Commission (2002). Economic Revitalization and Involuntary Displacement in North-Northeast Portland: An Issues Analysis. PDC, September.

Redding, S., \& Venables, A. J. (2002). The Economics of Isolation and Distance. Nordic Journal of Political Economy, 28, 93-108.

Reynolds, K. E., Ganesh, J., \& Luckett, M. (2002). Traditional malls vs. factory outlets: comparing shopper typologies and implications for retail strategy. Journal of Business Research, 55(9), 687-696. 
Roberts, J. M. (2001). Realistic spatial abstraction? Marxist observations of a claim within critical realist geography. Progress In Human Geography, 25(4), 545-567.

Robson, G. and T. Butler (2001). Coming To Terms with London: Middle Class Communities in a Global City. International Journal of Urban and Regional Research, 25(1), March, pp. 70-86.

Rodgers, J. and A. Nicewander. (1988) Thirteen Ways to Look at the Correlation Coefficient. The American Statistician, 42(1), pp.59-66.

Rofe, M.W. (2003). I Want to Be Global” Theorising the Gentrifying Class as an Emergent Elite Global Community. Urban Studies, 40(12), pp. 2511-2526.

Rose, H. (1970). The structure of retail trade in a racially changing neighborhood. Geography Analysis. 1: pp. 135-148.

Roth, Victor J. (1993). "A theory of retail change". The International review of retail, distribution and consumer research. 3(2), p.167.

Rypkema, D.D. (2003) Commercial Gentrification: Beyond the Rhetoric. The Monthly Journal of the National Trust's National Main Street Center, (196), pp. 1-5. 
Sampson, R., J. Morenoff, and T. Gannon-Rowley. (2002). Assessing "Neighborhood Effects": Social Processes and New Directions in Research. Annual Review of Sociology. 28, pp. 443-473.

Sassen, S. (1998). Globalization and Its Discontents: Essays on the New Mobility of People and Money. New York: New Press.

Satler, G. (2003). New York City Restaurants: Vernaculars of Global Designing. Journal of Architectural Education, pp. 27-39.

Schlosser, A. (1998). Applying the Functional Theory of Attitudes to Understanding the Influence of Store Atmosphere on Store Inferences. Journal of Consumer Psychology. 7(4), pp. 345-369.

Schuetza, J., J. Kolkob and R. Meltzerc. Are poor neighborhoods "retail deserts"? Regional Science and Urban Economics. 42 (1-2), pp.269-285.

Scott, A. (2006) Creative Cities: Conceptual issues and Policy Questions. Journal of Urban Affairs vol 28, no 1 pg 1-17

Searle, G. and J. Byrne (2002). Selective Memories, Sanitised Futures: Constructing Visions of Future Place in Sydney. Urban Policy and Research, 20(1), pp. 7-25. 
Slater, S, and J. Narver, The Positive Effect of a Market Orientation on Business

Profitability: A Balanced Replication, Journal of Business Research, 48(1), April 2000, pp. 69-73.

Smith, N. (2002). New Globalism, New Urbanism: Gentrification as Global Urban Strategy. Antipode, pp. 427-450.

Sorkin, M. (ed). (1992) (Neil Smith, "New City, New Frontier..." pgs. 61-93 in)

Variations on a Theme Park: The New American City and the End of Public Space. New York: Hill and Wang.

Stahl, K. (1987). Theories of Urban Business Location. Handbook of Regional and Urban Economics. E.S. Mills. Amsterdam: North-holland. 2: 760-820.

Storey, D. (1991) The Birth of New Firms-Does Unemployment Matter? A Review of Evidence. Small Business Economics. 3, pp. 167-178.

Storper, M., \& Manville, M. (2006). Behaviour, preferences and cities: urban theory and urban resurgence. Urban Studies, 43(8), 1247-1274.

Storper, M., \& Venables, A. J. (2004). Buzz: face-to-face contact and the urban economy. Journal of economic geography, 4(4), 351-370. 
Sullivan, D.M. (2000). Reassessing Gentrification: Measuring Residents' Opinion Using Survey Data. Urban Affairs Review, 42(4), pp. 583-592

Schwirian, K. (1983). Models of Neighborhood Change. Annual Review of Sociology. 9, pp. 83-102.

Tannier, C., \& Pumain, D. (2005). Fractals in urban geography: a theoretical outline and an empirical example. Cybergeo: European Journal of Geography.

Triplett, J. (2002). Industries, Products, and Aggregations: NAICS Provision of Information for the New Economy. Brookings Institution, Prepared for IAOS Meetings.

Thompson, C. and Z. Arsel. (2004). The Starbucks Brandscape and Consumers' (Anticorporate) Experiences of Glocalization. Journal of Consumer Research. 31, December, pp. 631-641.

Thompson, Donald L. (1967). "Consumer Convenience and Retail Area Structure.” Journal of Marketing Research 4 (1) (February 1): 37-44. doi:10.2307/3150162.

Vasanen, A. (2012). Functional Polycentricity: Examining Metropolitan Spatial Structure through the Connectivity of Urban Sub-centres. Urban Studies. 
Webb, M. D., \& Brown, L. A. (2012). Neighbourhood change in an era of promoting the American dream*. Regional Science Policy \& Practice, 4(4), 509-534.

Wiegand, N., E.D. Patterson, N. Zhou, S. Ventura and F. Cruz. (2003). Querying Hetereogeneous Land Use Data: Problems and Potential. NAICS paper.

Wilcox, P., N. Quisenberry, D. Cabrera, and S. Jones (2004). Busy Places and Broken Windows? Toward Defining the Role of Physical Structure and Process in Community Crime Models. The Sociological Quartery. 45(2), pp. 185-207.

Wilkinson, R. (1992). Income distribution and life expectancy. BMJ. 304, pp.165-168.

Williams, P., P. Hubbard, D. Clark and N. Berkeley. (2001). Consumption, exclusion and emotion: the social geographies of shopping. Social and Cultural Geography. 2(2), pp. 202-220.

Wolfe, D. A., \& Gertler, M. S. (2004). Clusters from the inside and out: local dynamics and global linkages. Urban Studies, 41(5-6), 1071-1093.

Wyly, E.K. and D.J. Hammel (1999). Islands of Decay in Seas of Renewal: Housing Policy and the Resurgence of Gentrification. Housing Policy Debate, 10(4), pp. 711-771. 
Xiong, H., S. Shekhar, P. Tan, and V. Kumar. (2004). Exploiting a support-based upper bound of Pearson's correlation coefficient for efficiently identifying strongly correlated pairs. In Proceedings of the tenth ACM SIGKDD international conference on Knowledge discovery and data mining (KDD '04). New York: ACM. pp.334-343.

Yang, Y., Zhou, W. Y., Zhang, W. C., \& Zhang, X. Z. (2008). A Fractal Study on the Spatial Structure of Urban System in the Three Economic Circles of China. Journal of Subtropical Resources and Environment, 4, 014.

Yeung, H.W. (2003). Practicing New Economic Geographies: A Methodological Examination. Annals of the Association of American Geographers, 93(2), pp. 442-462.

Zukin, S. (1989). Loft Living Culture and Capital in Urban Change. New York: Rutgers University Press.

Zukin, S. (1998). Urban Lifestyles: Diversity and Standardisation in Spaces of Consumption. 


\section{APPENDIX A -}

Neighborhoodbusinesses.ods (164kb) Requires Microsoft Excel 


\section{APPENDIX B -}

Neighborhoodmaps.pdf (662kb) Requires Adobe Acrobat Reader 